Motu Working Paper 21-03

\title{
Minimum Wages in New Zealand: Policy and practice in the 21st century
}

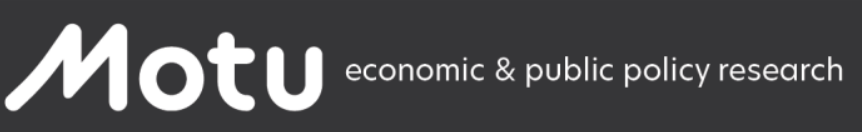

David C. Maré and Dean R. Hyslop

March 2021 


\title{
Document information
}

\section{Author contact details}

David C. Maré and Dean R. Hyslop

Motu Economic and Public Policy Research

PO Box 24390

Wellington 6142, New Zealand

E-mail: dave.mare@motu.org.nz, dean.hyslop@motu.org.nz

\section{Acknowledgements}

This research was supported by the Ministry of Business, Innovation and Employment (MBIE). We thank Bill Rosenberg and Rose Ryan for insightful and stimulating comments on an earlier draft of this paper.

We dedicate this paper to the memory of former Secretary of Labour, colleague and friend, Jas McKenzie, from whom we both learnt a lot about the New Zealand labour market. The last time we saw Jas, he expressed the view minimum wages have become New Zealand's de facto wages policy.

\section{Disclaimer}

Access to the data used in this study was provided by Stats NZ under conditions designed to give effect to the security and confidentiality provisions of the Statistics Act 1975. The results presented in this study are the work of the author, not Stats NZ or individual data suppliers.

These results are not official statistics. They have been created for research purposes from the Integrated Data Infrastructure (IDI) which is carefully managed by Stats NZ. For more information about the IDI please visit https://www.stats.govt.nz/integrated-data/.

The results are based in part on tax data supplied by Inland Revenue to Stats NZ under the Tax Administration Act 1994 for statistical purposes. Any discussion of data limitations or weaknesses is in the context of using the IDI for statistical purposes and is not related to the data's ability to support Inland Revenue's core operational requirements.

\section{Motu Economic and Public Policy Research}

\author{
PO Box $24390 \quad$ info@motu.org.nz +64 49394250 \\ Wellington www.motu.org.nz \\ New Zealand
}

(C) 2021 Motu Economic and Public Policy Research Trust and the authors. Short extracts, not exceeding two paragraphs, may be quoted provided clear attribution is given. Motu Working Papers are research materials circulated by their authors for purposes of information and discussion. They have not necessarily undergone formal peer review or editorial treatment. ISSN 1176-2667 (Print), ISSN 1177-9047 (Online). 


\section{Abstract}

New Zealand has seen dramatic changes in minimum wage policies since 2000 . The adult minimum wage has increased $75 \%$ in $\mathrm{CPI}$-adjusted real terms. In addition, the youth minimum wage was abolished in two stages, resulting in a $125 \%$ increase in the real minimum wage for 16-19-year-old workers. We review the motivations for minimum wages and the changes and analyse how they have affected workers outcomes. We find that the minimum wage now strongly determines the wages of teenage workers, with the minimum wage now at the median wage of teenagers, and over half of $16-17$-year-olds, and about $40 \%$ of $18-19$-year-olds, earning at or below the minimum. Although we find no clear evidence that increases in the minimum wage have led to adverse employment effects, we expect there are downside risks for youth and low skilled workers' employment. As minimum wage workers are broadly spread across the household income distribution, we conclude that minimum wages are largely ineffective as a redistributive income support policy.

\section{JEL codes}

$\mathrm{J} 21, \mathrm{~J} 23, \mathrm{~J} 24, \mathrm{~J} 31, \mathrm{~J} 38$

\section{Keywords}

Minimum wages, employment, earnings inequality, income inequality

\section{Summary haiku}

Minimum wages:

Do they make a difference?

And if so, what for? 


\section{Table of Contents}

1 Introduction $\quad 1$

2 Background and review of timeline $\quad 2$

2.1 What is the rationale behind minimum wage policies? 3

2.2 Alternative inflation-adjusted minimum wage changes $\quad 8$

3 Review of recent minimum wage research $\quad 9$

$\begin{array}{llr}3.1 & \text { Recent international research } & 9\end{array}$

$\begin{array}{ll}3.2 & \text { NZ Time-series based research } \\ \end{array}$

$\begin{array}{llr}3.3 & \text { NZ cross sectional research } & 14\end{array}$

$\begin{array}{llr}3.4 & \text { NZ Qualitative research } & 20\end{array}$

4 What do recent data show? $\quad 21$

$\begin{array}{llr}4.1 & \text { Data Sources } & 21\end{array}$

$\begin{array}{llr}4.2 & \text { Descriptive patterns } & 23\end{array}$

5 Concluding discussion $\quad 41$

$\begin{array}{lll}5.1 & \text { What do minimum wages do? } & 41\end{array}$

$\begin{array}{lll}5.2 & \text { Implications for policy-setting } & 42\end{array}$

5.3 Continuing to build knowledge of minimum wage effects 44 


\section{Tables}

Table 1: Timeline of minimum wage policy changes since 2000

$\begin{array}{ll}\text { Table 2: Population characteristics } & 49\end{array}$

Table 3: Minimum Wage incidence by age group 50

Table 4: Minimum Wage incidence by selected demographic groups 51

Table 5: Minimum Wage incidence - teen industries 53

Table 6: Employment regressions on Kaitz index $\quad 54$

Table 7: Employment regressions on minimum wage bite $\quad 55$

Table 8: Counterfactual changes in Employees in response to MW change: 1997-2020 Estimation 56

Table 9: Counterfactual changes in Employment in response to MW change: 57

\section{Figures}

Figure 1: Real minimum wage trends under alternative inflation-adjustments 58

Figure 2: Trends in Minimum Wage, median wage, and Kaitz index 59

Figure 3: Distributional impact of the Minimum Wage 60

Figure 4: Cumulative change in the wage distributions - 2002-2008, and 2017-2020 61

Figure 5: Age profiles, 2000 and $2020 \quad 62$

Figure 6: Alternative measures of the Minimum Wage "bite” 64

Figure 7: Minimum Wages, employment, and study 66

Figure 8: Minimum wage and worker turnover rates $\quad 67$

Figure 9: Minimum wage incidence across Individual income distribution 68

Figure 10: Minimum wage incidence across Household income distribution 69

Figure 11: Incomes before and after being observed on the minimum wage 70 


\section{Introduction}

The past two decades have witnessed dramatic changes in the minimum wage landscape in New Zealand. The (adult) minimum wage has increased from \$7 per hour in 1999 to $\$ 18.90$ currently, representing a CPI-adjusted real increase of $75 \%$. In addition, the youth minimum wage (16-19 year olds), set at 60 percent of the adult rate in the 1990s, was eliminated between 2001 and 2008 , implying the real value of the minimum wage for youth workers has increased $124 \%$ since 1999. ${ }^{1}$

In this paper we provide a review of the minimum wage policy changes and the effects on workers' labour market outcomes, that have occurred since 2000. We start by documenting the timeline of minimum wage policy changes that have occurred and discuss possible alternative arguments for minimum wages in the context of these changes. We also document that the minimum wage increases over the period have been greater in CPI-adjusted than (Producer Price Index) PPI-adjusted terms, which suggests they have been more beneficial for workers than they have been costly to firms.

We then turn our attention to the data analysis. This is primarily based on data from the Household Labour Force Survey's (HLFS) annual June quarter Income Supplement (IS), which began in 1997. First, we focus on documenting changes over the period in the incidence of workers affected by the minimum wage, and how the minimum wage increases have affected the wage distribution, both for all workers and by identifiable subgroups. Second, we analyse the effects of minimum wages on employment; and how minimum wages affect employment turnover. Finally, we consider how effective minimum wages are as an income support policy, by analysing the incidence of minimum wages across both the individual and household income distributions.

The paper is organised as follows. In the next section we summarise the policy changes and review the possible rationales for these changes. Section 3 contains a review of the recent international, and the New Zealand, literature on the effects of minimum wages on employment and other outcomes. In section 4 we describe the HLFS and other IDI data used in our analysis,

\footnotetext{
${ }^{1}$ The abolition of the youth minimum wage rate was accompanied by the introduction of a 'training' minimum wage for youth in recognised training; and 'new entrant' (later 'starting out') minimum wages for inexperienced youth workers early in their employment spells. In each case, these minimum wages were set at $80 \%$ of the adult minimum wage. We discuss these in more detail in section 2.
} 
and present and discuss our results. The review concludes with a summary discussion in section 5.

\section{Background and review of timeline}

New Zealand entered the millennium with an adult minimum wage of $\$ 7$ per hour, that applied to workers aged 20 and over, and a youth minimum wage for 16-19 year-old workers, set at 60 percent of the adult rate ( $\$ 4.55$ per hour). Since then, minimum wages have increased dramatically to the current level of $\$ 18.90$ per hour, applying from aged 16 , representing a $75 \%$ CPI-adjusted real increase for adults. Table 1 summarises the timeline of main minimum wage policy changes over the past two decades.

Over this period there have been two main strands of policy changes. First, under the Labour coalition governments from 1999-2008 and since 2017, there have been steady increases in the inflation-adjusted real value of the (adult) minimum wage. From a worker's consumption perspective, ${ }^{2}$ the CPI-adjusted real minimum wage increased 34\% between 1999 and 2008, and is projected to increase about 19\% between 2017 and 2021 (based on the announced increase of the minimum wage to $\$ 20$ in April 2021). The minimum wage increases were more modest under the National coalition government, but still increased $14 \%$ in real value over the 2008-2017 period. Comparative OECD data shows NZ's minimum wage increased from $50 \%$ of the median wage in 2000 to $59 \%$ in 2008 (and from $45 \%$ to $51 \%$ of the average wage) and was then stable at $59-60 \%$ of the median wage until 2017 (51-52\% of the average wage). In comparison to other countries, these relative changes have been large with New Zealand's minimum wage moving from about the middle of the range of developed countries to near the top. ${ }^{3}$

Second, under the first Labour coalition government, the youth minimum wage rate was abolished in three tranches: first, the age range was changed from 16-19 to 16-17 in 2001; second, for $16-17$ year olds, the youth-to-adult relativity rate was increased from $60 \%$ to $70 \%$ in 2001 , then to $80 \%$ in 2002 , before being abolished in 2008 . Combined with the increasing (adult) minimum wage rates, these changes resulted in the minimum wage that applied to teenage

\footnotetext{
${ }^{2}$ In section 2.2 below, we consider the implications of alternative inflation-adjustments for the minimum wage changes, based on Producers Price Index for Inputs (PPII) or Outputs (PPIO), and Capital Goods Price Index (CGPI).

3 In comparison, Australia's minimum wage relative to the median (average) wage fell from $58 \%(50 \%)$ in 2000 to $55 \%$ $(47 \%)$ in 2017 ; the US federal minimum wage fell from $36 \%$ to $34 \%$ of the median wage ( $29 \%$ to $24 \%$ of the average); while the Canadian minimum wage rose from $41 \%$ to $46 \%$ of the median wage ( $38 \%$ to $41 \%$ of the average), mostly after 2009 ; and the UK minimum wage increased steadily from $41 \%$ to $54 \%$ of the median wage (and $34 \%$ to $44 \%$ of the average wage).
} 
workers increasing 124\% in real value between 1999 and 2008: for 18-19 year olds, this included a $65 \%$ increase in 2001 when the adult age was lowered to 18 ; and for $16-17$ year olds, this included 15-16\% increases in each of 2001 and 2002, and a 28\% increase when the youth rate was abolished in 2008.

In addition to these main policy changes, there have also been various changes in minimum wage exemptions, for youth workers in particular. These have generally included provision of lower minimum wage for youth, new teenage workers or those undertaking recognised training. Prior to 2001, there was a youth rate that applied to workers under the age of 20. This was set at 60 percent of the adult minimum in 1997, rising to 80 percent of the adult minimum in 2003. From March 2001 until April 2008, the youth rate applied only to workers under the age of 18 .

Since 2003, the sub-minimum rate has applied to varying groups of workers. First, in 2003 the training exemption was replaced with a 'Training minimum wage' at the sub-minimum rate, for workers whose employment agreement included a certain level of relevant training towards an NZQA qualification. From April 2008 when the youth minimum wage rate was abolished, a 'New Entrant minimum wage' was introduced at the sub-minimum rate, and applied to 16-17 year olds who had completed less than 3 months and 200 hours of total employment. From April 2013, a new 'Starting Out wage' replaced the 'New Entrants minimum wage', and the 'Training minimum wage' for trainees under the age of 20. The 'Starting Out wage' applies the sub-minimum rate to the first six months of work for 16-17 year olds in the first 6 months with a new employer, and for 18-19 year olds entering employment after 6 months receiving a social security benefit. It also applies to 16-19 year olds in a recognised industry training course involving at least 40 credits per year. The Training minimum wage continues to apply to trainees aged 20 and over who are required to undertake industry training of at least 60 credits a year.

\subsection{What is the rationale behind minimum wage policies?}

A key challenge for evaluating the effectiveness of minimum wage policies is the lack of a clear statement of what minimum wages aim to achieve. Minimum wage policies can potentially contribute to several key policy objectives. They do not, however, operate in isolation, and their impacts depend on their interactions with other policy settings in areas such as industrial relations, tax and benefit policies, employment and training policies, and business support, making evaluation even more challenging. 
In New Zealand, minimum wages were first introduced as a component of the industrial relations system, introduced with the Industrial Conciliation and Arbitration Act 1894. The setting of an agreed minimum wage was a means of preventing strikes and lockouts, replacing these "crude modes of settlement" (Hammond, 1917, p. 405) with compulsory arbitration. Agreed minimum wages also served to reduce price competition between employers who were able to remain profitable when paying higher wages (W. Rosenberg, 1971). It is difficult to disentangle the effects of minimum wages from the other elements of the industrial relations system.

In this section, we discuss four of the more commonly posited broad rationales for minimum wage policies, in the context of New Zealand's changes over the past two decades. Brosnan (2019) identifies a range of objectives to which minimum wage policies may contribute. These include providing income support to alleviate poverty; reducing injustice and employer exploitation in the labour market; helping to develop the economy by nudging firms and workers to be more productive; and on the basis of equality and human rights.

\subsubsection{Income support and poverty alleviation}

By design, minimum wages have their most direct effect on low-pay. The ILO Minimum WageFixing Machinery Convention, 1928 (No. 26), which New Zealand has ratified, captures a commitment to setting minimum wages as a targeted complement to other forms of wage setting. Minimum wages are to be used where "no arrangements exist for the effective regulation of wages by collective agreement or otherwise and wages are exceptionally low".

Reducing low pay is not the same as alleviating poverty, although the two are obviously related. Even workers paid above the minimum wage may face poverty if they need to support a large family, and low-paid workers may live in high-income households. At times, the level of the wage has been explicitly linked to living standards rather than just to relatively low pay levels. In New Zealand, the cost of living was first explicitly mentioned as a criterion for the level of the minimum wage in 1902 (Hammond, 1917, p. 418). By the 1930s, minimum wage levels were part of a redistributive income support policy to alleviate poverty by ensuring workers earn a wage sufficient to support themselves and their family. For example, the Industrial Conciliation and Arbitration Amendment Act of 1936 directed the Arbitration Court "... to fix a basic wage for male and female workers ... " and, for the male workers' wage, to "... take into consideration what will be adequate to supply the needs of a man, his wife and three children up to a reasonable standard of comfort." (ACIL (1994), page 3). Although the family wage concept was formally abandoned when the Minimum Wage Act 1945 was passed, and the 
setting of separate rates for men and women was eliminated with the 1972 Equal Pay Act, questions of income adequacy remain a part of current minimum wage debates in New Zealand. ${ }^{4}$ NZCTU (2015) states that "the underlying reason for minimum wage laws . . is to ensure workers have enough to live on". In recent years, discussions linking wage levels and income adequacy have been more focused on the Living Wage (St John \& So, 2017; https://www.livingwage.org.nz.). NZCTU notes that the minimum wage could become a structurally less important wage floor if wages are determined by Fair Pay agreements, Living Wages, and pay equity settlements.

The potential contribution of minimum wage policies as income support or for poverty alleviation depend also on the interaction with alternative income support policies, which are an important feature of New Zealand's welfare system. The growth of family support tax credit policies over recent decades (such as Working for Families) should make minimum wages less important in this regard. ${ }^{5}$ Such tax credit policies typically include incentives or obligations for low income family heads to increase their labour supply, with the tax credits providing earnings subsidies for low earners. One resulting concern is that, by increasing the labour supply of low skilled workers, such policies may put downward pressure on low wages (Leigh, 2010; Rothstein, 2010).

In the presence of in-work income support policies the level of the minimum wage has a direct effect on whether the costs of income support are borne by the government or by employers. By providing a wage floor, minimum wages may limit the implicit subsidy to firms, and complement tax credit policy. ${ }^{6}$ To our knowledge this argument has not been made in recent NZ debates.

\subsubsection{Fairness}

A second potential rationale for minimum wages is that they assist in reducing injustice from employer exploitation of low skilled workers, and "help ensure a just and equitable share of the fruits of progress to all" (International Labour Organisation, 2016, s. 1.1). For example: "[54] The MW Act exists to provide minimum essential terms and conditions of employment and to avoid the exploitation of employees with little or no bargaining power." (Chief Judge Colgan, quoted in

\footnotetext{
${ }^{4}$ Similarly, in the US "A family with two kids that earns the minimum wage still lives below the poverty line. That's wrong...Tonight, let's declare that in the wealthiest nation on Earth, no one who works full time should have to live in poverty." - President Barack Obama, State of the Union Address (February 12, 2013).

${ }^{5}$ Although workers without families and children are generally excluded from such tax credit support.

${ }^{6}$ Neumark and Wascher (2011) discusses the issues and analyses the relationship between minimum wages and the Earned Income Tax Credit (EITC) in the US. See also Lee and Saez (2012).
} 
the NZCTU's (2015) submission to the 2015 Minimum Wage Review, p. 78). This argument depends on there being a degree of non-competitiveness in the labour market. For example, in a textbook competitive labour market context in which firms are price and wage-takers, no exploitation occurs; rather there are workers who are prepared to work for low wages and there are low-wage jobs available. In contrast, in a monopsonistic or imperfectly competitive labour market, in which firms have some wage-setting power, their greater bargaining power over workers may result in workers earning lower wages than they otherwise would in a competitive market.

We consider the focus of this argument is one of 'low pay', distinct from the low-income support issue discussed previously. To the extent the prevailing wage is lower than a competitive market wage, minimum wages provide a mechanism for ensuring more equitable outcomes. In an imperfectly competitive labour market, setting a minimum wage above the prevailing wage and up to the competitive wage is predicted to increase both the wage earned by such workers, and also the level of employment. In contrast, in a competitive labour market, a minimum wage set above the prevailing (competitive) wage is predicted to reduce employment below the competitive level.

\subsubsection{Productivity and economic performance}

A third rationale claimed for (higher) minimum wages is that they can improve worker or firm productivity performance. For example, “A low minimum wage keeps New Zealand's general wage levels low and traps many workers and employers in a low-wage low-skill equilibrium. It consequently has negative consequences for productivity, equality, poverty, the gender pay gap and labour participation rates." (NZCTU, 2015, s. 7) There are several possible channels by which minimum wages may affect productivity, either directly through greater worker effort, or indirectly by encouraging low wage workers or firms to invest in more training to improve their skill levels, or by encouraging firms to change their production technologies and raise labour productivity or by encouraging the reallocation of workers to more productive firms (International Labour Organisation, 2016).

Efficiency wage models imply that a higher minimum wage for low-skilled workers will encourage greater effort and motivation and so higher productivity (Coviello et al., 2018; Riley \& Bondibene, 2017). Higher wages may also reduce turnover and result in higher productivity; in addition, lower turnover may increase incentives for firms to provide training and raise productivity (Acemoglu \& Pischke, 1999). Alternatively, higher minimum wages may cause productivity gains via job-reallocation from lower wage to higher wage firms (Dustmann et al., 
2019). In related research, Acemoglu and Pischke (2003) analyse the effects of minimum wage changes on firm provided training. They argue that training is predicted to decrease in competitive labour markets, but increase in non-competitive markets because higher minimum wages will induce firms to train their unskilled workers. They find no evidence that minimum wages reduce training, but also little evidence that training is increased.

Historically, minimum wage setting has been considered as a tool in macroeconomic stabilisation policy. Endres (1990) documents the debates of the 1930s about how best to manage the level of real wages in order to stimulate aggregate economic activity. This approach to 'wages policy' has been largely absent from minimum wage debates in recent decades, when minimum wages have been considered primarily as an element of microeconomic policy.

\subsubsection{Human rights}

Finally, minimum wage policy changes have been argued on human rights grounds. Although potentially related to injustice and labour market exploitation, we believe this involves a separate issue. For example, one factor behind the abolition of the youth minimum wage in 2008 was that it discriminated against young workers on the basis of their age. This change resulted in a single minimum wage, albeit with exemptions for 'new-entrants' or 'starting-out' teenage workers, and those undertaking approved training, being expected to achieve potentially multiple objectives. Thus, when considering what is a relevant minimum wage, this necessarily applies to all workers. In contrast, different workers often have different skills, needs and expectations; and, importantly, these vary over the life cycle. ${ }^{7}$ An implication of this is that an appropriate minimum wage for prime-aged adult workers is likely to differ from that for young workers.

In fact, New Zealand is relatively unusual among developed countries with minimum wage legislation in currently not having separate minimum wage rates for younger workers. For example, age-based ('junior pay') rates are common in award settings in Australia. The UK currently has four age-based minimum wages, as well as a minimum wage for Apprentices: a minimum wage (the National Living Wage, NLW) for workers aged $25+(£ 8.72 /$ hour effective 1 April 2020), $£ 8.20 /$ hour (94\% of the NLW) for workers aged $21-24, £ 6.45 /$ hour ( $74 \%$ of the NLW) for workers aged $18-20$, and $£ 4.55 /$ hour ( $52 \%$ of the NLW) for workers aged $16-17 .{ }^{8}$ In the

\footnotetext{
${ }^{7}$ For example, human capital theory implies, and empirical analysis confirms that average wages increase dramatically during the early years of workers careers, before flattening out and declining during their later years (Heckman et al., 2003; Polachek, 2008).

8 In 2015, the UK government set a target for the NLW to increase to $60 \%$ of median earnings by 2020 (its current level), and has set a new target to increase the NLW to two-thirds of median earnings by 2024 .
} 
Netherlands, the minimum wage varies across each year-of-age: effective 1 July 2020, from

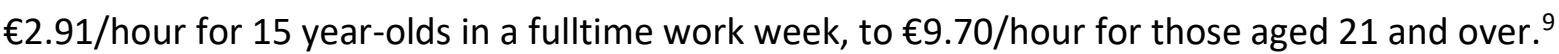

\subsection{Alternative inflation-adjusted minimum wage changes}

We begin by considering the growth in the inflation-adjusted real adult minimum wage since 1999, based on alternative inflation adjustments. To the extent alternative inflation indexes are highly correlated and move closely together, the choice of which to use as the deflator is largely moot. However, if the indexes are less correlated, the choice may become more important, and the relevant deflator depends on the focus of the question.

For this comparison we consider four separate indexes. First, the Consumers Price Index (CPI), which is the more relevant deflator when considering workers' (consumption) purchasing power. Second, the Producers Price Index for Inputs (PPII) is likely more relevant in terms of firms' production costs, giving how labour costs change relative to other inputs used by firms. Third, the Producers Price Index for Outputs (PPIO) is relevant in terms of the marginal revenue product firms earn from their outputs, by measuring how the minimum wage changes relative to the value of firms' outputs. Finally, we consider the Capital Goods Price Index (CGPI), which will measure how minimum wages are changing in relation to the price of firms' capital investments. Figure 1 graphs the trends in the real minimum wage, as adjusted by each of these four price indexes, since 1999. The minimum wage is expressed in June-quarter $2020 \$$-values for each series (i.e., the minimum wage is $\$ 18.90$ in June-quarter 2020 for each series), and shows how the minimum wage increased relative to each index over time.

Although the series in Figure 1 imply strong increases in inflation-adjusted minimum wages over the period using each index, the cumulative differences vary quite noticeably. In particular, the minimum wage grew strongest relative to the CPI, rising 75\% from \$10.80 in 1999 to $\$ 18.90$ in $2020 ;^{10}$ while the growth was weakest relative to PPII, with the minimum wage increasing 55\% from $\$ 12.16$ in 1999 to $\$ 18.90$ in 2020. (The increases relative to PPIO and CGPI were $59 \%$ and $66 \%$ respectively.) That is, the wedge been the CPI and PPII changes over the period which underly these differences, means that the spending power of minimum wage workers increased $75 \%$ over the period while their cost relative to firms' other inputs only increased $55 \%$. In this sense, the minimum wage increases have been relatively more beneficial

\footnotetext{
9 The minimum wage also varies according to the length of the fulltime work week (36, 38 and 40 hours).

10 The CPI series includes an estimated 2\% increase in December quarter 2010 due to the increase in GST from $12.5 \%$ to $15 \%$. As this increase occurred in conjunction with reductions in income tax rates, adjusting minimum wages using the headline CPI will tend to overstate the effect on workers' consumption power associated with this change.
} 
to workers' (consumer) spending power than they have been detrimental to firms' production costs.

\section{Review of recent minimum wage research}

\subsection{Recent international research}

Research on the effects of minimum wages on employment remains active internationally. Much of the research is US based, reflecting the availability of cross-state variation in minimum wages associated with different state and federal minimum wage rates, and more recently also within state county and city minimum wage setting providing further variation. However, minimum wage research has also become more active in the UK, since the introduction of the national minimum wage rates in the late 1990s, as well as other countries. Our reading of the recent literature is that minimum wages have relatively benign (or even positive) labour market effects on low-skilled workers employment prospects. However, there continues to be a relatively contested and heated debate around this conclusion. For this reason, we briefly review the main results from the two competing strands of recent research.

The first strand of research we review are papers by Dube and co-authors (Allegretto et al., 2017; Dube, 2019). Dube (2019) provides a broad review of the (mostly US) international minimum wage literature for the UK Low Pay Commission, in which he reports that the median estimate of the own-wage employment elasticity (OWE) for affected groups is -0.16 , and for broader groups of workers the median OWE is -0.04 . Thus, although there is variation across studies, he concludes that "... the weight of the evidence suggests any job losses are quite small." (p.50). However, he does caution that the evidence of high minimum wage effects is still developing, with the caveat that the evidence is based on state-level variation in minimum wages below 60 percent of the median wage, although some county-level variation in minimum wages up to 80 percent of the median. In pondering the issue of how minimum wage increases have been absorbed if not through employment losses, Dube discusses the evidence on product price and productivity as margins of responses, and firms' monopsony labour market power for why employment effects are relatively small.

The second strand can be summarised by a series of papers involving Neumark and coauthors (Neumark, 2019; Neumark et al., 2014; Neumark \& Wascher, 2011, 2017). In his review of the employment effects of higher minimum wages, Neumark (2015b) argues that addressing counterfactual control issues results in adverse employment effects with elasticities on the 
order of $-0.1--0.3$ for young workers. Curiously this range includes Dube's (2019) -0.16 median OWE estimate, suggesting different interpretations of the same results. In addition, Neumark (2015a) argues that, although raising minimum wages benefits some workers, it is a poorly targeted income support policy for low income families. ${ }^{11}$

A series of papers (Allegretto et al., 2011, 2017; Neumark et al., 2014; Neumark \& Wascher, 2017) debate the credible econometric identification of minimum wage effects using state level variation. The contested issues include whether the use of state and year fixed effects, and local area controls, absorb potentially endogenous variation that would bias the resulting estimates, or throw away too much potentially useful (i.e. exogenous) variation and rendering the resulting estimates largely uninformative. In addition, is a debate around the use of close geographic areas as counterfactual comparisons versus the use of other areas based on synthetic control methods. While Allegretto et al. (2011) and Allegretto et al. (2017) argue that geographically-close areas are likely to provide better controls, Neumark et al. (2014) argue that minimum wage increases may be more endogenous within close geographic areas. ${ }^{12}$ There is no simple resolution to these arguments; however they provide a useful reminder to carefully assess the robustness of the identification in any research.

While the bulk of international minimum wage research has focused on identifying employment effects, there are also many studies that have examined other outcomes for workers and firms, and broader impacts across the labour market and economy. A broad overview of these studies is provided by Belman \& Wolfson (2014), Dube (2019) and in an annex to ILO (2016).

\subsection{NZ Time-series based research}

The early New Zealand research on the effects of minimum wages used time series analysis of aggregate data. Appendix Table A1 summarises this research, which also includes Pacheco (2011), which was based on unit record data but used time series variation. The research generally adopts a regression specification, such as:

$$
\log \left(Y_{t}\right)=\alpha+\sum_{j=0}^{J} \gamma_{j} \log \left(R M W_{t-j}\right)+\sum_{k=0}^{K} \theta_{k} \log \left(D_{t-k}\right)+v t+\rho X_{t}+u_{t}
$$

where $Y_{t}$ is an outcome of interest (such as the employment rate) measured in period $\mathrm{t}$ (generally quarterly), $R M W_{t}$ is a measure of either the real or relative minimum wage (e.g.

\footnotetext{
${ }^{11}$ We discuss this issue further in the context of NZ evidence in section 3.3.2, and our re-analysis in section 4.2.6, below.

${ }^{12}$ As Neumark (2019) states "As Jeffrey Clemens once remarked, 'If the regions are so damn similar, why do they have different minimum wages?"” (p.308).
} 
measured relative to the PPII or average wage), $D_{t}$ is a measure of the economic cycle (e.g. the prime aged unemployment rate, or GDP growth), $t$ provides a linear time trend, $X_{t}$ is a vector of other control variables (e.g. education enrolment rates), and $u_{t}$ is an error term to capture other unobserved factors. Measured quarterly, to allow for dynamic adjustment, the model may include current and previous lags of the minimum wage variable and business cycle (e.g. $J=$ $K=4$ would allow adjustment to occur over four quarters). The coefficient $\gamma_{j}$ measures the period- $t$ elasticity of response in the outcome to the minimum wage $j$-quarters ago; and the sum of these $\left(\sum_{j=0}^{J} \gamma_{j}\right)$ is the total long-run elasticity.

The first paper in this literature is Maloney's (1995) analysis of the effects of minimum wages on the employment of young adults (aged 20-24) over the period 1985-93. There were substantial increases in the adult minimum wage in 1985 and 1987, albeit from a relatively low level, supporting the ability to identify employment impacts. The adult minimum was $31 \%$ of the average wage in February 1985, rising to 50\% in September 1985. Maloney estimated separate regressions for young adults and for teenagers (aged 16-19), for whom the minimum wage did not apply until the 1994 introduction of the youth minimum wage. He specified $Y_{t}=$ $E_{A g e, t} / E_{25+, t}\left(E_{A g e, t}\right.$ is the employment rate of 20-24s and 16-19s respectively), $R M W_{t}=$ $M W_{t} / A v g W_{t}\left(A v g W_{t}\right.$ is the average hourly wages of all workers), included five lags $(J=5)$, and controls for an linear time trend, quarterly seasonal indicators, the unemployment rate of workers aged $25+$, and relative age-specific benefit and education enrolment rates. Although the minimum wage coefficients of interest are generally not individually statistically significant, Maloney estimated statistically significant cumulative employment effects for young adults, and also positive employment spillovers to teenagers, at a time when the minimum wage for youth was considerably lower than it is today. The estimates imply a $10 \%$ (relative to average wage) increase in the minimum wage would reduce young adult employment by 3.5\% (5.7\% with no qualifications), and increase youth employment by $6.9 \%$, relative to adult employment.

Chapple (1997) extended and re-evaluated Maloney's specification with additional data (1985-97). Chapple again focused on young adult employment $\left(Y_{t}\right.$ is the employment rate of 2024 year olds), specified the minimum wage relative to the producers' output price index (PPIO) and included four quarter lags; he also controlled for the employment rate for the rest of the population, current and four lags of both the average wage relative to PPIO and the PPII relative 
to PPIO, a linear trend and quarter seasonal indicators. ${ }^{13}$ Based on the preferred (full specification), Chapple estimated the long run employment elasticity with respect to the real minimum wage, controlling for average wage movements, was -0.18 and not statistically significant. ${ }^{14}$ Chapple concludes that negative employment effects associated with minimum wage increases are not robust to variation in period and model specifications, and recommends caution in interpreting results for policy decisions. In particular, Chapple emphasises the major policy and structural changes that occurred over the period, including the introduction of the Employment Contracts Act (ECA) in 1991 and the youth minimum wage in 1994.

Pacheco \& Maloney (1999) analyse the minimum wage effects on the employment of women with no qualifications, using HLFS data over 1985-2000. Based on similar specifications to those above, they obtain cumulative employment elasticities that generally insignificantly different from zero (elasticities typically less than -0.2 for groups aged $15+$ and $20+$; and about 0.2-0.4 for 20-29 year olds); and only find statistically significant negative effects (of about -0.4) when they exclude the time trend.

The final employment analysis by Pacheco (2011) analyses the effects of minimum wage changes on youth and young adult (aged 16-29) employment rates, and focuses on the effects when the minimum wage is potentially binding, using unit record HLFS data over the period 1986-2004. Because she is using unit record data, Pacheco is able to control for a relatively rich set of covariates, including individual and household demographics, but the main identification comes from the time variation in the minimum wages (deflated by PPII), which is specified as the current and four quarter lags.

Pacheco's base results show statistically significant positive employment effects (elasticity 0.03) over all 16-29 year olds (which masks small negative elasticities for 16-17, 20-24 and 25-29 year olds, and a slightly larger elasticity for 18-19 year olds); but the reported effects when the minimum wage is binding are consistently negative, with the elasticity ranging from -0.11 for 20 24 year olds to -0.82 for $16-17$ year olds). However, the reliability of the reported sampling errors is concerning: i.e. given the identifying variation is essentially time series, there appears to be no adjustment for group-level clustering of the estimated standard errors (e.g. see Moulton, 1986); in addition, whether the minimum wage is binding is estimated, and there is no

\footnotetext{
13 This specification frees up the restrictions imposed on the relevant price deflator and population employment rate. Chapple also tested and rejected the need for an indicator variable to control for the 1994 introduction of the youth minimum wage.

${ }^{14}$ To examine heterogeneous effects across industries, Chapple also estimated annual industry panel models based on Quarterly Employment Survey (QES) data from 1980 to 1997, which also show small negative employment effects.
} 
adjustment for this. As a result, we expect the reported standard errors are an order of magnitude too small, implying deceptively strong statistical significance.

In other research, Pacheco and Cruickshank (2007) analyse the effects of minimum wage changes in education enrolment of teenagers and young adults using a synthetic panel data set over the period 1986-2004. The theoretical effects are ambiguous: on one hand higher minimum wages potentially raise the opportunity cost of remaining in education; on the other hand, especially if there are adverse employment effects, higher minimum wages may increase the value of education. The education enrolments are derived from Ministry of Education $(\mathrm{MOE})$, and the specification controls for age-specific education spending, fixed effects and interactions with the prime-aged male unemployment rate and a linear time trend. Although the focus is on the coefficient of the ( $\log$ ) real minimum wage (deflated by the PPII), the models also include an indicator for the introduction of the youth minimum wage in 1994. Pacheco and Cruickshank find consistently negative (and generally statistically significant) minimum wage effects on education enrolments of 16-19 year-olds (elasticity about -0.1), and positive but insignificant effects for 20-24 year-olds. In addition, the coefficient on the youth minimum wage dummy variable is consistently positive, implying higher teenage enrolment after 1994. This suggests either a complicated relationship or, perhaps more likely, further evidence on the nonrobustness of time-series based analysis over this period.

\subsubsection{DOL / MBIE annual review modelling}

MBIE's current in-house model for estimating the minimum wage effects on employment is based on this time series literature. It adopts a model of the following form:

$$
\log \left(Y_{t}\right)=\alpha+\sum_{i=1}^{4} \beta_{i} \log \left(Y_{t-i}\right)+\sum_{j=0}^{4} \gamma_{j} \log \left(\text { Kaitz }_{t-j}\right)+\sum_{k=0}^{4} \theta_{k} \log \left(D_{t-k}\right)+v t+\rho X_{t}+u_{t}
$$

where $\mathrm{Y}$ is the labour market (LM) outcome of interest (e.g. employment, FTE employment, hours worked); Kaitz is the minimum wage index, measured as the ratio of the minimum wage to average wage (presumably the full-population or adult working wage); $D$ is some economic cycle control variable; $X$ a vector of other control variables (seasonal, other policy controls); $t$ is a (linear) time trend; and $u$ is a random error.

Importantly, the model may be estimated either for full-population aggregate outcomes, or for population sub-groups - e.g. by age group, sex, or ethnicity. However, when estimated as single equations for sub-populations, only own-group elasticity are estimated: in particular, it does not allow any (cross-elasticity) interdependencies between the groups. 
Given the major policy and other structural changes that have occurred over the estimation period since the mid-1980s, we consider the time-series based analyses relatively fragile with respect to the adopted specifications. Arguably more recent subperiods (e.g. since the mid-1990s) are potentially more stable, leading to more robust analyses. However, even then, any analysis relies on the assumption that the underlying relationship of interest is constant, or changes can be adequately controlled for. A limitation of the policy modelling, which is common to most of the time series studies, is that it aims to identify only the short- to medium-run employment effects, and does not attempt the (considerably more challenging) task of modelling the broader impacts that may arise through changes in aggregate demand and prices, or fiscal impacts.

\subsection{NZ cross sectional research}

We next review the NZ evidence based on unit record analysis, which we classify as cross sectional identification and research. Appendix Table A2 summarises the literature that we review here: as well as analysing the effects of minimum wages on employment, it also covers other topics, including the analysis of the incidence of minimum wages across workers, the effects on wage and income inequality, and the effects on firm share prices. We begin by reviewing the research on employment effects, and then proceed to that covering other topics.

\subsubsection{Estimated impacts on employment}

Hyslop and Stillman $(2004,2007,2011)$ provide analyses of the impacts of discrete increases in youth minimum wages on teenage employment following the 2001 and 2008 policy changes. Each study adopts a regression-adjusted difference-in-difference approach to identify the relevant effect, measured as the change in employment rate from before to after the policy change of teenagers directly-affected by the policy change relative to young adults not directly affected. This approach relies on the common-trends assumption that, in the absence of the policy change, the employment rates of teenagers and young adults would move in parallel, so that changes in the employment rate of young adults provides a valid counterfactual for that of teenagers absent the policy change.

As discussed above, the 2001 policy change lowered the age of eligibility for the adult minimum wage from 20 to 18 , and raised the youth minimum wage from $60 \%$ to $80 \%$ of the adult rate in two annual steps. Hyslop and Stillman's $(2004,2007)$ research design compared the employment rates of $18-19$ s and $16-17$ s separately to that of $20-24$ year olds. Also, to allow for possible indirect employment spillover effects from teenagers to young adults, they assumed 
this was restricted to 20-21 year-olds (as close substitutes), and that 22-24 year-olds were not indirectly affected. ${ }^{15}$ They find no evidence of any immediate employment loss for 18 -19s or 16 17s, but some weak evidence of small employment loss after 3 years: about 2 percentage points (pp) for 18-19s (implying an elasticity of around -0.03), and 2-4 pp for 16-17s (elasticity of between -0.05 and -0.1 ). They also found some evidence $16-17$ year olds increased they hours worked by $10-20 \%$.

Hyslop and Stillman (2011) similarly analysed the effect of the 2008 policy that abolished the youth minimum wage, thus lowering the eligibility age for the adult minimum to 16 years. This analysis focused on 16-17 year-olds, and compared changes in their employment rate with that of 20-21 year-olds (thus allowing $18-19$ s to be indirectly affected via spillover). In contrast to the previous analysis, Hyslop and Stillman concluded that the minimum wage increase lowered the employment rate of 16-17 year-olds by 3-6 pp in 2009 and 2010 (implying an elasticity of between -0.1 and -0.2 ), with some apparent employment substitution towards 18 19 year-olds. The adverse employment effects were apparently concentrated among those also studying; with the employment rate of non-students increasing about $3 \mathrm{pp}$. Hyslop and Stillman also found some evidence that both education enrolment and unemployment of $16-17 \mathrm{~s}$ increased, while the inactivity rate declined.

Eckert et al. (2018) revisit these two policy changes in an attempt to rationalise their divergent impacts, using linked employer-employee data (LEED) from 2000-2011 for 16-24 yearolds. To do this, they focus on differences in the level of the "bite" of the minimum wage (measured as minimum wage/average wage) over the period, as well as possible differences in the impacts over the business cycle (proxied by the unemployment rate of 25-64 year-olds). Eckert et al. find evidence that the impacts on employment are stronger as both the minimum wage bite increases and the state of the business cycle worsens, with both the main effects and also their interaction having statistically significant coefficients. For example, they estimate that a $20 \%$ higher minimum wage results in about $0.38 \mathrm{pp}$ employment loss, while a $5 \mathrm{pp}$ increase in unemployment reduces employment by about $0.12 \mathrm{pp}$, and both effects combined would reduce employment by about $0.51 \mathrm{pp}$. These results help to explain, at least partially, the differences in estimated impacts associated with the two reforms. In addition, Eckert et al.

\footnotetext{
15 For example, if employers substituted away from teens and employed 20-21 year-olds instead, this would cause the employment rate of 20-21s to increase as well as that of teens to decrease: comparing changes in these would bias upwards the adverse employment effect for teens. Given the smaller increase in minimum wages for 16-17 year-olds, arguably firms may have also substituted from 18-19 to 16-17 year-old workers.
} 
(2018) find that the employment effects associated with the minimum wage bite occur primarily through a reduction in firm hiring, with there being no significant effect on worker separations.

A standard result from production theory is that the labour demand response to minimum wage changes will be larger for firms with greater exposure to minimum wage workers. The final paper we review, Hyslop et al. (2012), addresses this issue, and tests whether the employment response of firms varies systematically according to their level of teen employment, using LEED over the period 1999-2007. The changes in youth minimum wages over the period increased the relative wages of teenagers by $5-10 \%$. They document that although the effect on firms' average wage bill was small (about 0.5\%), it was somewhat larger (1.5\%) for firms in the four main teen industries, and about $5 \%$ on average for a significant fraction of high teenage employing firms. Although the analysis was largely circumstantial, in that the LEED did not identify workers' hourly wage rates, they did find support for the hypothesis that high teenemployers had exhibited greater response to the minimum wage increases. They reduced their teen employment by 15-20 percentage points relative to other firms; and also had lower survival rates (about $5 \%$ among those in the main-teen industries, and $10-20 \%$ in other industries).

\subsubsection{Effects on firm performance, wage and income inequality, and poverty}

Panel B of Table A2 summarises minimum wage research on other outcomes. This includes the effects on expected firm profitability (Pacheco \& Naiker, 2006); the effects of the youth minimum wage increases on wage inequality (Pacheco, 2009a); and the effects on household income distribution and poverty rates (Maloney \& Pacheco, 2012).

Pacheco and Naiker (2006) provide some analysis of the possible effects of minimum wage increases on firm share prices. Using an event study approach, they focus on daily share price responses to ten youth minimum wage policy announcements between November 1999 and December 2000, for 32 firms in high minimum wage industries (Retail, Textile and Apparel, Accommodation, Cafes and Restaurants, and Agriculture, Forestry and Fishing). The results are generally both inconclusively signed and statistically insignificant. Although the authors interpret this as "surprising given significant minimum wage reform ... ", the initial reform had a relatively small effect on wages (Hyslop \& Stillman, 2007), and the average effect on firms' wage bills of increasing minimum wages for teenagers was quite modest even within the main teenage industries (Hyslop et al., 2012). In addition, the inconclusive results may be due to the sample of firms being either too small, selective, or poorly identified in terms of their exposure to minimum wage workers. 
Pacheco (2009a) uses HLFS-IS data over 1997-2007 to analyse the effects of the large changes in youth minimum wages on wage inequality. Comparing changes in youth versus adult wage dispersion over the period, she shows there were relatively large reductions in youth wage inequality between 1997-99 and 2005-07. This occurred particularly in the lower tail of the wage distributions where the $50 / 10$ ratio fell 0.13 for youth compared to a 0.02 increase for adults. Using estimates from HLFS-IS data for the period 1998-2015, Rosenberg (2017) estimates that the average wages of workers in the lowest wage decile increased nearly $40 \%$ in real terms, much stronger than the $18-20 \%$ increases for workers in deciles $2-6$, and roughly equal to the average wage increase of workers in the top decile. Rosenberg also graphs the trends in the adult minimum wage and the decile- 1 upper boundary over the period: this shows the minimum wage gradually increases, and since 2006 has converged with the decile-1 boundary wage. This implies the minimum wage increases have been the dominant cause of the substantial increase in the decile-1 average wages.

Maloney and Pacheco (2012) first document strong increases in the incidence of minimum wage workers between 1997 and 2008: from 1-2\% to 12\% overall, and from about 2\% to over $60 \%$ among teenagers, and from $3-4 \%$ to over $30 \%$ in minimum wage dominant industries. However, they show that minimum wage workers are broadly spread across the household equivalised income distribution, albeit with a tendency for such workers to be over-represented in deciles 2-4, and under-represented in deciles 7-10. Because of this, Maloney and Pacheco conclude that the increases in minimum wages over the period had only mild effects on household poverty. For example, based on simulations, in the 'best case' scenario assuming no employment effects, they estimate that a $10 \%$ increase in the minimum wage would reduce the poverty rate by $0.08 \mathrm{pp}(0.36 \%)$; and assuming a labour demand elasticity of -0.3 for minimum wage employment, they estimate such a minimum wage increase would reduce poverty by about $0.05 \mathrm{pp}(0.23 \%)$.

Alinaghi et al. (2019) use the Treasury's TaxWell-B microsimulation model to provide a more formal analysis of the effect of increasing the minimum wage on household income inequality. The TaxWell-B model was based on 2012/13 Household Economic Survey (HES) data, and they simulated the effect of an increase in the minimum wage from $\$ 13.50$ to $\$ 16.50$ (corresponding to an increase from about $50 \%$ to $60 \%$ of average wages). Alinaghi et al. also estimate relatively modest effects of the hypothesised minimum wage increase on inequality, although somewhat greater than Maloney and Pacheco's (2012) estimates - e.g. the Gini 
coefficient is estimated to fall $1.7 \% .{ }^{16}$ However, as TaxWell models only the direct effects of the minimum wage increase and labour supply responses, with no labour demand or wage spillover effects associated with higher minimum wages, the results will be upward-biased in the presence of adverse employment effects.

\subsubsection{The incidence of minimum wages}

In panel $\mathrm{C}$ of Table $\mathrm{A} 2$ we summarise research that focuses on the incidence of minimum wages across workers and firms. In two companion papers Pacheco (2007) and Pacheco (2009b) analyse the incidence, characteristics of minimum (and sub-minimum) wage workers, and changes in these over the period 1997-2004. ${ }^{17}$ Pacheco (2009b) first shows that the characteristics of sub-minimum and minimum wage workers are broadly similar, although subminimum wage workers are slightly more similar to other workers than those earning minimum wages, suggesting sub-minimum workers are a mix of low-wage workers and others with mismeasured wages. The average incidence of sub-minimum and minimum wage workers was $5.75 \%$ over the period, increasing from $4.6 \%$ to $8.1 \%$ between 2000 and 2004 . The incidence was higher among younger, female, Maori, Pacifica, part-time workers, and those with no qualifications. As well as there being a higher incidence of minimum wage workers, these groups also showed relatively strong growth in incidence over the period. Pacheco (2007) concludes that age is the dominant characteristic associated with the rising incidence over the period, which is not surprising this covers the initial youth minimum wage reform.

Maloney and Pacheco (2010) extend Pacheco's analyses to consider how to interpret the minimum wage incidence in the presence of possible behavioural responses by firms (i.e. reduced employment) to rising minimum wage levels over the period 1997-2008. Maloney and Pacheco classify minimum wage workers using two criteria: narrowly as those who are paid strictly less than or equal to the prevailing minimum wage; or more broadly those who are paid less than $5 \%$ above the minimum wage. They again show strong increases in the incidence of

\footnotetext{
${ }^{16}$ They also consider alternative Atkinson inequality measures. Except for the measure with the highest degree of relative inequality aversion reported $(\varepsilon=2.0)$, inequality is estimated to decrease by between $1.5 \%(\varepsilon=1.4)$ and $3.5 \%(\varepsilon=0.1)$. In contrast, the measure with $\varepsilon=2.0$ is estimated to increase by $0.3 \%$. The lower reductions in inequality as $\varepsilon$ increases is presumably because minimum wage workers are over-represented in deciles 2-5 (Maloney \& Pacheco, 2012), so that the minimum wage increase benefits this group at the expense of the bottom decile. Also, tabulations of the impacts on the Atkinson measures with and without the modelled increase in labour supply of low-wage workers, implies that most of the simulated inequality reductions are due to increasing labour supply, and relatively little is associated with the direct effect of higher wages, which was the focus of Maloney and Pacheco's analysis (2012).

17 Pacheco classified minimum wage workers as those whose wage was between the minimum wage and $10 \%$ above the minimum wage.
} 
minimum wage workers over the period using either criteria: using the narrow measure, from $2.5 \%$ in 2000 to $10.4 \%$ in 2008 (and from $3.0 \%$ to $14.7 \%$ using the broad measure).

They then propose a decomposition of changes in the incidence $(P)$ for different age groups over time into a mechanical component $\left(P^{M}\right)$ associated with the increase in minimum wage assuming no change in either employment or the wage distribution, a behavioural component $\left(P^{B}\right)$ associated with any employment loss from a minimum wage increase, and other factors that change the wage distribution $\left(P^{O}\right)$, such as general wage increases or minimum wage spillover effects:

$$
\Delta P_{i t}=\Delta P_{i t}^{M}+\Delta P_{i t}^{B}+\Delta P_{i t}^{O} \text {, for age group-i in year-t, }
$$

where $\Delta P_{i t}=P_{i t}-P_{i t-1}$, etc. Minimum wage increases larger than nominal wage growth are expected to increase the total incidence of minimum wage workers: it will increase the mechanical component, may reduce the behavioural component if there is employment loss, and have an ambiguous effect on the other component. Although $\Delta P_{i t}^{M}$ can be directly estimated as the fraction of workers in year-(t-1) that have wages between the year-(t-1) and year-t minimum wages, $\Delta P_{i t}^{B}$ and $\Delta P_{i t}^{O}$ must be modelled. Maloney and Pacheco make the fairly strong identifying assumption that a simple linear relationship exists between $\Delta P_{i t}^{B}$ and changes in the minimum wage $\left(\Delta m w_{i t}\right)$, and that $\Delta P_{i t}^{O}$ is fully captured by age-group and year-specific additive effects. They then regress the difference between actual and mechanical changes on $\Delta m w_{i t}$, age-group and year-effects.

Maloney and Pacheco find that, across age groups between 1997 and 2008, the year-toyear actual increase in minimum wage incidence is about one-third of the increase in the mechanical component on average. Conditional on their identifying assumptions, they find no significant contribution associated with $\Delta m w_{i t}$, and conclude that there were no systematic employment losses associated with the rising minimum wages. The lower-than-expected increase in incidence is attributed to wage increases that move the affected workers above the new minimum wage.

\subsubsection{DOL / MBIE annual review analysis}

MBIE's regular annual minimum wage reviews make use of the income survey microdata primarily to show the composition of the minimum wage workforce by key demographic or firm characteristics. They do provide overall incidence rates for workers being paid at or around the 
minimum wage ${ }^{18}$ but their summaries generally focus on composition (what proportion of minimum wage workers have particular characteristics) rather than on incidence (what proportion of workers with particular characteristics are paid the minimum wage). Their analysis also estimates the impact that minimum wage changes would have on the incomes of households, using a range of model households defined by location, hours of work, household size.

\subsection{NZ Qualitative research}

MBIE's National Survey of Employers collects topical information on a range of employment issues. The range of questions varies each year but generally includes at least some information about employers' use of minimum wages. In 2018/19, around 2,300 employers were surveyed. Twenty-seven percent of employers reported paying at least one employee on the adult minimum wage. Around a quarter of those employers reported paying more than half of their workers at the level of the adult minimum wage, although for $44 \%$ of employers, the adult minimum was paid to less than $10 \%$ of employees.

The 2018/19 survey included a question about employer responses to increased minimum wages. Over half of employers (56\%) reporting doing nothing different. However, twenty-one percent of employers reported increasing the prices of goods and services, effectively passing on some of the cost of increases to consumers. A further $21 \%$ reported reductions in either working hours $(8 \%)$ or employment, by not replacing staff who left $(13 \%)$. Consistent with evidence presented below, $29 \%$ of employers reported that the increase in minimum wages resulted in their increasing wages for employees already earning above the level of the minimum wage.

Houghton (2012) combined insights from the 2011 National Survey of Employers with more in-depth qualitative interviews with 53 employers in late 2011, who were spread across the country, and from four sectors of the economy: Hospitality, Retail, Manufacturing and Agriculture, forestry and fishing. Her study provides an interesting analysis of employer awareness and responses to minimum wage changes.

\footnotetext{
${ }^{18}$ The incidence rates reported by MBIE are slightly lower than the incidence rates reported in section 4 below. MBIE do not include workers on extremely low wage rates, on the reasonable grounds that these are highly likely to be a result of reporting or measurement errors.
} 
Houghton (2012) concluded that small increases, that keep the minimum wage constant, were generally able to absorbed by firms and had little impact on their behaviour. In contrast, firms reported a combination of wage and hiring responses to larger minimum wage increases, including reducing hours of work or number of workers, not filling vacancies, using more casual workers, raising expectations when hiring, substituting capital, and some reported they would hire fewer youth workers, as they were viewed as being less productive than older employees. Other non-labour responses included raising prices, reducing other costs, and some hospitality employers reported closing some of their outlets.

This qualitative evidence is complementary to the recent quantitative research and concludes that the minimum wage effects are mixed across employers. This emphasises the difficulty of measuring adverse employment effects in response to small increases in the minimum wage; and the importance of the minimum wage being substantively binding to be able to identify a response. ${ }^{19}$ Thus, small or non-binding increases can generally be absorbed by firms, making any adverse effects difficult to detect. This helps to understand why the two comparable studies of the 2001 and 2008 youth minimum wage reforms by Hyslop and Stillman (2011) reached quite different results. Although the scale of the increases were large in each case (in fact the first reform increases were larger), minimum wages were substantially more binding by 2008 than in 2001. A third potential factor is the state of the business cycle, which also differed for the two reforms.

\section{What do recent data show?}

\subsection{Data Sources}

Our data analysis uses data from various sources. The primary source comes from the annual June-quarter HLFS-Income Supplement (IS), since it commenced in 1997 until 2020. The IS exists as standalone data from 1997-2006, and is available within the Statistics New Zealand Integrated Data Infrastructure (IDI) from 2007. ${ }^{20}$ Over the period 2007-2020, we have matched the IS data to the IDI annual incomes table to facilitate analysis on the effects of minimum wages on workers earnings dynamics, and also on the individual and household income distributions.

\footnotetext{
19 For example, she points out that "(I)mpacts on employment are related to how binding the minimum wage is in the labour market and the scale of the increase" (p. 3, emphasis added).

${ }^{20}$ The HLFS was first included in the IDI in December quarter 2006. Although this results in the 2006 IS being partially included, we only use the IDI matched data from 2007.
} 


\subsubsection{Income Survey/Income supplement}

We have analysed Income Survey data from 1997 to 2020. The Income Survey has been run each June quarter - initially as a supplement to the Household Labour Force Survey (HLFS) and, since June 2016, as part of the HLFS. The survey has changed over time ${ }^{21}$ with revisions to questionnaire wording, routing, and coding. Data for 1997 to 2006 were drawn from standalone annual files. For later years, we have used the versions of the IS and HLFS data that are included in the IDI - with separate tables for 2007-2015 and 2016-20120. Notwithstanding the differences in data naming, definition and coding, we have combined IS information from the 3 main sources, to create a fairly consistent dataset covering the entire period. All our estimates are weighted, using the most recently available final sample weights. Overall, despite the inevitable imprecision of survey responses and the many changes to the Income Survey over time, ${ }^{22}$ we judge that data we analyse below is sufficiently similar across years. We have informally checked for obvious discontinuities in the key variables we use and are satisfied that the changes we observe are genuine.

In the interests of consistency over time, we have focused on a wage measure that captures total actual hourly earnings from main job - a measure that is captured fairly consistently over time, and restricted attention to people who said that they were employees. ${ }^{23}$ Whichever wage measure is chosen, there are many implausible values for hourly wages. At the extreme, some employees appear to have wages of only a few cents per hour. On inspection of the underlying survey responses, it is apparent that at least some of the extreme high or low values for hourly wages are a result of reporting or recording errors, or reflect inaccuracies or inconsistencies in the conversion of annual or weekly earnings and hours to an estimate of the hourly wage. We have included these implausible hourly wage observations in our analysis, rather than selectively dropping only a subset of the more obvious anomalies. Consequently, employees recorded as earning less than the minimum wage do not necessarily represent noncompliance.

\footnotetext{
${ }^{21}$ http://datainfoplus.stats.govt.nz/Item/nz.govt.stats/60252f6c-8057-49d5-9766-db880e27d00f

22 Major changes include survey redevelopment in 1998, a move to computer assisted interviewing in 2005, and the integration of the IS into the HLFS in 2016 http://datainfoplus.stats.govt.nz/Item/nz.govt.stats/60252f6c-8057-49d5-9766db880e27d00f.

${ }^{23}$ For the 2007-2015 period, we examined the sensitivity of estimated minimum wage incidence using a range of alternative measures that are available for this subperiod. Estimates were only slightly altered if we used: regular hourly earnings; earnings from highest-hourly-rate job; average hourly rate over all jobs; excluding proxy and imputed responses; unweighted estimates; actual as opposed to usual earnings; and exclusion of overtime earnings. The redevelopment of the IS in 2016 resulted in clearer identification of self-employed workers, some of whom were previously classified as employees. This change slightly reduced the proportion of employees with very low or, to a lesser extent, very high wage rates. We believe that this change had a relatively minor impact on the patterns we report.
} 


\subsubsection{IRD administrative income data}

For the subset of IS data that is available in the IDI (2007-2020), it is possible to obtain a measure of annual income from all sources for each IS respondent. We use tax-year incomes from the IDI, which include earnings, transfer earnings, as well as self-employed, rental income, and shareholder and partnership income. The timing of tax-year income more closely aligns to the annual income period reported on in the IS than does the alternative (calendar year) summary in the IDI. There is a strong correlation between annual income measures from the IS and those derived from administrative sources, although both are likely to be imperfect. Where IDI annual income is not observed for an IS respondent, we instead annualise the weekly income amount reported in the IS, by multiplying the weekly amount by 52 .

We derive a measure of household income by adding the administrative income measures for all adults in each household, and calculating equivalised income by the square root of the number of people (adults and children) in the household - an equivalisation approach widely used by the OECD.

\subsection{Descriptive patterns}

\subsubsection{Overall profile of minimum wage workers}

Table 2 summarises the characteristics of the adult population that we examine in more detail below, in the years 1997, 2008 and 2020. We provide information on some broad demographic groupings by age, sex, ethnicity, and highest qualification. The first panel of the table shows what proportion of the working age population falls into each of the broad groupings. Age and sex composition are fairly stable over time, although the proportion of the population aged 65 years and over has risen from 15 percent in 1997 to 19\% in 2020. The ethnicity classification reflects total responses - respondents to the IS can identify with more than one ethnic group, and can thus be included in more than one ethnic group in the table. The main ethnicity change over the study period is a substantial increase in the prevalence of people in the 'other ethnicity' group, being people who did not identify as 'European', 'Maori', or 'Pasifika', and a corresponding decline in the proportion identifying as European. Finally, the share of the population with no qualifications has been dropping steadily, and the proportion with a degree or higher qualification has risen from 12 percent to 29 percent.

The second panel shows the composition of employees, which differs from the population composition because of differing employment rates and the likelihood of being an employee (rather than self-employed or unpaid family worker). Young people, people with low 
qualifications, and people aged 65 and over are all under-represented as employees because of low employment rates. Although employment rates for people aged 65 and over have been rising strongly over recent decades, they still accounted for only 5 percent of employees in 2020, in contrast to their 19 percent share of the adult population.

The composition of minimum wage earners in large part reflects the sizes of the underlying populations, as shown in the third panel of Table 2. Prime aged (aged 25-64) people account for a high proportion (49 percent in 2020) of minimum wage earners, and also a high proportion (66 percent) of the adult population. Similarly, most minimum wage earners (62 percent) identify as European, which is not surprising given that people identifying as European account for 70 percent of adults.

A clearer view of which groups are most strongly affected by the minimum wage is evident in the final panel, which shows the proportion of employees in each group who are paid at or below the minimum wage. Overall, this proportion has risen from 4 percent in 1997 to 9 percent in 2020, reflecting the increase in the real value of the minimum wage. For 16 to 17 year old workers, however, around half were on the minimum wage in 2020, down slightly from 64 percent in 2008, when the youth minimum wage was abolished. Similarly, 38 percent of $18-19$ year old employees were paid at or below the minimum wage in 2020. Other groups that have a disproportionate share of employees on the minimum wage include young adults aged 20-24 (20 percent), people with school qualifications as their highest qualification (15\%), or with no qualification (13\%), and Pasifika (13\%).

The remainder of section 4.2 provides more in-depth description and analysis of the patterns of employment and minimum wage incidence that are shown in Table 2.

\subsubsection{The 'bite' of the minimum wage is increasing}

In 1997, the adult minimum wage was 56 percent of the median hourly wage. By 2008, it had increased to 64 percent, and by 2020, to 71 percent. This ratio, known as the Kaitz index (Kaitz, 1970 ) is a commonly used measure of the degree to which the minimum wage affects the distribution of wages. The Kaitz index is available for many countries, ${ }^{24}$ allowing international comparisons to be made. The median value in 2019 of the Kaitz index for the 31 countries tabulated by the OECD is 51 percent. New Zealand's 2019 value (66 percent) is fifth highest, below only Colombia (90\%), Turkey (75\%), Chile (70\%) and Costa Rica (69\%). New Zealand's 2020 Kaitz index of 70 would place it third in the 2019 rankings. The announced 2021 increase in

\footnotetext{
${ }^{24}$ Data for 31 countries is available from https://stats.oecd.org/viewhtml.aspx?datasetcode=MIN2AVE\&lang=en .
} 
the New Zealand minimum wage to $\$ 20$ is likely to keep New Zealand high in the international rankings.

Interpreting what an internationally-high Kaitz value means for New Zealand requires consideration of how spread out the wage distribution is. A high minimum wage relative to the median wage will affect a higher proportion of employees if the wage distribution is relatively spread out, and it is this interaction that determines how much the minimum wage affects the wage distribution. At low values of the Kaitz index, a relatively small proportion of employees will have their wage rates determined by the statutory minimum. As the Kaitz index rises, the proportion of employees directly affected rises increasingly rapidly, as any increase in the minimum wage affects more dense parts of the wage distribution. Figure 2 illustrates the relationship between the prevailing minimum wage and the median wage, for selected age subgroups, as well as overall. For 16-17 year olds, the median wage has been equal to the prevailing minimum wage since 2008 , when the adult rate was extended to this age group. The Kaitz index has therefore been equal to 1 since 2008. For 18-19 year olds, the Kaitz index increased to $85 \%$ in 2001 , when they were covered by the adult rate, and has remained high between 96 and 99 percent since then.

\subsubsection{Wage distributions are becoming more compressed}

A visual summary of what these Kaitz values mean for the distribution of wages is presented in Figure $3 .{ }^{25}$ The top left panel show the wage distribution for 16-17 year olds, for three subperiods: 1997-2000; 2008-2011; and 2018-2020. In the early period, the wage distribution was spread out, and there was only a very small proportion of 16-17 year old employees earning at or below the prevailing youth minimum wage (shown by the left-most vertical line). The corresponding panel of Table 3 shows that in 1997, only $4.0 \%$ of $16-17$ year olds were directly affected by the level of the minimum wage. By 2008-2010, the wage distribution had become very concentrated at the level of the minimum wage, with $67 \%$ of $16-17$ year olds being paid at or below the minimum wage in 2008. The rise in the minimum wage between 2008-11 and 2018-20 is evident in Figure 3 as a rightward shift in the vertical line indicated the level of the adult minimum wage. The peak of the wage distribution was similarly shifted rightwards, although the proportion of employees at or below the minimum wage fell slightly to $57 \%$ in 2020 (Table 3).

\footnotetext{
${ }^{25}$ Throughout the remainder of the paper, our analysis of wage distributions is restricted to the subsample of observations for whom we observed non-missing and non-zero wages.
} 
While there is some density at wage levels below the minimum wage in later years, we regard this mostly as measurement error, together with spillover of mass associated with estimating the density near the spike, rather than evidence of non-compliance. ${ }^{26}$ Furthermore, it appears that very few employees were paid at the legal sub-minimum rates documented in section 2 and Table 1, with only slightly raised density below the minimum wage in most years. ${ }^{27}$ Even in the final years of the youth minimum wage, it appeared that many 16 to 17 year olds were already being paid at the adult rate. As documented by Pacheco (2009b), workers with measured wages below the level of the minimum wage have characteristics similar to those of minimum wage workers, and we therefore refer to workers earning at or below the minimum wage as minimum wage earners.

The pattern seen for 16 to 17 year olds, of an increasingly 'peaked' wage distribution that is clearly tied to the level of the minimum wage, is evident also for $18-19$ year olds, $43 \%$ of whom were paid at or below the minimum wage in 2020 . For $20-24$ year olds, the rising minimum wage has also compressed the lower half of the wage distribution. In 1997-2000, there was no discernible peak at the level of the adult minimum wage, and only $7 \%$ of workers were paid at or below that rate in 1997. In 2008-2011, the upper half of the 20-24 year old wage distribution was similar to what it was in 1997-2000, albeit slightly more compressed downward due to the impact of the GFC. In contrast, the lower half of the distribution was compressed at the level of the minimum wage - a compression that became more pronounced as the minimum wage rose through to 2018-20. The proportion of 20-24 year old employees at or below the minimum wage was $13 \%$ in 2008 and $21 \%$ in 2020 , considerably lower than the corresponding ratio for younger age groups.

Although the compression is less pronounced for older age groups, ${ }^{28}$ the concentration of younger workers at lower wage levels means that the compression is evident in the aggregate wage distribution shown as the final panel of Figure 3. There is an increasingly steep 'cliff' on the left of the wage distribution, reflecting the growing proportion of employees whose wages are directly affected by the minimum wage. This proportion rose to 10.3 percent in 2008 , and remained high, at $9.3 \%$ in 2020 .

\footnotetext{
${ }^{26}$ Breaches of Minimum Wage legislation clearly do occur, as evidenced by Employment Court rulings (https://employmentcourt.govt.nz/judgments/). However, these do not appear to be widespread. Furthermore, most of the sub-minimum records appear to be more likely due to issues of reporting rather than genuine cases of non-compliance. 27 Based on detailed analysis of youth wages between 2007 and 2011, Hyslop and Stillman (2011) concluded there was little evidence of firms paying youth the New Entrants' Wage from 2008.

28 In fact, there appears to be quite strong shifts in the wage distribution of over-65 year olds. We suspect these are more related to employment changes among older workers, who experienced a three-to-four fold increase in their employment rate over the period.
} 
As well as a minimum wage increase directly affecting the wages of workers previously earning below that rate, it may also indirectly affect the wages of workers earning above that rate if firms seek to maintain relativity across workers or jobs with different skill levels. In order to investigate this, requires some allowance for secular changes in the wage distribution over time. For example, median real wages increased about $1.5 \%$ annually on average over the period which, all else equal such changes, will tend to increase wages across the distribution. To adjust for secular changes, we first normalise wages relative to year-specific medians, and then compare changes in the normalised distributions over time. The adopted median-normalisation implicitly assumes that, in the absence of minimum wage effects, all wages increase at the same (annual median) rate over time: we discuss the adequacy of this assumption below.

We focus on wage changes over two distinct periods of minimum wage increases: first, over the period 2002 to 2008; and second, over the recent period from 2017 to 2020. In Figure 4 we describe the cumulative two-year changes in the wage distribution relative to 2002 over the earlier period; and the cumulative annual distribution changes relative to 2017 over the later period. The height of the plotted line shows the change in the proportion of employees paid less than each wage level. A negative change in the cumulative density indicates that a lower proportion of employees are being paid below that level. The vertical dashed line in each graph indicates the base-year (2002 or 2017) adult minimum wage, and the vertical solid line the current-year minimum wage. The three left hand graphs suggest the earlier minimum wage increases had relatively little overall effect on the wage distribution, either below or above the minimum wage, until 2008 . The third graph implies that, by $2008,6 \%$ of workers with wages below the 2008 minimum had been brought up to the 2008 minimum wage, while there is no evidence of any displacement above that level.

In contrast to the earlier period, the right hand graphs suggest the minimum wage increases since 2017 have had a much stronger effect on the wage distribution. From 2017, over $5 \%$ of workers with wages below the minimum wage in 2018 moved up, and 10-11\% moved up in 2019 and 2020. Also, more importantly there appear to have been noticeable spillover effects above the minimum wage in each year, which extended to close to the median wage in these years: e.g. there were $4 \%$ fewer wages at or below -0.10 ( $10 \%$ below the median) in 2020 compared to 2017. However, how much of these shifts are directly attributable to the minimum wage changes is unclear, with other factors such as low-wage pay-equity settlements and some large employers becoming Living Wage employers, directly affecting wage changes in this 
range. ${ }^{29}$ The Care and Support Workers settlement alone accounts for an upward shift in density of two to three percent of employees between 2017 and 2018.

The other comment of note here is the relative (in)stability of the wage distributions over the two periods. In particular, the changes across the distribution during the 2002-08 period suggest normalising wages (simply) by the year-medians may not be adequate for controlling for secular changes; while the comparative stability of the top half of the distributions suggests the normalisation is more robust over the 2017-20 period.

Figure 5 provides a more detailed view of how the wage distributions have changed between 2000 and 2020 for employees of different ages. Panel (a) shows both the employment rate (proportion of population who are employees receiving wages or salaries) by age, and the wage rate conditional on being an employee. The two lower lines show the age-specific employment rates for 2000 and 2020. The main changes over this period were the increase in employment rates for older workers and a decline in employment rates for 16 and 17 year olds. Older worker employment rates rose from about age 50, and more than doubled, from 16 percent to 41 percent, for 64 year olds. Average real wage increases were particularly strong for younger workers, and somewhat lower than average for workers in their 20s. The increase for teenagers captures the distributional shifts evident in Figure 3 , which are clearly related to minimum wage changes.

The pattern of relatively strong average wage growth for younger workers shown in panel (a) reflects particularly strong growth for lower-paid young workers. Panel (b) of Figure 5 shows strong wage growth for teen workers at both the $10^{\text {th }}$ and $25^{\text {th }}$ percentile. In 2020 , the younger worker portion of the age earnings profile had flattened considerably, with 20 year olds at the $10^{\text {th }}$ and $25^{\text {th }}$ percentile of the age-specific wage distribution earning only 5 to 10 percent higher more than analogously defined 16 year olds - down from a difference of more than $50 \%$ in 2000. Furthermore, the $10^{\text {th }}$ and $25^{\text {th }}$ percentile were relatively close to each other in 2020 up until about age 30 , reflecting wage compression at the lower end of the distribution. Although the relatively strong wage growth for younger workers was most pronounced for lower-paid teens, some compression is also evident throughout the distribution. Panel (c) shows age profiles of wages at the median, $75^{\text {th }}$ and $90^{\text {th }}$ percentiles of the age-specific wage distributions.

\footnotetext{
${ }^{29}$ For example, the Care and Support Workers settlement substantially increased the wages of perhaps 55,000 workers from near minimum wage levels in 2017, with further increases taking effect in 2018, 2019 and 2021. The 2017 rates applied from 1 July 2017, so will first be seen in IS data in 2018. The agreement was extended to around 5,000 mental health workers in 2018. Pay equity settlements for teacher aides in 2020 affected around 20,000 workers, although payments were not made until November 2020, and will therefore not be reflected in the data we use.
} 
To illustrate the differences more clearly in growth rates across ages and at different points in the distribution, panel (d) of Figure 5 plots the growth rates (change in log(wage) between 2000 and 2020). For workers aged over about 35, wage growth varied around a level of roughly $30 \%$ over the 20 years, with somewhat higher growth at the upper end of the distribution ( $75^{\text {th }}$ and $90^{\text {th }}$ percentiles). In contrast, at the $10^{\text {th }}$ and $25^{\text {th }}$ percentiles of $16-17$ year old employees' wage distribution, real wages more than doubled (log change greater than 0.7 ), and even at the $75^{\text {th }}$ percentile, wage growth was above $50 \%$. For employees aged in their 20 s, wage growth was relatively slow except for the lower 10 percent of employees. For the rest of the 20s wage distribution, growth was generally below 25\%, with the slowest growth (10 to 15 percent) at the $90^{\text {th }}$ percentile.

The impact of any increases in the level of the minimum age depends on the density of the wage distribution between the current and proposed minimum wage, and the patterns in Figure 3 and Figure 5 demonstrate a compression of wages, especially at the lower end of the wage distribution, and especially for younger workers. An increasing share of workers were paid at levels closer to the minimum wage. The changing influence of the minimum wage is thus not well captured by the Kaitz index, since the proportion affected is related non-linearly to the distance between the minimum wage and the median wage.

In light of this, in Figure 6 we illustrate three alternative measures of the degree to which the minimum wage 'bites' into the wage distribution . Figure 6(a) relates to all industries, and Figure $6(\mathrm{~b})$ to the 'Teen' industries. The first measure is the proportion of employees that would be directly affected if the wage were set at the following year's level. ${ }^{30}$ The panels for teen workers in Figure 6 show the non-linear relationship between the Kaitz index and the bite measure. For 16-17 year olds, the proportional increase in the bite is much stronger than the proportion increase in the Kaitz. Furthermore, the bite measure shows a more strongly increasing impact in recent years, especially for 18-19 year olds, for whom there is relatively little change in the Kaitz index.

The second 'bite' measure is similar to the first, but adjusts for the relative wage levels of employees who are directly affected and those who are not. It multiplies the proportion of workers affected by their average weekly wage, and expresses the bite as a proportion of the overall weekly wage. This second "Bite(2)" measure shows a very similar pattern to the first bite measure, albeit at a somewhat lower level. The final measure is measure discussed above, being

\footnotetext{
${ }^{30}$ This will overstate the likely impact of a future increase because real wage increases over time will tend to move the entire wage distribution rightwards, moving some workers 'out of reach' of the estimated bite.
} 
the proportion of employees earning at or below the level of the current minimum wage. This is similar to the other bite measures, although it does diverge in recent years, when more substantial increases in the minimum wage have resulted in a more pronounced difference between the current and next year's minimum. ${ }^{31}$

Table 4 documents the size of the various bite measures for each of the demographic subgroups shown in Table 2, and how these have changed over time. The table shows not only the overall bite, but also the various measures of minimum wage bite for prime aged employees (aged 25-64), to provide an alternative measure that complements the age-related insights show in Table 3.

The salience of the minimum wage also varies across firms, with the size of the minimum wage bite varying considerably across industries. Figure $6(\mathrm{~b})$, and Table 5 , show that the minimum wage has a considerably stronger effect on the wage distribution in teen industries. ${ }^{32}$ For this group of industries, the average Kaitz index was 87.5 percent in 2020, and the proportion of employees paid at or below the minimum wage in 2020 was 23 percent. For 16-17 year olds employed in these industries, the proportion was 61 percent. The minimum wage bite in 2020, as reflected in the proportion of employees being paid below the 2021 minimum wage level of $\$ 20$, was 38 percent in these industries, and 74 percent for $16-17$ year olds. These industries are not only high-teen industries, they are also more likely to pay adult workers at minimum wages.

\subsubsection{Minimum wages and employment}

Figure 7 and Figure 8 provide some simple descriptive evidence on the relationship between minimum wage levels and employment, prior to a more formal examination in the next section. Figure 7 shows the time series changes in minimum wage bite, employment rates, and proportion of each age group that is not employed but studying. The strongest pattern is evident for 16-17 year olds. Their 2008 move to the adult minimum wage greatly increased the minimum wage bite, which has remained high ever since. Employment rates for 16-17 year olds fell from 45 percent in 2008 to $36 \%$ in 2009, and have not been above $32 \%$ since then. The initial fall predated the impact of the GFC, but was no doubt affected somewhat by the recession that

\footnotetext{
31 Maloney and Pacheco (2010) found that actual minimum wage incidence (our Bite(3)) is only about a third of the incidence implied by our prospective Bite(1). Our estimates suggest that there is a much closer correspondence between these two measures.

32 Industry coding is available only from 2001. Teen industries refers to industries that have a relatively high proportion of young minimum wage workers: Agriculture; Retail Trade; and Accommodation and Food Services. The Wholesale Trade industry is also included for 2001-2010 because it is coded together with Retail Trade in the base data.
} 
started in early 2008 due to slowing exports. The employment rate has, however, remained low for 16-17 year olds since 2008, despite overall employment growth. The lower employment rates have been accompanied by an increase in the proportion of 16-17 year olds who reported studying while not employed. This could reflect a reduction of employment for students, or an increase in study rates. A similar, though less pronounced, switch from employed to studying while not employed is evident for 18-19 year olds as well, although their employment rate has returned to what it was in 2005.

Further evidence of the changing nature of work for teens can be seen in Figure 8, which decomposes employment growth for each age group (and overall) into contributions from job starts ("accessions"), job ends ("separations"), and the net effect of the changing age distribution. ${ }^{33}$ Overall, the rate of accessions and separations declined in New Zealand between 2000 and 2019 - as it has in many countries. The pattern for teen workers is, however, distinctive. In 2009, there was a sharp drop in both the accession and separation rates for teen workers. From 2011, the accession rate rose again, although for neither 16-17 year olds nor 1819 year olds has it returned to pre-2008 levels. In contrast, the separation rate has remained low, particularly for younger teens. The implication of this is that a higher proportion of teen jobs are of longer duration. Further evidence of this pattern is the fact that the 'net ageing' rate became more strongly negative for teen workers - there was a reduction in teen employment not because of a decline in accessions or a rise in separations, but because a higher share of teen workers remained employed and left the age group because they got older. Further analysis would be needed to determine whether this pattern arose because the employment declines that were evident in Figure 7 were concentrated among employees who had previously been employed in short-term jobs, or if job tenure increased more generally.

One final piece of descriptive evidence on employment impacts is the proportion of overall labour costs accounted for by minimum wage workers. Hyslop et al. (2012) found that labour demand responded more strongly to wage changes when the changes accounted for a large proportion of labour costs. The final row in each block of Table 3 provides an estimate of the proportion of wage costs accounted for by minimum wage workers, based on employeeweighted weekly earnings. Across all employees, minimum wage workers accounted for 3.9 percent of wage costs in 2020, up from 1.4 percent in 1997. The cost share of 16-17 year old employees declined substantially between 2008 (0.5\%) and 2020 (0.2\%), despite the high

\footnotetext{
33 Rates are calculated as the average of monthly rates, and measured as $\frac{F l o w_{t}}{\left(E m p_{t}+E m p_{t-1}\right) / 2}$, which gives an index in the range between -2 and 2 .
} 
proportion of 16-17 year olds directly affected by the minimum wage. Employment declines for this group, and increases in employment and wage levels for other age groups have diluted the contribution of this group to overall labour costs. In the light of the earlier findings from Hyslop et al. (2012), this suggests that employers may have become less responsive to teen minimum wage changes. Determining the net effect of minimum wage changes on employment requires a more structured examination, to which we now turn.

\subsubsection{Regression analysis of employment impacts}

As discussed in section 3.2.1 above, MBIE's annual minimum wage review includes an aggregate time series regression analysis of the effects of the minimum wage on employment. In this section, we provide some exploratory regression analysis of this relationship using the full range of HLFS-IS microdata over the period 1997-2020. The objective of this analysis is twofold: first, to broadly replicate the aggregate analysis; and second, to explore the possibility of using a more coherent analytical approach to estimating varying employment responses across different sub-populations.

Our approach is to begin with a specification that mimics the aggregate analysis approach, and then to explore various deviations from this specification. In particular, we start with the aggregate Kaitz index as the minimum wage measure of interest and assume constant effects. We then explore possible heterogeneous employment responses across sub-group, followed by considering sub-group Kaitz indexes, and then using an alternative 'bite' measure of the minimum wage.

We first discuss the results of our Kaitz-index based regression analyses, which are summarised in Table 6. All of the results presented are based on regressions that control for age (16-17, 18-19, 20-24, 25-64, 65+), sex, ethnicity (European, Maori, European-Maori, Pasifika, and other), and qualifications (none, school, post-school, and degree qualifications), include linear time trends for the employment rate of those aged 25 and over, and also include GDP growth as a control variable for business cycle variation. ${ }^{34}$ The results in column (1) estimate a statistically insignificant coefficient on the Kaitz index of 0.04 , which implies a $10 \%$ increase in the minimum wage relative to the median wage is associated with 0.4 percentage points (pp) higher employment; and we estimate a statistically significant coefficient on GDP growth of 0.2 , which implies 3\% (relative to 0\%) GDP growth is associated with $0.6 \mathrm{pp}$ higher employment. In

\footnotetext{
34 The inclusion of linear trends is in line with the aggregate specifications used. In exploratory regressions, we allowed for separate trends for teenagers (16-19), young adults (20-24), prime aged (25-64), and older workers (65 and over). Largely consistent with employment rate trends over the period, the results implied no significant trends for teenagers and young adults, and constant trends for the prime-aged and older workers.
} 
column (2), we allow the minimum wage effect to vary over the business cycle by interacting the Kaitz and GDP growth variables: this results in statistically insignificant main-effect coefficients that are similar to those in column (1), while the coefficient on the interaction term suggests the minimum wage employment effects during economic upswings are mildly positive. ${ }^{35}$ Recognising that employment effects vary over the business cycle more for some groups (e.g. younger workers) than others, in column (3) we extend this specification to allow the business cycle effects to vary by age-group, with results similar to those in column (2).

The final aggregate-Kaitz index specification we report, in column (4), allows the responsiveness to vary by age-group by interacting the Kaitz and age-group indicators. The results suggest statistically significant negative aggregate minimum wage effects on 16-17 year olds' employment (elasticity of -0.6 , implying a $10 \%$ higher minimum wage is associated with $6 \%$ lower employment), essentially zero effect on 18-19 year olds' employment, and statistically significant positive effects on each of the adult groups' employment (elasticities of 0.1-0.15). This pattern of estimates is partially consistent with the notion that younger workers will be more exposed to minimum wage effects, either because their employment is more responsive to shocks represented by the Kaitz index or perhaps because (as seen above) the effective minimum wage bite that they face is effectively stronger than for older workers. ${ }^{36}$ Nonetheless, the results in column (4) imply a positive relationship between minimum wages and employment for most age-groups of workers.

In the next three columns (5-7) of Table 6, we replace the aggregate Kaitz-index with agegroup specific indexes, and re-estimate analogous specifications to those in columns (1-3). The results are broadly comparable, with statistically insignificant minimum wage estimates, to the earlier results: the exception being in column (6), which shows statistically significant positive minimum wage effects during economic upswings.

For the final set of results, presented in columns (8-11), we extend the idea of age-group specific Kaitz-indexes to a broader range of population subgroups. Given five age-, two sex-, five ethnic-, and four qualification-groups, a full set of interactions would provide 200 cells, which we consider too detailed. Instead, we define 18 mutually exclusive population cells, based on

\footnotetext{
35 While we are cautious about interpreting the weak results on cyclical variation in the employment impact of minimum wages, we note that Sabia $(2014,2015)$ also finds evidence that minimum wages are more likely to reduce employment growth in downturns than in booms.

${ }^{36}$ The coefficients for younger workers may be somewhat muted by the lack of variation in the Kaitz index, which has been close to 1 in recent years.
} 
some aggregations of these characteristics. ${ }^{37}$ The first three columns (8-10) again are for the analogous specifications to those in (1-3), and provide similar insignificant results. The final specification again interacts the cell-group Kaitz index with the main group indicators to allow the employment responses to the level of the Kaitz to vary. The results suggest relatively responsive effects, with the main effect (for 25-64 year old European men with post-schooling qualifications) implying a 10\% higher Kaitz is associated with 3.8\% lower employment; and the interactions implying stronger negative effects for women, teenagers and young-adults. However, contrary to most predictions, the results suggest positive employment response for those with lower (at most school) qualifications, and also find no difference for non-Europeans.

Based on the results from these regressions, we conclude that finding any robust employment response to a Kaitz-index measure is difficult. There are several possible reasons for this, including: there is no robust relationship between the level of minimum wages and employment; or that the aggregate Kaitz-index is too coarse to identify employment responses across different sub-populations, and any employment response requires a more nuanced specification. In particular, the fact that the Kaitz index for 16-17 year olds teens has been equal to 1.0 and has not varied in recent years prevents us from identifying any relationship between minimum wages and employment for this group.

Partly to explore the latter issue, we next consider an alternative measure of how binding the minimum wage is, and re-examine the employment minimum wage relationship. To do this, we define the minimum wage bite (MW-bite) as the fraction of workers last year who earned less than this year's minimum wage: this provides a measure of the fraction of workers potentially affected by the current minimum wage (Bite(1) above).

We present regression results in Table 7 where again we consider aggregate, age-group, and cell-group specific MW-bite measures. The first specification replicates the specification in column (1) of Table 6, replacing the aggregate Kaitz-index with the aggregate MW-bite: we estimate a statistically significant positive coefficient on the MW-bite variable, which implies a 1 percentage point increase in the bite is associated with a 0.13 percent increase in employment.

\footnotetext{
37 In particular, we specify the following cells: 1 . Non-European teens; 2 . European teens; 3. Non-European 20-24 year olds with no post-school qualifications; 4. Non-European 20-24 year olds with post-school qualifications; 5 . European 20-24 year olds with no post-school qualifications; 6 . European 20-24 year olds with post-school qualifications; 7 . Non-European 65 and over with no post-school qualifications; 8. Non-European 65 and over with post-school qualifications; 9. European 65 and over with no post-school qualifications; 10. European 65 and over with post-school qualifications; 11 . Non-European 25-64 year old Women with no post-school qualifications; 12 . European 25-64 year old Women with no post-school qualifications; 13 . Non-European 25-64 year old Women with post-school qualifications; 14 . European 25-64 year old Women with post-school qualifications; 15 . Non-European 25-64 year old Men with no post-school qualifications; 16. European 25-64 year old Men with no post-school qualifications; 17. Non-European 25-64 year old Men with post-school qualifications; and 18. European 25-64 year old Men with post-school qualifications.
} 
Next, to allow for possible non-linear bite effect, we include the squared term in the specification in column (2): this suggests a statistically significant convex employment relationship with the MW-bite, in which the effect is positive when the bite is lower than 0.1, and negative for higher values. In the third column, we instead interact the age-group indicators with the linear MW-bite variable: this finds a positive and significant main effect (for 25-64 year olds), and a statistically significant negative interaction for 16-17 year olds, suggesting adverse employment effects only for the youngest age group (elasticity of about -0.85 ).

In columns (4) and (5), we use the age-group specific MW-bite variable and allow a quadratic specification: column (4) also allows age-group specific business cycle effects. The results imply statistically significant convex employment MW-bite relationships: the effect of the MW-bite is positive (negative) when the bite is lower (greater) than about 0.25 . In terms of the level of the bite observed for different workers, this implies that, at current minimum wage levels, the employment effects are expected to be negative for teenagers, and positive for older aged workers.

In column (6) we replace the age-specific bite variable with the broader cell-group MWbite measure. The results of this regression also indicate a statistically significant convex employment relationship, with coefficients about twice as large as in column (4). This implies expected positive (negative) employment effects when the bite is less (greater) than about 0.33, and again implies negative employment effects for teenagers at current minimum wage levels.

For the final specification, in column (7), we drop the quadratic term and instead include interactions between the MW-bite and the main cell-group dimensions to assess heterogeneous responses across the groups. These results are broadly in line with those in column (11) of Table 6. The main effect is negative (for 25-64 year old European men with post-school qualifications), implying a $1 \mathrm{pp}$ increase in the bite is associated with 0.38 percent lower employment. In addition, the interactions imply statistically significantly stronger adverse effects for the other age groups, insignificantly different effects for women and non-Europeans, and a significant positive effect on employment of low-skilled workers.

In summary, the results using the MW-bite measure are somewhat (statistically) stronger than using a Kaitz-index, and suggest the employment response to minimum wages is likely nonlinear and potentially negative as the minimum wage binds for a larger share of workers. Also, consistent with the Kaitz-index results in Table 6, these results imply that the effects appear to be better identified when based on more targeted (sub-group) than aggregate measures. Nonetheless, consistent with MBIE's aggregate time analysis, the results presented here using 
either measure are comparatively underwhelming in terms of finding robust evidence of adverse employment effects associated with minimum wage increases. However, we believe the specifications discussed represent more coherent methods to estimating heterogeneous responses across sub-populations that the aggregate model approach based on sub-sample analyses.

\subsubsection{Counterfactual Employment changes}

To indicate the nature and magnitude of employment effects implied by the regressions reported in the previous section, Table 8 presents the results of two counterfactual exercises. First, based on the Kaitz-based regression estimates shown in the final column of Table 6, we show the implied change in the number of employees that would result from an increase in the minimum wage (and therefore of the Kaitz index) from its actual level in a year, to the following year's level.

$$
\begin{aligned}
& \text { Counterfactual } 1=E\left[E m p_{t} \mid \log \widetilde{(\text { Kaltz })}\right]-E\left[E m p_{t} \mid \log \left(\text { Kaitz }_{t}\right)\right] \\
& \text { where } \log \widetilde{(\text { Kaltz })}=\log \left(\frac{M W_{t+1}}{M W_{t}} \text { Kaitz }_{t}\right)=\log \left(\text { Kaitz }_{t}\right)+\log \left(\frac{M W_{t+1}}{M W_{t}}\right)^{38}
\end{aligned}
$$

The results of these calculation are shown in the first 3 columns of Table 8 , for the years 2018, 2019 and 2020, and separately for selected demographic subgroups. The counterfactual analysis implies that the rising Kaitz index (annual increases in log(Kaitz) of 0.057 to 0.070 ) is associated with statistically insignificant rises in employment for 2018 and 2019 of 4,500 and 1,800 , and a small decline for 2020 . The sub-group changes reveal limited evidence of employment declines in response to higher minimum wages. Statistically significant declines are evident only for 18-19 year olds (around -500), for the 'other ethnicity' group (around -3000) and for high qualification groups. Counterfactual employment for people with post-school or higher qualifications is lower by around 60,000 each year, roughly balancing sizeable increases for workers with lower qualifications. The losses for highly qualified workers are puzzling as they are least likely to be paid at or around the minimum wage. Significant positive effects are evident not only for lower-qualified workers, but also for men, for workers aged 65 and over, and for Maori and Pasifika.

The second counterfactual exercise follows a similar calculation, but this time based on the final column of Table 7, which uses the cell-group-specific prospective minimum wage bite

\footnotetext{
${ }^{38}$ Although the $\log$ (Kaitz) measure used in the regression is defined separately for each cell-group, the counterfactual change in any year is common across groups, as it depends only on the proportional increase in the minimum wage. For 16-17 year olds, who have a Kaitz of 1.0, the counterfactual value of Kaitz will be greater than one. This is due to the fact that for the purposes of counterfactual analysis, the median is held fixed at the level in year $t$.
} 
(the proportion of the previous year's employees who were paid below the current year's minimum wage) to capture minimum wage variation.

Counterfactual $2=E[$ Emp $\mid \widetilde{\text { mbite }}]-E\left[E m p \mid m w b i t e_{t}\right]$

where mwbite $_{t}=\%$ of $E m p_{t-1}$ paid below $M W_{t}$

$\widetilde{\text { mbite }}=\%$ of Emp end $_{\text {pelow }} M W_{t+1}$

The results of these calculation are shown in columns 4 to 9 of Table 8, for the years 2018, 2019 and 2020, and separately for selected demographic subgroups. The table shows the average change in group-specific bite, as well as the implied change in the number of employees. Note that both of these counterfactual exercises are based on the person-level regressions, and the implied changes for different subgroups therefore sum to the overall change, providing a coherent picture of implied effects.

The counterfactual employment changes based on the 'minimum wage bite' specification are shown in the remaining columns of Table 8. For each year, the group-specific average change in bite is shown as well as the implied change in employment. The largest changes in bite are evident for teens, who also have significant employment declines in response to increased minimum wage bite. ${ }^{39}$ Apart from the teen effects, and lowered employment for more highly qualified workers, the counterfactuals are variable across years. In response to similar sized increases in bite in 2018 and 2019, employment increases are mainly for men in 2018 and mainly for women in 2019. Similarly, patterns for older workers, and by ethnicity are quite different across the two years.

The variability of results from the counterfactual exercises reflect the comments about the fragility of the regression estimates noted in the previous section. Although basing counterfactual calculations on microdata regressions has the advantage of generating an internally consistent set of estimates for different subgroups, the ability to identify reliable and stable estimates of minimum wage effects is limited, at least based on the relatively parsimonious regression specifications considered here.

Table 9 compares the counterfactual employment increases with actual changes in employment, and with the estimates of 'employment restraint' that were included in official Minimum Wage reviews in 2018 and 2019. The combined picture is far from coherent. MBIE estimated that the minimum wage increases that occurred in 2019 and 2020 would restrain

\footnotetext{
39 In 2020, the counterfactual bite is lower than the actual bite, meaning that the implied employment changes generally have the opposite sign to those for 2018 and 2019. The lower average counterfactual group-specific bite arises because the proportion of employees in 2020 who were paid less than the 2021 minimum wage of $\$ 20$ was lower than the proportion of 2019 employees paid less than the 2020 minimum wage of $\$ 18.90$.
} 
employment by around 8,000 and 6,500 respectively. Actual employment grew by 32,400 between 2018 and 2019, and by 19,600 between 2019 and 2020 .

The comparison of actual growth in the number of employees with the counterfactual changes discussed above also shows marked discrepancies. The actual changes were an increase of 14,400 between 2018 and 2019, and a decline of 11,000 between 2019 and 2020, reflecting in large part the impact of Covid on the number of wage and salary employees. In 2018-19, the Kaitz and minimum wage bite counterfactuals show similar increases of around 2,000. However, in 2019-20, they differ by more than 18,000 .

Furthermore, we re-estimated the regression models using data only from 2008, when youth minimum wages had been abolished, and generated corresponding counterfactual employment changes. We undertook this re-estimation to capture a period when the size of the minimum wage bite for teens was more similar to the levels seen in 2018-2020. The resulting counterfactuals are summarised in the final panel of Table 9 , and demonstrate the fragility of estimates to the chosen time period as well as the choice of minimum wage measure. The counterfactuals show generally smaller implied employment changes that are not closely related to the other estimates in the table.

It is perhaps not surprising that the counterfactual estimates and MBIE's estimates of employment restraint do not match the actual changes. The two need not agree, as we cannot tell what employment growth would have been in the absence of the minimum wage increases. However, the differences do point to the fact that any minimum wage impact is not a dominant factor in employment growth. What is particularly disappointing is that the alternative estimates produce such a wide range of estimates. In 2018-19, the estimates range from $-8,000$ to $+2,000$ and in $2019-20$, from $-6,500$ to $+18,000$. Further refinements of the estimation specification and approach may yield more stable and defensible measures of the employment impacts of minimum wages in New Zealand but such measures remain elusive at this stage.

\subsubsection{Minimum wage as income support}

We next analyse how effective minimum wages are as a means of income support. To do this, we examine the incidence of minimum wage workers (defined as those with reported wages less than or equal to the prevailing minimum wage rate) across the income distribution, and compare this incidence to the transfer income share of total income. We compare and contrast the contributions to individual incomes and, because welfare is generally measured at the family or household level, also to household incomes. 
Figure 9 summarises our analysis with regards to individuals' annual income in 2007 and $2020 .{ }^{40}$ For each year, we stratify the individual income distribution into percentiles. First, in panel (a) we graph the average log(income), and the wage and salary employment rate, in each percentile. This shows low average incomes, together with low employment rates, ${ }^{41}$ across the bottom three deciles, with the dip in employment rate over the second and third decile corresponding to the range of main benefit incomes. Reflecting that labour earnings are the primary source of income for most people, the wage and salary employment rate is consistently between 0.7 and 0.9 for those in the top six deciles of the distribution as incomes rise. Average $\log$ (incomes) increased around 15 percent between 2007 and 2020 across much of the distribution, with stronger (about 25 percent) increases between the $35^{\text {th }}$ and $45^{\text {th }}$ percentiles, corresponding to the range where there were also noticeably large increases in employment rates.

In panel (b) we graph the fraction of minimum wage workers in each percentile, and also the average transfer income share of total income. As expected, minimum wage workers are concentrated in the lower half of the income distribution. The fraction of minimum wage workers peaks at around $12-14 \%$ of those in the second and fourth deciles, with the dip between these associated with the high fraction of beneficiaries, as reflected by the large share of transfer income. There has been an increase in the fraction of minimum wage earners across the third decile, and in the fifth and sixth deciles, between 2007 and 2020. The incidence of minimum wage workers declines steadily above (about) the $45^{\text {th }}$ percentile in both years, with almost no such workers in the top three deciles. We expect that the part- versus full-time (including part- versus full-year) employment intensity of workers over the year largely explains the broad spread of minimum wage workers across the lower half of the income distribution, and that those with grossly mis-reported low wages explain most of those earning higher incomes.

In contrast to the spread of minimum wage workers, panel (b) shows that receipt of transfer income is concentrated in deciles 2-4, with the transfer income share of total income peaking at over 50 percent in the third decile. Panel (b) also shows the transfer income share has become more concentrated in deciles 2-4 between 2007 and 2020, which is consistent with the employment changes seen in panel (a).

\footnotetext{
402007 is the first year that we are able to measure annual incomes in the IDI for the HLFS sample.

${ }^{41}$ About $7 \%$ of individuals in each year have zero (or negative) annual income, while an average log(income) of about 7.25 at the $10^{\text {th }}$ percentile corresponds to around $\$ 1,500$.
} 
Recognising the sharing of resources and roles within families or households, measures of income adequacy and welfare support are generally based on family or household incomes. To account for this, we next repeat this analysis based on household annual income and stratify across the percentiles of the equivalised household annual income distribution. The results are summarised in Figure 10. First, panel (a) shows a broadly similar pattern of average log (household income) as was seen for log (individual income) in Figure 9, except that there are essentially no households with zero income (approximately 1 percent of households in each year have negative income). In addition, while the employment rate is below 30 percent in the bottom decile, it rises steadily over the next $2-3$ deciles, after which it is between 0.7 and 0.8 .

In contrast, the spread of minimum wage workers and the transfer share of income across the household income distribution are relatively different compared to across the individual income distribution seen in Figure 9. In particular, the transfer share of income becomes more concentrated in the bottom quarter of the distribution (especially deciles 1-2), accounting for over half of total household income in the bottom decile, and less than 10 percent of income above the third decile. In contrast, although the fraction of minimum wage workers is highest in the second and third deciles (peaking at about 10 percent at some percentiles), minimum wage workers are very broadly distributed across the household income distribution. For example, the fraction of minimum wage workers is about 5 percent in the sixth decile (and the seventh decile in 2020). In fact, the share of minimum wage workers appears to have become more broadly distributed over the period, with increasing fractions apparent in the top four deciles: by 2020, there are non-trivial fractions of minimum wage workers in the top four deciles.

These patterns emphasise that, although minimum wage workers are more concentrated among lower income individuals, and to a lesser extent more likely to be in the lower income households, the latter relationship is relatively weak. Thus, as a redistributive income support policy, the minimum wage is relatively blunt and far less targeted and effective than the current set of welfare and transfer policies.

Figure 11 provides a summary of individual income dynamics before and after being observed in the IS in a minimum wage job. This summary uses information on employees observed in the IS who have IDI personal income information in the three years prior and the three years after the IS reference year. For 16-19 year olds, this restriction limits attention mainly to older teenagers. Income growth for teenage minimum wage earners is substantial, particularly prior to the reference year. However, such growth is also evident for non-MW teens, reflecting part-year incomes in earlier years as well as earnings growth among new 
entrants. Growth in average incomes for teens is slow ${ }^{42}$ in the two to three years after the reference year but is not significantly different for MW earners compared with non-MW earners. In fact, there are no statistically significant differences in average earnings growth between MW earners and non-MW earners for any of the three age groups.

\section{$5 \quad$ Concluding discussion}

Our main conclusion from this review is that minimum wages in New Zealand over the past two decades de facto have become a teenage wage setting policy. Over half of 16-17 year old employees, and 43 percent of 18-19 year old employees are paid at or below the minimum wage. Minimum wages are also a prominent feature of wage-setting in particular industries, which we refer to as 'teen industries'. Over 20 percent of employees in retail, agriculture, and hospitality industries are minimum wage earners, and they account for 12 percent of weekly labour costs for the industry.

The concentration of minimum wage incidence is relevant for the appraisal of whether minimum wages deliver on their assumed objectives, and for the consideration of minimum wage policies. It also helps to focus the avenues of research that are most likely to be informative about the advantages and disadvantages of minimum wage policies.

\subsection{What do minimum wages do?}

It is difficult to find a clear articulation of the rationale for current Minimum Wage policies in New Zealand. Our review of the effects of minimum wages does not, therefore constitute an evaluation of current minimum wage policies. Instead, in this summary we consider how effective New Zealand's minimum wages are with reference to the four possible rationales for minimum wage policies as outlined in section 2.1. First, as a redistributive income support policy, minimum wages are inevitably limited, given that they cannot directly affect households where nobody is employed. However, our analysis in Figure 10 implies that minimum wages are largely ineffective as a redistribution tool, given the broad incidence of minimum wage workers across the household income distribution - many people on low hourly rates of pay are nevertheless in households where incomes are not particularly low. This is particularly the case when compared to transfer income, which much more effectively targets households in the

\footnotetext{
${ }^{42}$ Because the selection of the sample requires people to be employees in the reference year, slow income growth reflects spells out of employment in other years.
} 
lowest three deciles. Not surprisingly, policies designed to target low household incomes are more effective at reaching people with low household incomes.

Second, to protect disadvantaged low-skilled workers from employer exploitation. The contribution to this potential rationale and aim is difficult to assess. However, arguably the absence of clear adverse employment effects suggests that minimum wages are (at least) not disadvantaging low-skilled workers by increasing their risk of non-employment. The lack of adverse employment effects is consistent with the presence of monopsony power. The fact that higher minimum wages raise the earnings of some low-paid workers effectively increases the bargaining power and resources to low-paid workers. Our analysis cannot identify the presence or strength of exploitation but if it is present, minimum wages will provide some protection.

Third, as a policy to improve worker or firm productivity. Again, this is difficult to assess formally from the analysis we have done. The turnover analysis discussed in section 4.2.4 and illustrated in Figure 8 is suggestive of an association between minimum wages and job tenure for affected workers but further analysis of how this relates to hiring and job search costs, and the allocation of workers to more productive firms is needed before any conclusions can be reached about whether the impacts rise or lower overall economic performance. Similarly, the changes in study patterns seen in Figure 7 are worth investigating further as a possible link between minimum wages and skill acquisition.

Finally, human rights as a justification for abolishing the youth minimum wage. Again, this is difficult to assess within the scope of our analysis. However, we note that there are several age-based policies with arguably less economic rationale - e.g., the $20 \%$ discounted rate for JSS recipients age under $25 .{ }^{43}$ The continuation of the Starting-out and Training minimum wages implicitly recognises the link between wages and human capital; the relevant question is whether the specified time periods and training conditions provide adequate support for human development. The absence of any noticeable incidence of these exceptions suggests firms may consider the administrative and compliance costs too great for them to be worthwhile.

\subsection{Implications for policy-setting}

The analysis in this report highlights some key considerations for minimum wage policy and design, though it falls short of providing specific guidance on the appropriate level of the minimum wage.

\footnotetext{
${ }^{43}$ The judgement around the recent voting-age challenge noted the contradiction between the Bill of Rights guaranteed right to vote for those age 18 and older, while the right not to be subject to age discrimination applied from age 16.
} 
The first insight is that, despite the fact that the minimum wage is a simple and universal policy, the impacts of minimum wages are very concentrated - on teen employees, and on particular industries. As shown in Table 2, even though almost half of minimum wage earners (workers earning at or below the minimum wage) are aged 25-64, minimum wage earners account for only about $5 \%$ of such workers. In contrast, over half (57\%) of $16-17$ year olds are minimum wage earners, with relatively high incidence also among $18-19$ year olds (43\%) and young adults (20-24 year olds: $21 \%$ ). Setting minimum wage levels based on aggregate indicators such as the overall Kaitz index will not necessarily yield minimum wage levels that are appropriate for the employees or firms where they matter most. More refined policy setting requires greater awareness and knowledge of the impact that minimum wages will have on particular wage sub-distributions. Even though New Zealand's Kaitz index is internationally high, it greatly understates the impact that the minimum wage can have for particular subgroups, and is uninformative when it reaches its maximum of 1 , as it has for 16-17 year olds.

The second insight is that minimum wage policies should not be considered in isolation. To the extent that minimum wages are intended as an income support policy, they should be designed and evaluated in the context of other income support policies. Our analysis in section 4.2.7 demonstrates that the minimum wage is less well targeted than other existing income support policies.

The analysis in the paper also points to some issues relevant for minimum wage setting in 2020, though it does not provide specific guidance on how best to respond to the issues. First, on the timing of minimum wage increases: there is some weak evidence in the regression analysis that minimum wage effects on employment are more positive/ less negative during cyclical upswings. This is consistent with the insights from Sabia $(2014,2015)$, who finds stronger negative employment effects in downswings. Minimum wage setting needs to take into account the extent of recovery or recession expected in 2021, although this is uncertain. Furthermore, in a low inflation environment, the extent to which prospective incidence (Bite(1)) translates to higher actual incidence is raised, so the positive and negative impacts of minimum wage increases are likely to be magnified.

Finally, on the modelling of employment effects, which is a key input into advice on minimum wage changes: our microdata approach to modelling and estimation provides a way of assembling a consistent set of impacts for different subgroups. The reliability of the counterfactual estimates that we derive is, however not clearly better than those obtained using the existing modelling approach. Neither approach seems to provide a completely reliable basis 
for developing policy advice, and neither can be readily validated or rejected by subsequent data, given the range of other factors at play.

\subsection{Continuing to build knowledge of minimum wage effects}

Our review of New Zealand empirical research on the impacts of minimum wage effects reveals the prevalence of studies that have focused on estimating employment effects of minimum wages, generally finding weak evidence of employment losses. There is, however, scope to pursue this line of research further given the current minimum wage settings. It would also be desirable to counter the lack of research on some of the broader, medium term effects of minimum wages, though establishing firm facts on these may be even more challenging than credibly identifying employment impacts

\subsubsection{Further research to refine estimation of employment impacts}

Two features of the current minimum wage landscape justify further research on employment impacts. First, the bite of the minimum wage is historically high, and second, the bite is concentrated particularly on teens and on teen industries. Research focused on the most affected parts of the labour market has more chance of reaching firm conclusions, given the size of potential impacts. The focus of future research could usefully be re-oriented, along the lines recommended by Manning (2020), to identifying at what level the minimum wage starts to affect the labour market. New Zealand may be better placed than most countries to identify this, given the relatively high level of the minimum wage, especially for the most affected groups.

Focused research on the most affected industries could take the form of industry case studies, testing for interactions between wage setting and firm decisions about technology choice, recruitment decisions, and training. Particular attention could be paid to the role of competition in the labour market (monopsony power) and product market (monopoly power) in shaping the ability of firms to absorb higher minimum wage costs or pass them on to product prices. A combination of qualitative and quantitative approaches would help to underpin and test any emerging insights.

Research focused on the most affected workers could take the form of quantitative or qualitative analyses of teen and young adult workers and their employers. Research questions could relate to issues such as worker and employer decisions about training and further education to detect changing skill mixes in response to minimum wage changes (eg: Clemens et al. (2020)); or about attitudes to short v longer term job spells - to help in uncovering the 
reasons behind the apparent decline in turnover rates, especially for young workers. Analysis of administrative data on job turnover as well as on education and training participation would complement qualitative research focused on the same questions. There is scope to pursue further analysis of the turnover patterns discussed in section 4.2.4, to understand how minimum wages interact with the distribution of job duration and tenure.

\subsubsection{Interactions with other policies}

Policy analysis of income support policies and their work incentives is generally done taking minimum wages as given, and minimum wage policy options are generally analysed taking income support policies as given. There is certainly scope to do further analysis of how the design of minimum wage and income support policies interact, possibly building on the microsimulation approach of Alinaghi et al. (2019), and possibly incorporating labour demand behaviour as well.

\subsubsection{Broader impacts on labour market performance}

The concentration of high minimum wage incidence on particular firms, industries, and workers also provides some scope to investigate the possible positive effects of minimum wages in weeding out less productive firms, encouraging greater skill acquisition, or inducing the introduction of more productive technologies. Identifying whether these longer term dynamic changes are occurring, and separating the effects of minimum wages from other labour market trends may prove even more challenging than isolating employment impacts. However, New Zealand's rich business microdata may provide opportunities to identify effects from heterogeneous impacts even among groups of the most affected firms, building on studies such as Hyslop et al. (2012). 


\section{References}

Acemoglu, D., \& Pischke, J.-S. (1999). The structure of wages and investment in general training. Journal of Political Economy, 107(3), 539-572.

Acemoglu, D., \& Pischke, J.-S. (2003). Minimum wages and on-the-job training. Research in Labor Economics, 22(2003), 159-202.

ACIL Economics \& Policy Pty Ltd. (1994). What Future for New Zealand's Minimum Wage Law? For the New Zealand Business Roundtable.

Alinaghi, N., Creedy, J., \& Gemmell, N. (2019). The Redistributive Effects of a Minimum Wage Increase in New Zealand A Microsimulation Analysis. Victoria University of Wellington, Chair in Public Finance.

Allegretto, S., Dube, A., \& Reich, M. (2011). Do minimum wages really reduce teen employment? Accounting for heterogeneity and selectivity in state panel data. Industrial Relations: A Journal of Economy and Society, 50(2), 205-240.

Allegretto, S., Dube, A., Reich, M., \& Zipperer, B. (2017). Credible research designs for minimum wage studies: A response to Neumark, Salas, and Wascher. ILR Review, 70(3), 559-592.

Belman, D., \& Wolfson, P. J. (2014). What does the minimum wage do? WE Upjohn Institute.

Brosnan, P. (2019). The minimum wage in a global context. In J. Michie (Ed.), The Handbook of Globalisation, Third Edition (pp. 189-201). Edward Elgar Publishing.

Chapple, S. (1997). Do Minimum Wages Have an Adverse Impact on Employment? Evidence from New Zealand. Labour Market Bulletin, 2, 25-50.

Clemens, J., Kahn, L. B., \& Meer, J. (2020). Dropouts Need Not Apply? The Minimum Wage and Skill Upgrading (No. 0898-2937). National Bureau of Economic Research.

Coviello, D., Deserranno, E., \& Persico, N. (2018). Minimum Wage and Individual Worker Productivity: Evidence from a Large US Retailer. Workforce Science Project of the Searle Center for Law, Regulation, and Economic Growth, Northwestern University.

Dube, A. (2019). "Impacts of minimum wages: Review of the international evidence. Independent Report, Https://Www. Gov. Uk/Government/Publications/Impacts-of-Minimum-Wages-Review-of-theInternational-Evidence.

Dustmann, C., Lindner, A., Schönberg, U., Umkehrer, M., \& Vom Berge, P. (2019). Reallocation effects of the minimum wage: Evidence from Germany. mimeo.

Eckert, L., Hyslop, D., Stillman, S., \& Wunsch, C. (2018). Minimum wages and the business cycle [Manuscript, University of Basel].

Endres, A. (1990). The economics of wages and wages policy in the depression and recovery period: Distinctive elements in the New Zealand debate, 1931-1936. New Zealand Journal of Industrial Relations, 15(1).

Hammond, M. B. (1917). The Regulation of Wages in New Zealand. The Quarterly Journal of Economics, 31(3), 404-446.

Heckman, J. J., Lochner, L. J., \& Todd, P. E. (2003). Fifty Years of Mincer Earnings Regressions (NBER Working Paper No. 9732). NBER.

Houghton, R. (2012). Employers' perspectives-part two: The minimum wage system. Ministry of Business, Innovation \& Employment.

Hyslop, D. R., Maré, D. C., Stillman, S., \& Timmins, J. (2012). Heterogeneous Firm Responses to Rising Teenage Wages. Labour, 26(4), 436-454.

Hyslop, D. R., \& Stillman, S. (2004). Youth Minimum Wage Reform and the Labour Market. New Zealand Treasury.

Hyslop, D. R., \& Stillman, S. (2007). Youth minimum wage reform and the labour market in New Zealand. Labour Economics, 14(2), 201-230.

Hyslop, D. R., \& Stillman, S. (2011). The impact of the 2008 youth minimum wage reform. Labour \& Immigration Research Centre, Department of Labour, Wellington, August.

International Labour Organisation. (2016). Minimum Wage Policy Guide. ILO. www.ilo.org/minimumwage

Kaitz, H. (1970). Experience of the past: The national minimum wage. US Department of Labor, Bureau of Labor Statistics: Youth Unemployment and Minimum Wages, 1657.

Lee, D., \& Saez, E. (2012). Optimal minimum wage policy in competitive labor markets. Journal of Public Economics, 96(9-10), 739-749.

Leigh, A. (2010). Who benefits from the earned income tax credit? Incidence among recipients, coworkers and firms. The BE Journal of Economic Analysis \& Policy, 10(1).

Maloney, T. (1995). Does the adult minimum wage affect employment and unemployment in New Zealand? New Zealand Economic Papers, 29(1), 1-19. 
Maloney, T., \& Pacheco, G. (2010). Interpreting changes in minimum wage incidence rates. Australian Journal of Labour Economics, 13(3), 219.

Maloney, T., \& Pacheco, G. (2012). Assessing the possible antipoverty effects of recent rises in age-specific minimum wages in New Zealand. Review of Income and Wealth, 58(4), 648-674.

Manning, A. (2020). The elusive employment effect of the minimum wage. Journal of Economic Perspectives.

Moulton, B. R. (1986). Random group effects and the precision of regression estimates. Journal of Econometrics, 32(3), 385-397.

Neumark, D. (2015a). Reducing poverty via minimum wages, alternatives. FRBSF Economic Letter, 38, 1-5.

Neumark, D. (2015b). The effects of minimum wages on employment. FRBSF Economic Letter, 2015(37), $1-5$.

Neumark, D. (2019). The econometrics and economics of the employment effects of minimum wages: Getting from known unknowns to known knowns. German Economic Review, 20(3), 293-329.

Neumark, D., Salas, J. I., \& Wascher, W. (2014). Revisiting the minimum wage-Employment debate: Throwing out the baby with the bathwater? Ilr Review, 67(3_suppl), 608-648.

Neumark, D., \& Wascher, W. (2011). Does a higher minimum wage enhance the effectiveness of the Earned Income Tax Credit? ILR Review, 64(4), 712-746.

Neumark, D., \& Wascher, W. (2017). Reply to "credible research designs for minimum wage studies." ILR Review, 70(3), 593-609.

NZCTU. (2015). Submission to the Minimum Wage Review 2015. New Zealand Council of Trade Unions.

Pacheco, G. (2007). The changing role of minimum wage in New Zealand. New Zealand Journal of Employment Relations, 32(3), 1.

Pacheco, G. (2009a). Revisiting the link between minimum wage and wage inequality: Empirical evidence from New Zealand. Economics Letters, 105(3), 336-339.

Pacheco, G. (2009b). Who are minimum and sub-minimum wage workers? International Journal of Manpower.

Pacheco, G. (2011). Estimating employment impacts with binding minimum wage constraints. Economic Record, 87(279), 587-602.

Pacheco, G., \& Cruickshank, A. A. (2007). Minimum wage effects on educational enrollments in New Zealand. Economics of Education Review, 26(5), 574-587.

Pacheco, G., \& Maloney, T. (1999). Does the minimum wage reduce the employment prospects of unqualified New Zealand women? Labour Market Bulletin, 1999, 51-69.

Pacheco, G., \& Naiker, V. (2006). Impact of the minimum wage on expected profits. International Review of Applied Economics, 20(4), 469-490.

Polachek, S. W. (2008). Earnings over the lifecycle: The Mincer earnings function and its applications (Vol. 16). Now Publishers Inc.

Riley, R., \& Bondibene, C. R. (2017). Raising the standard: Minimum wages and firm productivity. Labour Economics, 44, 27-50.

Rosenberg, B. (2017). Shrinking portions to low and middle-income earners: Inequality in wages and selfemployment 1998-2015. NZ Council of Trade Unions.

Rosenberg, W. (1971). An Early View of the New Zealand System of Industrial Conciliation and Arbitration: F. R. Chapman (1849-1936). Labour History, 20, 9-16. JSTOR. https://doi.org/10.2307/27508007

Rothstein, J. (2010). Is the EITC as good as an NIT? Conditional cash transfers and tax incidence. American Economic Journal: Economic Policy, 2(1), 177-208.

Sabia, J. J. (2014). The effects of minimum wages over the business cycle. Journal of Labor Research, 35(3), 227-245.

Sabia, J. J. (2015). Do minimum wages stimulate productivity and growth? IZA World of Labor, 221.

St John, S., \& So, Y. (2017). Does the Living Wage ensure an adequate standard of living for families? Policy Quarterly, 13(3). 
Table 1: Timeline of minimum wage policy changes since 2000

\begin{tabular}{|c|c|c|c|}
\hline \multirow[b]{2}{*}{$\begin{array}{l}\text { Announcement } \\
\text { date }\end{array}$} & \multirow[b]{2}{*}{$\begin{array}{l}\text { Effective } \\
\text { date }\end{array}$} & \multicolumn{2}{|c|}{ Minimum Wage } \\
\hline & & Adult(1) & $\begin{array}{c}\text { Sub-minimum rate } \\
\text { (Youth / Starting } \\
\text { Out/ Training/ } \\
\text { New Entrant) }\end{array}$ \\
\hline & 1 March 1997 & 7.00 & 4.20 \\
\hline & 6 March 2000 & 7.55 & 4.55 \\
\hline 14 December 2000 & 5 March 2001 & 7.70 & 5.40 \\
\hline 30 January 2002 & 18 March 2002 & 8.00 & 6.40 \\
\hline 19 December 2002 & 24 March 2003 & 8.50 & 6.80 \\
\hline 23 February 2004 & 1 April 2004 & 9.00 & 7.20 \\
\hline 21 December 2004 & 21 March 2005 & 9.50 & 7.60 \\
\hline 21 December 2005 & 27 March 2006 & 10.25 & 8.20 \\
\hline 18 December 2006 & 1 April 2007 & 11.25 & 9.00 \\
\hline 19 December 2007 & 1 April 2008 & 12.00 & 9.60 \\
\hline 9 February 2009 & 1 April 2009 & 12.50 & 10.00 \\
\hline 27 January 2010 & 1 April 2010 & 12.75 & 10.20 \\
\hline 7 February 2011 & 1 April 2011 & 13.00 & 10.40 \\
\hline February 2012 & 1 April 2012 & 13.50 & 10.80 \\
\hline 26 February 2013 & 1 April 2013 & 13.75 & 11.00 \\
\hline 24 February 2014 & 1 April 2014 & 14.25 & 11.40 \\
\hline 26 February 2015 & 1 April 2015 & 14.75 & 11.80 \\
\hline 29 February 2016 & 1 April 2016 & 15.25 & 12.20 \\
\hline 24 January 2017 & 1 April 2017 & 15.75 & 12.60 \\
\hline 22 December 2017 & 1 April 2018 & 16.50 & 13.20 \\
\hline 19 December 2018 & 1 April 2019 & 17.70 & 14.16 \\
\hline 18 December 2019 & 1 April 2020 & 18.90 & 15.12 \\
\hline 17 December 2020 & 1 April 2021 & 20.00 & 16.00 \\
\hline
\end{tabular}

Notes: Eligibility conditions for the sub-minimum rate varied over time, as detailed in section 2. 
Table 2: Population characteristics

\begin{tabular}{|c|c|c|c|c|c|c|c|c|c|c|c|c|c|}
\hline & & \multicolumn{3}{|c|}{$\begin{array}{l}\text { Proportion of Working Age } \\
\text { population (age } 16 \text { and over) }\end{array}$} & \multicolumn{3}{|c|}{ Proportion of Employees } & \multicolumn{3}{|c|}{ Proportion of MW-earners } & \multicolumn{3}{|c|}{$\begin{array}{l}\text { Incidence: MW-earners as a } \\
\text { proportion of row employees }\end{array}$} \\
\hline & & 1997 & 2008 & 2020 & 1997 & 2008 & 2020 & 1997 & 2008 & 2020 & 1997 & 2008 & 2020 \\
\hline \multicolumn{2}{|l|}{ Total } & $100 \%$ & $100 \%$ & $100 \%$ & $100 \%$ & $100 \%$ & $100 \%$ & $100 \%$ & $100 \%$ & $100 \%$ & $4 \%$ & $10 \%$ & $9 \%$ \\
\hline \multirow[t]{5}{*}{ Age } & $16-17$ & $4 \%$ & $4 \%$ & $3 \%$ & $3 \%$ & $3 \%$ & $2 \%$ & $5 \%$ & $22 \%$ & $10 \%$ & $5 \%$ & $64 \%$ & $48 \%$ \\
\hline & $18-19$ & $3 \%$ & $3 \%$ & $3 \%$ & $4 \%$ & $4 \%$ & $3 \%$ & $\mathrm{~S}$ & $13 \%$ & $14 \%$ & $S$ & $36 \%$ & $38 \%$ \\
\hline & $20-24$ & $10 \%$ & $9 \%$ & $9 \%$ & $13 \%$ & $10 \%$ & $11 \%$ & $22 \%$ & $13 \%$ & $24 \%$ & $7 \%$ & $13 \%$ & $20 \%$ \\
\hline & $25-64$ & $68 \%$ & $68 \%$ & $66 \%$ & $79 \%$ & $80 \%$ & $79 \%$ & $70 \%$ & $48 \%$ & $49 \%$ & $3 \%$ & $6 \%$ & $5 \%$ \\
\hline & 65 \& over & $15 \%$ & $16 \%$ & $19 \%$ & $1 \%$ & $3 \%$ & $5 \%$ & $3 \%$ & $4 \%$ & $4 \%$ & $13 \%$ & $14 \%$ & $7 \%$ \\
\hline \multirow[t]{2}{*}{ Sex } & Men & $49 \%$ & $48 \%$ & $49 \%$ & $52 \%$ & $50 \%$ & $50 \%$ & $46 \%$ & $42 \%$ & $46 \%$ & $3 \%$ & $8 \%$ & $8 \%$ \\
\hline & Women & $51 \%$ & $52 \%$ & $51 \%$ & $48 \%$ & $50 \%$ & $50 \%$ & $54 \%$ & $58 \%$ & $54 \%$ & $4 \%$ & $12 \%$ & $10 \%$ \\
\hline \multirow[t]{4}{*}{ Ethnicity } & European & $83 \%$ & $78 \%$ & $70 \%$ & $84 \%$ & $78 \%$ & $69 \%$ & $71 \%$ & $69 \%$ & $62 \%$ & $3 \%$ & $9 \%$ & $8 \%$ \\
\hline & Maori & $12 \%$ & $12 \%$ & $13 \%$ & $11 \%$ & $13 \%$ & $13 \%$ & $20 \%$ & $18 \%$ & $16 \%$ & $7 \%$ & $14 \%$ & $10 \%$ \\
\hline & Pasifika & $4 \%$ & $5 \%$ & $6 \%$ & $5 \%$ & $5 \%$ & $7 \%$ & $8 \%$ & $8 \%$ & $9 \%$ & $7 \%$ & $16 \%$ & $13 \%$ \\
\hline & Other & $5 \%$ & $12 \%$ & $18 \%$ & $4 \%$ & $11 \%$ & $19 \%$ & $5 \%$ & $15 \%$ & $23 \%$ & $5 \%$ & $14 \%$ & $10 \%$ \\
\hline \multirow[t]{4}{*}{ Qualifications } & No quals & $32 \%$ & $24 \%$ & $16 \%$ & $20 \%$ & $18 \%$ & $11 \%$ & $39 \%$ & $28 \%$ & $16 \%$ & $7 \%$ & $15 \%$ & $13 \%$ \\
\hline & School qual & $33 \%$ & $25 \%$ & $30 \%$ & $27 \%$ & $24 \%$ & $29 \%$ & $25 \%$ & $41 \%$ & $49 \%$ & $4 \%$ & $17 \%$ & $15 \%$ \\
\hline & Postsch qual & $24 \%$ & $30 \%$ & $24 \%$ & $34 \%$ & $32 \%$ & $25 \%$ & $22 \%$ & $23 \%$ & $20 \%$ & $3 \%$ & $7 \%$ & $7 \%$ \\
\hline & Degree qual & $12 \%$ & $22 \%$ & $29 \%$ & $19 \%$ & $26 \%$ & $36 \%$ & $13 \%$ & $8 \%$ & $15 \%$ & $3 \%$ & $3 \%$ & $4 \%$ \\
\hline \multicolumn{2}{|l|}{ TOTAL (000) } & $2,806.8$ & $3,253.3$ & $3,920.1$ & $1,383.1$ & $1,776.4$ & $2,115.3$ & 54.0 & 179.2 & 185.9 & & & \\
\hline \multicolumn{2}{|c|}{ percent of total population } & $100 \%$ & $100 \%$ & $100 \%$ & $49 \%$ & $55 \%$ & $54 \%$ & $2 \%$ & $6 \%$ & $5 \%$ & & & \\
\hline \multicolumn{2}{|c|}{ Annual Personal income } & $\$ 33,752$ & $\$ 39,929$ & $\$ 47,492$ & $\$ 44,954$ & $\$ 52,430$ & $\$ 63,847$ & $\$ 19,643$ & $\$ 21,724$ & $\$ 28,649$ & & & \\
\hline \multicolumn{2}{|c|}{ Equiv. HH Annual Income } & $\mathrm{n} / \mathrm{a}$ & $\$ 51,750$ & $\$ 64,036$ & $\mathrm{n} / \mathrm{a}$ & $\$ 62,145$ & $\$ 76,582$ & $\mathrm{n} / \mathrm{a}$ & $\$ 44,868$ & $\$ 57,406$ & & & \\
\hline
\end{tabular}

Notes: S. suppressed in accordance with Statistics New Zealand confidentiality requirements. Source: Income Survey, 1997-2020 
Table 3: Minimum Wage incidence by age group

\begin{tabular}{|c|c|c|c|}
\hline & 1997 & 2008 & 2020 \\
\hline Real Median Wage (\$2020) & 19.57 & 23.02 & 27.00 \\
\hline Real Adult Minimum Wage (\$2020) & 10.96 & 14.55 & 18.90 \\
\hline Real sub-minimum wage $(\$ 2020)$ & 6.58 & 11.64 & 15.12 \\
\hline \multicolumn{4}{|l|}{ Employment rate } \\
\hline Kaitz index & 53.5 & 63.9 & 69.9 \\
\hline Bite (1) \% of employee below next MW & $4.0 \%$ & $11.8 \%$ & $15.4 \%$ \\
\hline Bite (2) \% of wage bill below next MW & $1.4 \%$ & $4.2 \%$ & $6.9 \%$ \\
\hline Bite (3) \% at or below current MW & $4.0 \%$ & $10.3 \%$ & $9.3 \%$ \\
\hline MW worker share of total labour cost ${ }^{1}$ & $1.4 \%$ & $3.5 \%$ & $3.9 \%$ \\
\hline \multicolumn{4}{|l|}{ 16-17-year olds } \\
\hline - Employment rate & $44.1 \%$ & $44.5 \%$ & $30.2 \%$ \\
\hline - $\quad$ Kaitz index & $61.6 \%$ & $100.0 \%$ & $100.0 \%$ \\
\hline - $\quad$ Bite (1) \% of employee below next MW & $5.3 \%$ & $71.3 \%$ & $73.6 \%$ \\
\hline - $\quad$ Bite (2) \% of wage bill below next MW & $2.2 \%$ & $61.1 \%$ & $60.5 \%$ \\
\hline - $\quad$ Bite (3) \% at or below current MW & $5.3 \%$ & $66.7 \%$ & $57.2 \%$ \\
\hline - $\quad \mathrm{MW}$ worker share of total wage costs ${ }^{1}$ & $0.0 \%$ & $0.5 \%$ & $0.2 \%$ \\
\hline \multicolumn{4}{|l|}{ 18-19-year olds } \\
\hline - Employment rate & $58.7 \%$ & $60.1 \%$ & $56.4 \%$ \\
\hline - $\quad$ Kaitz index & $50.1 \%$ & $96.0 \%$ & $99.5 \%$ \\
\hline - $\quad$ Bite (1) \% of employee below next MW & $\mathrm{n} / \mathrm{a}$ & $40.7 \%$ & $63.9 \%$ \\
\hline - $\quad$ Bite (2) \% of wage bill below next MW & $\mathrm{n} / \mathrm{a}$ & $29.9 \%$ & $57.4 \%$ \\
\hline - $\quad$ Bite (3) \% at or below current MW & $\mathrm{n} / \mathrm{a}$ & $36.3 \%$ & $43.3 \%$ \\
\hline - $\quad \mathrm{MW}$ worker share of total wage costs ${ }^{1}$ & $\mathrm{n} / \mathrm{a}$ & $0.5 \%$ & $0.5 \%$ \\
\hline \multicolumn{4}{|l|}{ 20-24-year olds } \\
\hline - Employment rate & $67.6 \%$ & $66.4 \%$ & $70.8 \%$ \\
\hline - $\quad$ Kaitz index & $65.5 \%$ & $77.4 \%$ & $89.6 \%$ \\
\hline - $\quad$ Bite (1) \% of employee below next MW & $6.7 \%$ & $15.3 \%$ & $36.5 \%$ \\
\hline - $\quad$ Bite (2) \% of wage bill below next MW & $3.5 \%$ & $8.5 \%$ & $25.4 \%$ \\
\hline - $\quad$ Bite (3) \% at or below current MW & $6.7 \%$ & $12.8 \%$ & $21.3 \%$ \\
\hline - $\quad \mathrm{MW}$ worker share of total wage costs ${ }^{1}$ & $0.3 \%$ & $0.5 \%$ & $0.9 \%$ \\
\hline \multicolumn{4}{|l|}{ 25-64-year olds } \\
\hline - Employment rate & $73.7 \%$ & $79.9 \%$ & $82.2 \%$ \\
\hline - $\quad$ Kaitz index & $51.2 \%$ & $58.7 \%$ & $65.2 \%$ \\
\hline - $\quad$ Bite (1) \% of employee below next MW & $3.5 \%$ & $7.3 \%$ & $9.8 \%$ \\
\hline - $\quad$ Bite (2) \% of wage bill below next MW & $1.1 \%$ & $2.7 \%$ & $4.5 \%$ \\
\hline - $\quad$ Bite (3) \% at or below current MW & $3.5 \%$ & $6.2 \%$ & $5.6 \%$ \\
\hline - $\quad \mathrm{MW}$ worker share of total wage costs ${ }^{1}$ & $1.0 \%$ & $1.9 \%$ & $2.2 \%$ \\
\hline \multicolumn{4}{|l|}{65 -years and over } \\
\hline - Employment rate & $6.7 \%$ & $14.4 \%$ & $24.3 \%$ \\
\hline - $\quad$ Kaitz index & $63.6 \%$ & $75.0 \%$ & $72.9 \%$ \\
\hline - $\quad$ Bite (1) \% of employee below next MW & $14.8 \%$ & $17.0 \%$ & $13.9 \%$ \\
\hline - $\quad$ Bite (2) \% of wage bill below next MW & $\mathrm{n} / \mathrm{a}$ & $5.9 \%$ & $6.5 \%$ \\
\hline - $\quad$ Bite (3) \% at or below current MW & $14.8 \%$ & $15.0 \%$ & $7.7 \%$ \\
\hline - $\quad \mathrm{MW}$ worker share of total wage costs ${ }^{1}$ & $\mathrm{n} / \mathrm{a}$ & $0.1 \%$ & $0.1 \%$ \\
\hline
\end{tabular}

${ }^{1}$. Cost shares are based on employee-weighted weekly earnings

Notes: $n / a$ indicates suppressed values, in accordance with Statistics New Zealand's microdata output guide.

Source: Income Survey, 1997-2020 
Table 4: Minimum Wage incidence by selected demographic groups

\begin{tabular}{|c|c|c|c|c|c|c|}
\hline & \multicolumn{3}{|c|}{ All employees } & \multicolumn{3}{|c|}{ Prime aged } \\
\hline & 1997 & 2008 & 2020 & 1997 & 2008 & 2020 \\
\hline \multicolumn{7}{|l|}{ Men } \\
\hline - Kaitz index & $49.4 \%$ & $60.0 \%$ & $66.8 \%$ & $46.7 \%$ & $54.0 \%$ & $62.3 \%$ \\
\hline - $\quad$ Bite (1) \% of employee below next MW & $3.5 \%$ & $9.6 \%$ & $13.4 \%$ & $2.7 \%$ & $4.9 \%$ & $7.3 \%$ \\
\hline - $\quad$ Bite (2) \% of wage bill below next MW & $1.2 \%$ & $3.2 \%$ & $5.8 \%$ & $0.9 \%$ & $1.7 \%$ & $3.4 \%$ \\
\hline - $\quad$ Bite (3) \% at or below current MW & $3.5 \%$ & $8.5 \%$ & $8.5 \%$ & $2.7 \%$ & $4.4 \%$ & $4.5 \%$ \\
\hline - MW worker share of total wage costs ${ }^{1}$ & $0.8 \%$ & $1.6 \%$ & $2.0 \%$ & $0.5 \%$ & $0.8 \%$ & $1.0 \%$ \\
\hline \multicolumn{7}{|l|}{ Women } \\
\hline - $\quad$ Kaitz index & $59.0 \%$ & $68.6 \%$ & $73.9 \%$ & $57.0 \%$ & $63.2 \%$ & $68.7 \%$ \\
\hline - Bite (1) \% of employee below next MW & $4.5 \%$ & $13.9 \%$ & $17.5 \%$ & $4.3 \%$ & $9.7 \%$ & $12.3 \%$ \\
\hline - $\quad$ Bite (2) \% of wage bill below next MW & $1.7 \%$ & $5.7 \%$ & $8.5 \%$ & $1.6 \%$ & $4.2 \%$ & $6.1 \%$ \\
\hline - $\quad$ Bite (3) \% at or below current MW & $4.5 \%$ & $12.1 \%$ & $10.1 \%$ & $4.3 \%$ & $8.1 \%$ & $6.8 \%$ \\
\hline - MW worker share of total wage costs1 & $0.6 \%$ & $1.9 \%$ & $1.9 \%$ & $0.5 \%$ & $1.2 \%$ & $1.2 \%$ \\
\hline \multicolumn{7}{|l|}{ European ethnicity } \\
\hline - Kaitz index & $52.4 \%$ & $61.5 \%$ & $67.3 \%$ & $49.8 \%$ & $55.9 \%$ & $62.3 \%$ \\
\hline - $\quad$ Bite (1) \% of employee below next MW & $3.4 \%$ & $10.2 \%$ & $13.8 \%$ & $2.8 \%$ & $5.6 \%$ & $8.0 \%$ \\
\hline - $\quad$ Bite (2) \% of wage bill below next MW & $1.1 \%$ & $3.4 \%$ & $5.8 \%$ & $0.9 \%$ & $1.9 \%$ & $3.5 \%$ \\
\hline - $\quad$ Bite (3) \% at or below current MW & $3.4 \%$ & $9.1 \%$ & $8.4 \%$ & $2.8 \%$ & $4.9 \%$ & $4.6 \%$ \\
\hline - MW worker share of total wage costs1 & $1.0 \%$ & $2.3 \%$ & $2.4 \%$ & $0.7 \%$ & $1.2 \%$ & $1.2 \%$ \\
\hline \multicolumn{7}{|l|}{ Maori ethnicity } \\
\hline - Kaitz index & $62.3 \%$ & $72.7 \%$ & $75.7 \%$ & $58.8 \%$ & $68.6 \%$ & $70.0 \%$ \\
\hline - $\quad$ Bite (1) \% of employee below next MW & $7.1 \%$ & $16.1 \%$ & $18.7 \%$ & $6.4 \%$ & $11.1 \%$ & $12.0 \%$ \\
\hline - $\quad$ Bite (2) \% of wage bill below next MW & $3.1 \%$ & $6.9 \%$ & $10.2 \%$ & $2.6 \%$ & $4.5 \%$ & $6.6 \%$ \\
\hline - $\quad$ Bite (3) \% at or below current MW & $7.1 \%$ & $14.2 \%$ & $11.0 \%$ & $6.4 \%$ & $9.8 \%$ & $6.8 \%$ \\
\hline - MW worker share of total wage costs1 & $0.3 \%$ & $0.7 \%$ & $0.7 \%$ & $0.2 \%$ & $0.3 \%$ & $0.3 \%$ \\
\hline \multicolumn{7}{|l|}{ Pasifika ethnicity } \\
\hline - $\quad$ Kaitz index & $64.8 \%$ & $76.8 \%$ & $78.8 \%$ & $64.4 \%$ & $70.6 \%$ & $74.1 \%$ \\
\hline - $\quad$ Bite (1) \% of employee below next MW & $7.2 \%$ & $18.5 \%$ & $23.2 \%$ & $7.4 \%$ & $12.3 \%$ & $15.4 \%$ \\
\hline - $\quad$ Bite $(2) \%$ of wage bill below next MW & $3.7 \%$ & $10.0 \%$ & $13.4 \%$ & $3.6 \%$ & $6.7 \%$ & $8.7 \%$ \\
\hline - $\quad$ Bite (3) \% at or below current MW & $7.2 \%$ & $15.9 \%$ & $13.7 \%$ & $7.4 \%$ & $10.2 \%$ & $8.8 \%$ \\
\hline - MW worker share of total wage costs1 & $0.1 \%$ & $0.4 \%$ & $0.4 \%$ & $0.1 \%$ & $0.2 \%$ & $0.2 \%$ \\
\hline \multicolumn{7}{|l|}{ All other ethnicity } \\
\hline - Kaitz index & $54.2 \%$ & $69.5 \%$ & $73.1 \%$ & $53.8 \%$ & $63.2 \%$ & $70.4 \%$ \\
\hline - $\quad$ Bite (1) \% of employee below next MW & $4.6 \%$ & $17.4 \%$ & $18.3 \%$ & $4.0 \%$ & $13.8 \%$ & $13.7 \%$ \\
\hline - $\quad$ Bite (2) \% of wage bill below next MW & $1.7 \%$ & $7.1 \%$ & $8.7 \%$ & $1.5 \%$ & $6.0 \%$ & $6.8 \%$ \\
\hline - $\quad$ Bite (3) \% at or below current MW & $4.6 \%$ & $14.0 \%$ & $11.1 \%$ & $4.0 \%$ & $11.1 \%$ & $8.1 \%$ \\
\hline - MW worker share of total wage costs1 & $0.1 \%$ & $0.5 \%$ & $0.9 \%$ & $0.1 \%$ & $\begin{array}{l}0.4 \% \\
\text { (Conti }\end{array}$ & $\begin{array}{l}0.6 \% \\
\text { ued) }\end{array}$ \\
\hline
\end{tabular}


Table 4 (continued): Minimum Wage incidence by main demographic groups

\begin{tabular}{|c|c|c|c|c|c|c|}
\hline & \multicolumn{3}{|c|}{ All employees } & \multicolumn{3}{|c|}{ Prime aged } \\
\hline & 1997 & 2008 & 2020 & 1997 & 2008 & 2020 \\
\hline \multicolumn{7}{|l|}{ No qualifications } \\
\hline - Kaitz index & $65.3 \%$ & $78.4 \%$ & $80.5 \%$ & $65.1 \%$ & $75.0 \%$ & $77.9 \%$ \\
\hline - Bite (1) \% of employee below next MW & $7.6 \%$ & $18.3 \%$ & $22.6 \%$ & $6.9 \%$ & $13.9 \%$ & $19.1 \%$ \\
\hline - Bite (2) \% of wage bill below next MW & $3.1 \%$ & $9.3 \%$ & $12.9 \%$ & $2.8 \%$ & $7.0 \%$ & $10.7 \%$ \\
\hline - Bite (3) \% at or below current MW & $7.6 \%$ & $15.7 \%$ & $13.9 \%$ & $6.9 \%$ & $11.8 \%$ & $11.3 \%$ \\
\hline - $\mathrm{MW}$ worker share of total wage costs ${ }^{1}$ & $0.5 \%$ & $1.0 \%$ & $0.6 \%$ & $0.4 \%$ & $0.7 \%$ & $0.4 \%$ \\
\hline \multicolumn{7}{|l|}{ School qualifications } \\
\hline - Kaitz index & $58.1 \%$ & $75.0 \%$ & $82.2 \%$ & $53.7 \%$ & $62.6 \%$ & $73.1 \%$ \\
\hline - Bite (1) \% of employee below next MW & $3.6 \%$ & $19.1 \%$ & $27.2 \%$ & $3.1 \%$ & $7.3 \%$ & $13.9 \%$ \\
\hline - Bite (2) \% of wage bill below next MW & $1.4 \%$ & $6.9 \%$ & $14.4 \%$ & $1.1 \%$ & $3.0 \%$ & $7.6 \%$ \\
\hline - Bite (3) \% at or below current MW & $3.6 \%$ & $17.1 \%$ & $16.2 \%$ & $3.1 \%$ & $6.2 \%$ & $7.3 \%$ \\
\hline - $\mathrm{MW}$ worker share of total wage costs ${ }^{1}$ & $0.3 \%$ & $1.1 \%$ & $1.7 \%$ & $0.2 \%$ & $0.4 \%$ & $0.6 \%$ \\
\hline \multicolumn{7}{|l|}{ Post-school qualifications } \\
\hline - Kaitz index & $49.5 \%$ & $60.2 \%$ & $70.0 \%$ & $47.7 \%$ & $58.5 \%$ & $66.9 \%$ \\
\hline - Bite (1) \% of employee below next MW & $2.6 \%$ & $8.8 \%$ & $12.2 \%$ & $2.2 \%$ & $7.1 \%$ & $9.5 \%$ \\
\hline - Bite (2) \% of wage bill below next MW & $1.0 \%$ & $3.5 \%$ & $6.1 \%$ & $0.8 \%$ & $2.6 \%$ & $4.7 \%$ \\
\hline - Bite (3) \% at or below current MW & $2.6 \%$ & $7.5 \%$ & $7.6 \%$ & $2.2 \%$ & $6.0 \%$ & $5.9 \%$ \\
\hline - $\mathrm{MW}$ worker share of total wage costs ${ }^{1}$ & $0.4 \%$ & $0.9 \%$ & $0.9 \%$ & $0.3 \%$ & $0.6 \%$ & $0.6 \%$ \\
\hline \multicolumn{7}{|l|}{ Degree qualifications } \\
\hline - Kaitz index & $43.3 \%$ & $48.0 \%$ & $56.3 \%$ & $40.6 \%$ & $46.2 \%$ & $54.5 \%$ \\
\hline - Bite (1) \% of employee below next MW & $2.8 \%$ & $3.9 \%$ & $6.3 \%$ & $2.4 \%$ & $3.3 \%$ & $5.0 \%$ \\
\hline - Bite (2) \% of wage bill below next MW & $0.8 \%$ & $1.1 \%$ & $2.4 \%$ & $0.6 \%$ & $0.9 \%$ & $1.9 \%$ \\
\hline - Bite (3) \% at or below current MW & $2.8 \%$ & $3.3 \%$ & $3.9 \%$ & $2.4 \%$ & $2.8 \%$ & $3.1 \%$ \\
\hline - $\mathrm{MW}$ worker share of total wage costs ${ }^{1}$ & $0.2 \%$ & $0.3 \%$ & $0.6 \%$ & $0.1 \%$ & $0.2 \%$ & $0.5 \%$ \\
\hline
\end{tabular}

${ }^{1}$. Cost shares are based on employee-weighted weekly earnings

Source: Income Survey, 1997-2020 
Table 5: Minimum Wage incidence - teen industries

\begin{tabular}{lccc}
\hline \hline & 2001 & 2008 & 2020 \\
\hline Employment rate & $100 \%$ & $100 \%$ & $100 \%$ \\
Real Median Wage & 16.76 & 17.28 & 21.00 \\
Real Adult Minimum Wage & 11.30 & 14.55 & 18.90 \\
Real sub-minimum wage & 7.92 & 11.64 & 15.12 \\
Kaitz index (employee-weighted mean) & $65.3 \%$ & $82.6 \%$ & $87.5 \%$ \\
Bite (1) \% of employee below next MW & $7.1 \%$ & $26.9 \%$ & $37.7 \%$ \\
Bite (2) \% of wage bill below next MW & $2.7 \%$ & $13.1 \%$ & $22.6 \%$ \\
Bite (3) \% at or below current MW & $5.3 \%$ & $23.5 \%$ & $22.6 \%$ \\
MW worker share of total labour cost1 & $2.3 \%$ & $11.1 \%$ & $12.3 \%$ \\
& & &
\end{tabular}

1. Cost shares are based on employee-weighted weekly earnings

Source: Income Survey, 1997-2020 
Table 6: Employment regressions on Kaitz index

\begin{tabular}{|c|c|c|c|c|c|c|c|c|c|c|c|}
\hline & \multicolumn{4}{|c|}{ Aggregate Kaitz index } & \multicolumn{3}{|c|}{ Age-group Kaitz index } & \multicolumn{4}{|c|}{ Cell-group Kaitz index } \\
\hline & $(1)$ & $(2)$ & (3) & (4) & $(5)$ & $(6)$ & (7) & (8) & (9) & $(10)$ & $(11)$ \\
\hline \multirow[t]{2}{*}{ Log(Kaitz) } & 0.035 & 0.031 & 0.039 & & -0.012 & -0.044 & 0.002 & 0.031 & 0.058 & 0.041 & $-0.383 * * *$ \\
\hline & $(0.042)$ & $(0.050)$ & $(0.055)$ & & $(0.024)$ & $(0.032)$ & $(0.037)$ & $(0.031)$ & (0.039) & $(0.074)$ & (0.093) \\
\hline \multicolumn{12}{|l|}{$\log ($ Kaitz) * } \\
\hline \multirow[t]{2}{*}{ Age-1617 } & & & & $-0.627 * * *$ & & & & & & & \\
\hline & & & & $(0.097)$ & & & & & & & \\
\hline \multirow[t]{2}{*}{ Age-1819 } & & & & 0.024 & & & & & & & \\
\hline & & & & $(0.078)$ & & & & & & & \\
\hline \multirow[t]{2}{*}{ Teens } & & & & & & & & & & & $-0.640 * * *$ \\
\hline & & & & & & & & & & & $(0.080)$ \\
\hline \multirow[t]{2}{*}{ Age-2024 } & & & & $0.145^{* *}$ & & & & & & & $-0.214 * * *$ \\
\hline & & & & $(0.069)$ & & & & & & & $(0.082)$ \\
\hline \multirow[t]{2}{*}{ Age-2564 } & & & & $0.133 * *$ & & & & & & & \\
\hline & & & & $(0.054)$ & & & & & & & \\
\hline \multirow[t]{2}{*}{ Age-65+ } & & & & 0.099* & & & & & & & -0.167 \\
\hline & & & & (0.059) & & & & & & & $(0.108)$ \\
\hline \multirow[t]{2}{*}{ Female } & & & & & & & & & & & $-0.069 * *$ \\
\hline & & & & & & & & & & & $(0.028)$ \\
\hline \multirow[t]{2}{*}{ Low-quals } & & & & & & & & & & & $1.080 * * *$ \\
\hline & & & & & & & & & & & $(0.067)$ \\
\hline \multirow[t]{2}{*}{ Non-European } & & & & & & & & & & & 0.008 \\
\hline & & & & & & & & & & & $(0.037)$ \\
\hline \multirow[t]{2}{*}{ GDP growth } & & 0.233 & 0.346 & 1.110 & & $1.473 *$ & -0.275 & & -1.112 & 0.153 & -0.049 \\
\hline & & $(1.620)$ & $(1.595)$ & $(1.354)$ & & $(0.746)$ & $(1.114)$ & & $(0.852)$ & (2.168) & (0.651) \\
\hline \multirow[t]{2}{*}{ GDP growth } & $0.235^{* *}$ & 0.353 & & & $0.209 *$ & $0.919 * * *$ & & 0.221 & -0.303 & & 0.153 \\
\hline & (0.114) & $(0.871)$ & & & $(0.118)$ & (0.339) & & $(0.212)$ & $(0.404)$ & & $(0.315)$ \\
\hline R-squared & 0.197 & 0.197 & 0.197 & 0.198 & 0.197 & 0.197 & 0.197 & 0.206 & 0.206 & 0.207 & 0.213 \\
\hline
\end{tabular}

Notes: All specifications based on 1997-2020 HLFS-IS data with 672,501 observations, and include linear time trends (for those aged 25+), and controls for age, sex,

ethnicity, and qualifications. The cell-groups are defined across age, sex, ethnicity and qualification groups. Robust standard errors allowing for clustering at the age-group level (cell-group level for the cell-group Kaitz regressions) are in parentheses. ${ }^{* * *} p<0.01,{ }^{* *} p<0.05,{ }^{*} p<0.1$ 
Table 7: Employment regressions on minimum wage bite

\begin{tabular}{|c|c|c|c|c|c|c|c|}
\hline & \multicolumn{3}{|c|}{ Aggregate bite } & \multicolumn{2}{|c|}{ Age-group bite } & \multicolumn{2}{|c|}{ Cell-group bite } \\
\hline & (1) & $(2)$ & (3) & (4) & (5) & (6) & (7) \\
\hline \multirow[t]{2}{*}{ MW bite } & 0.127 & $0.996 * * *$ & $0.194 *$ & $0.246 * * *$ & $0.274 * * *$ & $0.591 * * *$ & $-0.380 * *$ \\
\hline & $(0.097)$ & $(0.285)$ & $(0.105)$ & (0.059) & $(0.057)$ & (0.106) & (0.172) \\
\hline \multirow[t]{2}{*}{ MW bite^2 } & & $-5.000 * * *$ & & $-0.523 * * *$ & $-0.535 * * *$ & $-0.905 * * *$ & \\
\hline & & (1.629) & & (0.081) & $(0.083)$ & (0.156) & \\
\hline \multicolumn{8}{|l|}{ MW bite * } \\
\hline \multirow[t]{2}{*}{ Age-1617 } & & & $-1.059 * * *$ & & & & \\
\hline & & & $(0.286)$ & & & & \\
\hline \multirow[t]{2}{*}{ Age-1819 } & & & 0.123 & & & & \\
\hline & & & $(0.162)$ & & & & \\
\hline \multirow[t]{2}{*}{ Teens } & & & & & & & $-0.970 * * *$ \\
\hline & & & & & & & (0.105) \\
\hline \multirow[t]{2}{*}{ Age-2024 } & & & 0.173 & & & & $-0.429 * * *$ \\
\hline & & & $(0.138)$ & & & & (0.109) \\
\hline \multirow[t]{2}{*}{ Age-65+ } & & & -0.010 & & & & $-0.572 * * *$ \\
\hline & & & $(0.117)$ & & & & (0.124) \\
\hline \multirow[t]{2}{*}{ Female } & & & & & & & -0.020 \\
\hline & & & & & & & $(0.028)$ \\
\hline \multirow[t]{2}{*}{ Low quals } & & & & & & & $1.333 * * *$ \\
\hline & & & & & & & (0.134) \\
\hline \multirow[t]{2}{*}{ Non-European } & & & & & & & -0.0163 \\
\hline & & & & & & & $(0.050)$ \\
\hline \multirow[t]{2}{*}{ GDP growth } & 0.285 & 0.148 & & 0.137 & & 0.263 & 0.273 \\
\hline & $(0.214)$ & (0.157) & & (0.129) & & $(0.281)$ & $(0.228)$ \\
\hline \multirow[t]{2}{*}{ GDP growth } & -0.490 & 1.215 & -0.200 & 0.689 & -0.024 & -0.104 & -0.113 \\
\hline & $(3.064)$ & (2.428) & $(2.678)$ & $(0.696)$ & $(1.003)$ & (1.176) & (0.914) \\
\hline R-squared & 0.196 & 0.196 & 0.197 & 0.197 & 0.197 & 0.205 & 0.209 \\
\hline
\end{tabular}

Notes: All specifications based on 1997-2020 HLFS-IS data with 644,763 observations, and include linear time trends (for those aged 25+), and controls for age, sex, ethnicity, and qualifications. The cell-groups are defined across age, sex, ethnicity and qualification groups. Robust standard errors allowing for clustering at the age-group level (cell-group level for the cell-group Bite regressions) are in parentheses. ${ }^{* * *} p<0.01,{ }^{* *} p<0.05,{ }^{*} p<0.1$ 
Table 8: Counterfactual changes in Employees in response to MW change: 1997-2020 Estimation

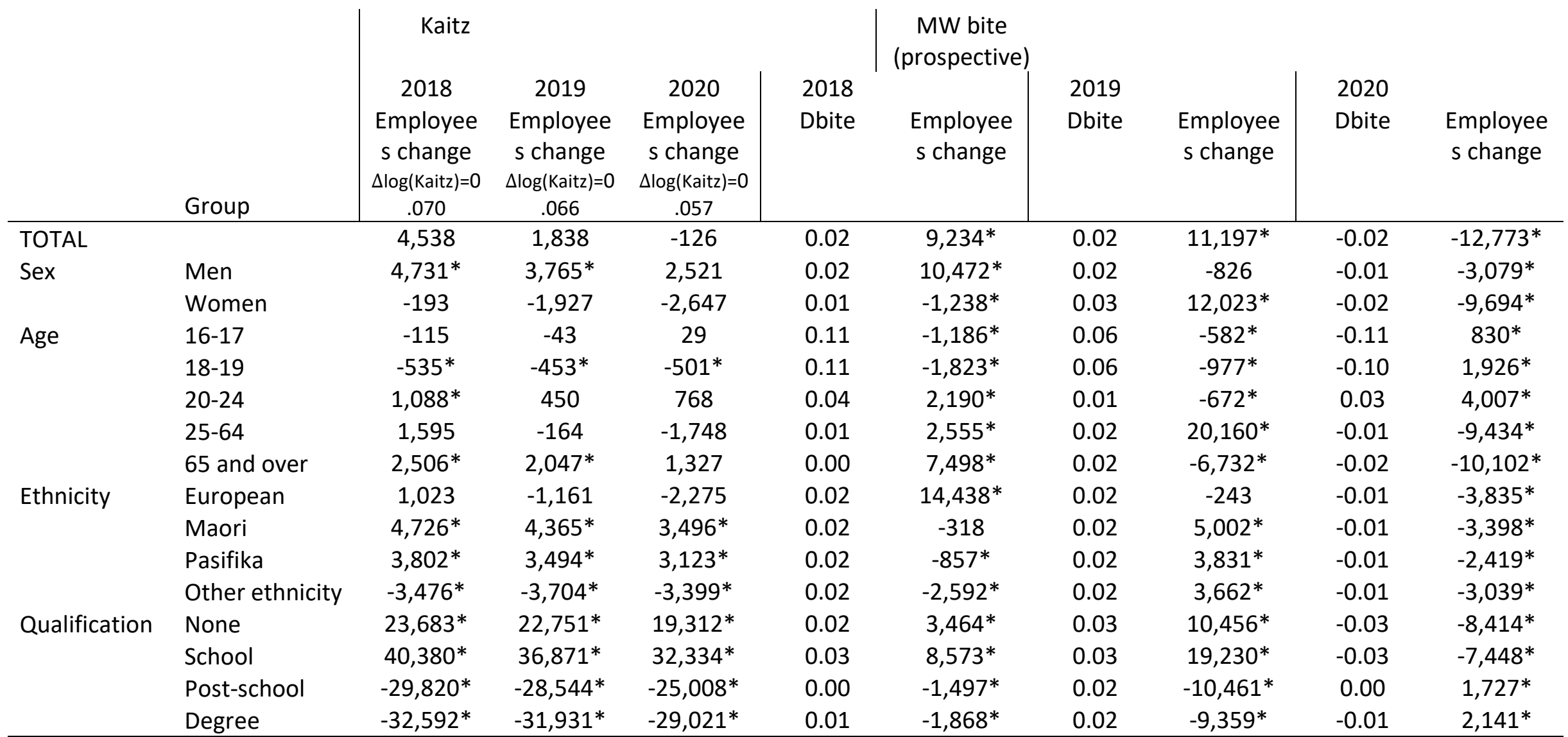

Note: asterisks $\left({ }^{*}\right)$ indicate that the change is significantly different from zero, at the $95 \%$ confidence level. Because the specification in the final column of Table 7 includes separate coefficients on cell-group-specific bite variables, and the counterfactual change in bite is also cell-groupspecific, standard errors are calculated using bootstrap methods, using 50 bootstrap iterations. Dbite refers to the counterfactual change in bite implied by the minimum wage change, as described in section 4.2.6. 
Table 9: Counterfactual changes in Employment in response to MW change:

\begin{tabular}{|c|c|c|}
\hline & 2018-2019 change & 2019-2020 change \\
\hline Actual Employment (aged 16-64) & $+32,400$ & $+19,600$ \\
\hline MBIE “Employment Restraint” & $-8,000$ & $-6,500$ \\
\hline Actual number of employees (aged 16-64) & $+14,400$ & $-11,000$ \\
\hline \multicolumn{3}{|l|}{ Counterfactuals (1997-2020 estimation) } \\
\hline Kaitz & $+2,032$ & -209 \\
\hline MW bite & $+1,736$ & $+17,929$ \\
\hline \multicolumn{3}{|l|}{ Counterfactuals (2008-2020 estimation) } \\
\hline Kaitz & -521 & -156 \\
\hline MW bite & $-2,110$ & +36 \\
\hline \multicolumn{3}{|c|}{$\begin{array}{l}\text { Note: Actual employment and employee changes from Income Survey. MBIE Employment } \\
\text { restraint numbers are from MBIE Minimum wage reviews } \\
\text { (https://www.mbie.govt.nz/business-and-employment/employment-and- }\end{array}$} \\
\hline
\end{tabular}


Figure 1: Real minimum wage trends under alternative inflation-adjustments

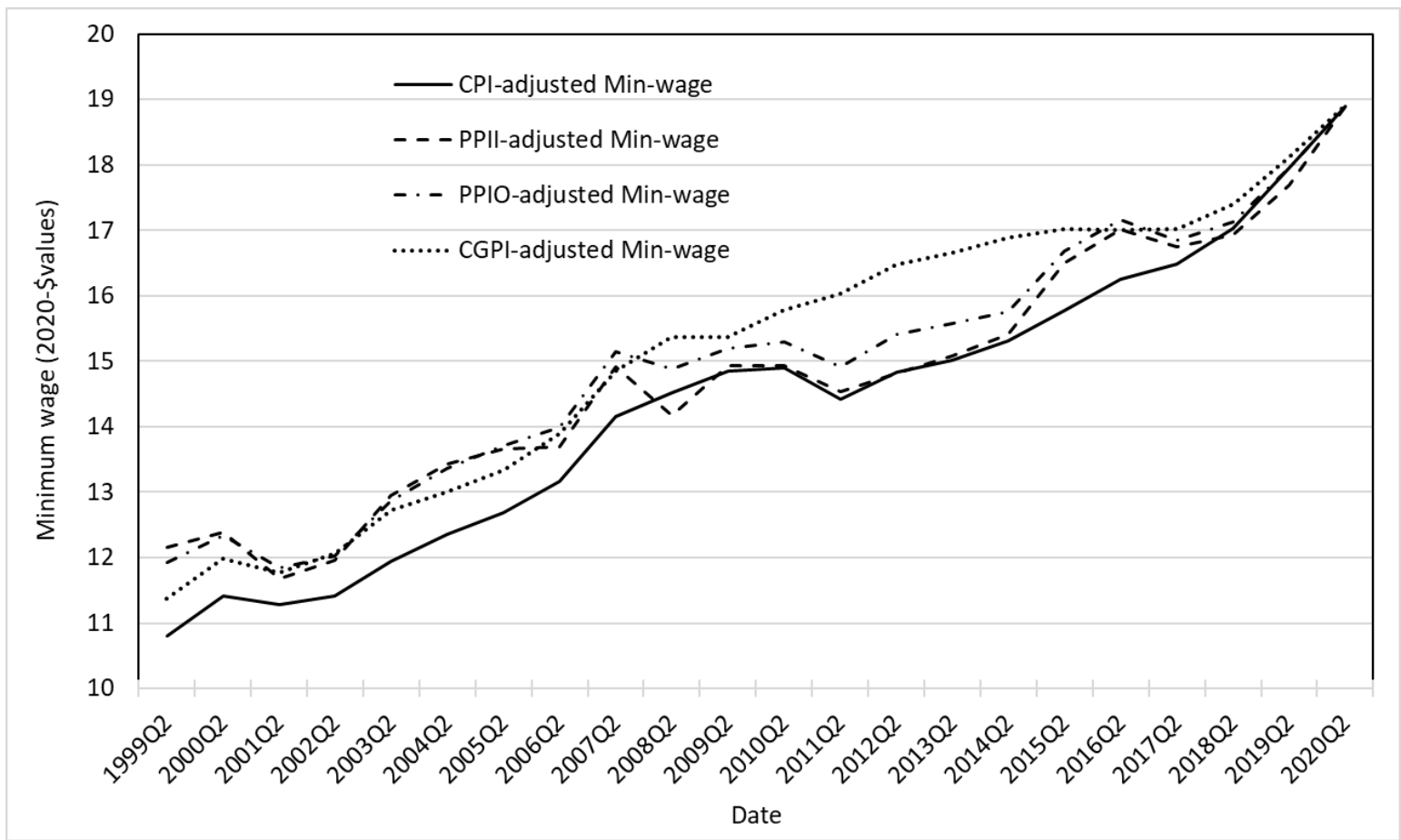

Notes: Each series is expressed in Quarter-2, 2020 -values, by adjusting the nominal minimum wage using the Consumers Price Index (CPI), the Producers Price Index-Inputs (PPII), the Producers Price Index-Outputs (PPIO), and the Capital Goods Price Index (CGPI) respectively. 
Figure 2: Trends in Minimum Wage, median wage, and Kaitz index
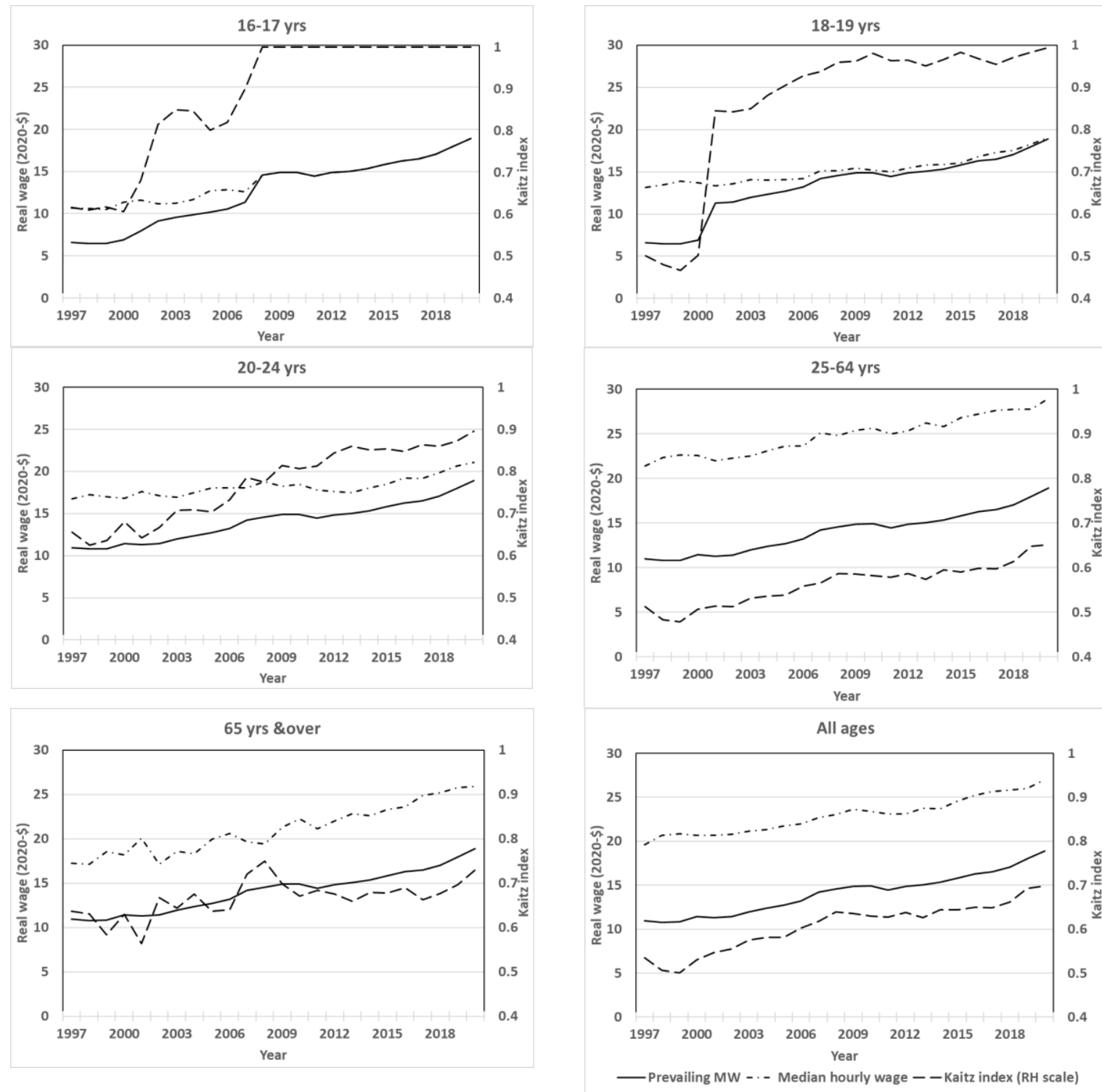

Source: Income Surveys 1997-2020. 
Figure 3: Distributional impact of the Minimum Wage
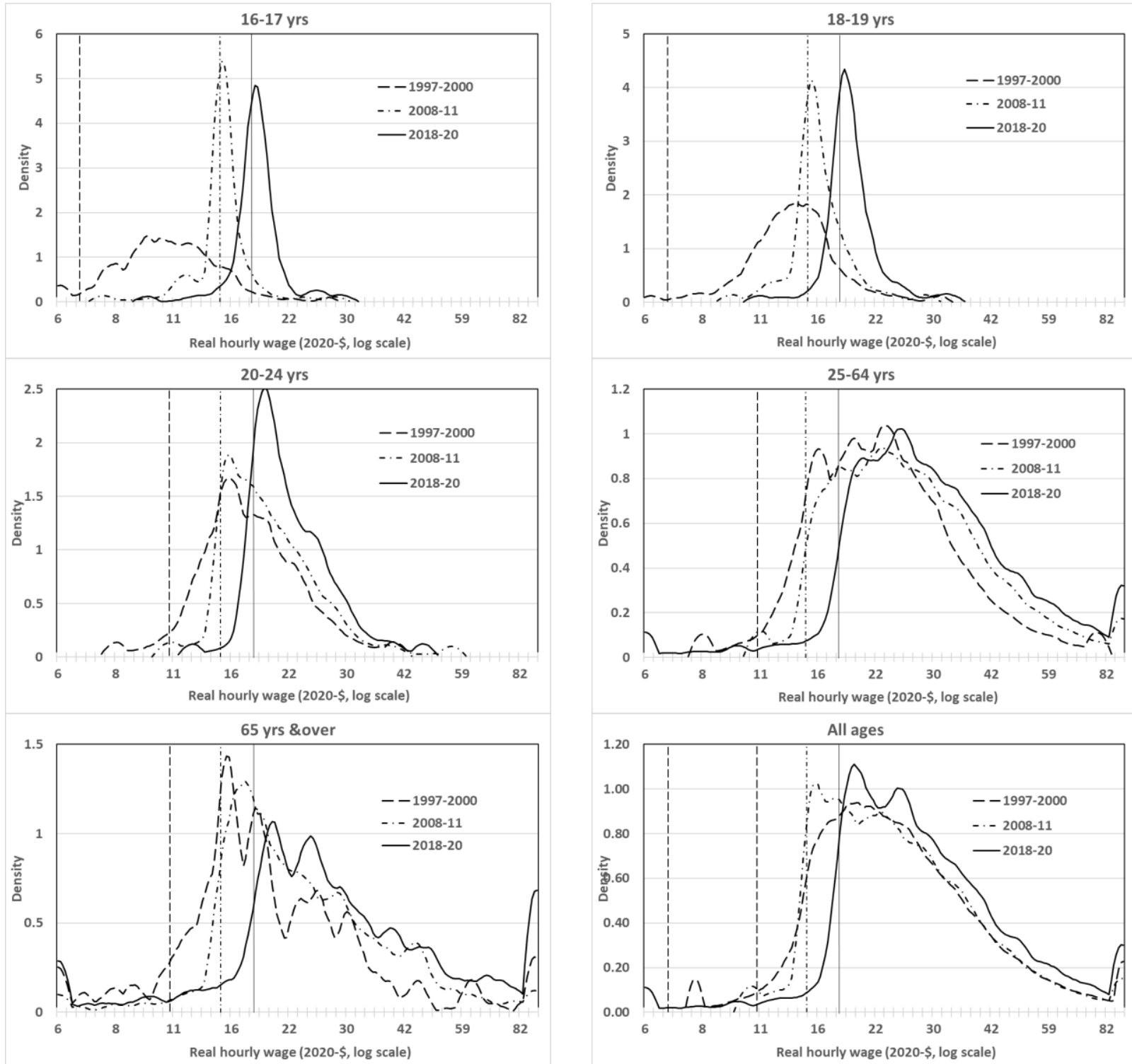

Notes: Distributions are censored at the $1^{\text {st }}$ and $99^{\text {th }}$ percentile values of overall wages in each period. Vertical lines indicate the (average) prevailing minimum wage applying to each group in 1997-00, 200811, and 2018-20.

Source: Income Surveys 1997-2020 
Figure 4: Cumulative change in the wage distributions - 2002-2008, and 2017-2020
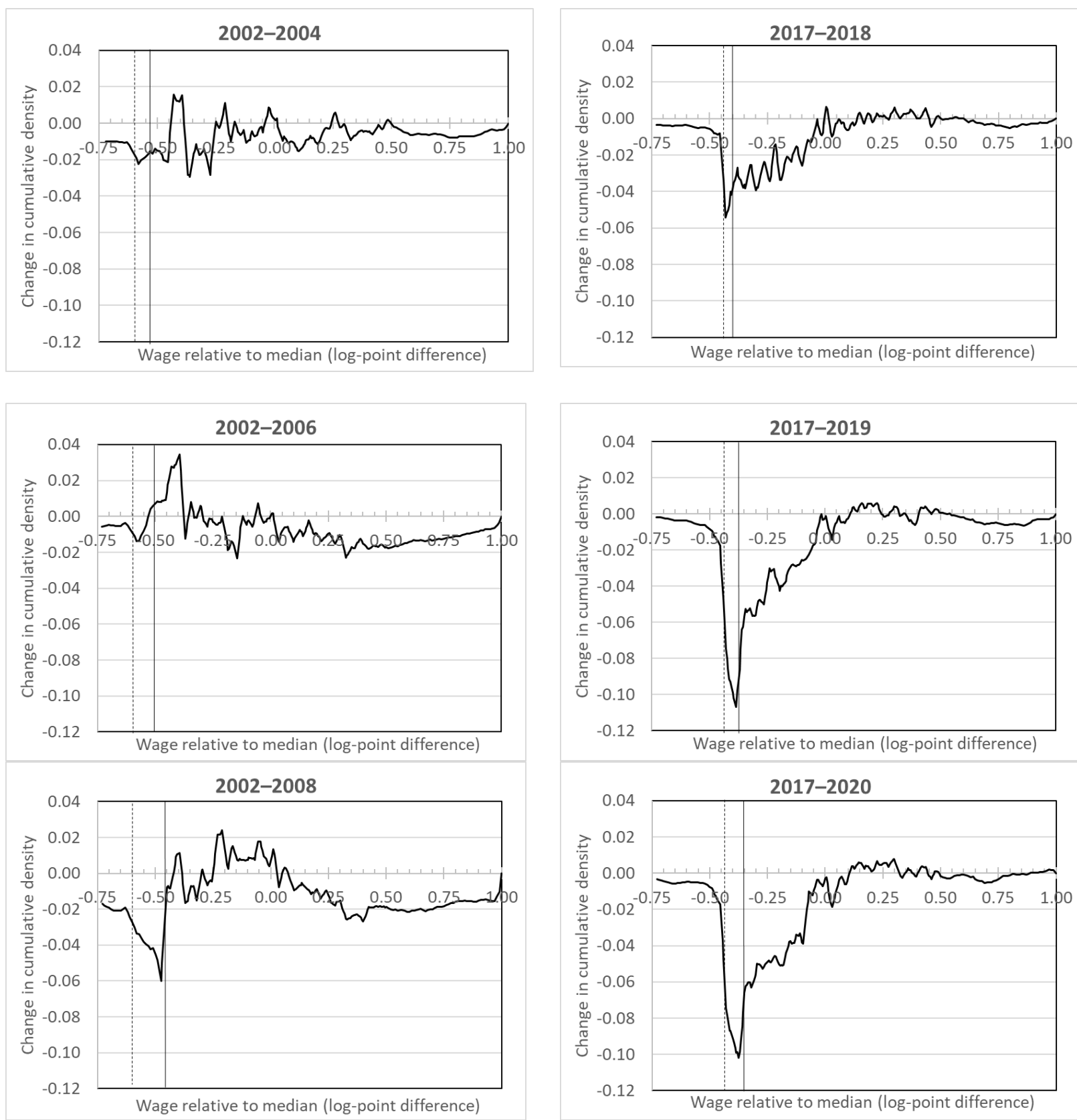

Notes: Each figures shows the (smoothed) difference in the cumulative density function (CDF) of wages from the base year (2002 or 2017).

Source: Income Surveys 1997-2020 
Figure 5: Age profiles, 2000 and 2020

(a) Employment and Average log(wage) profiles

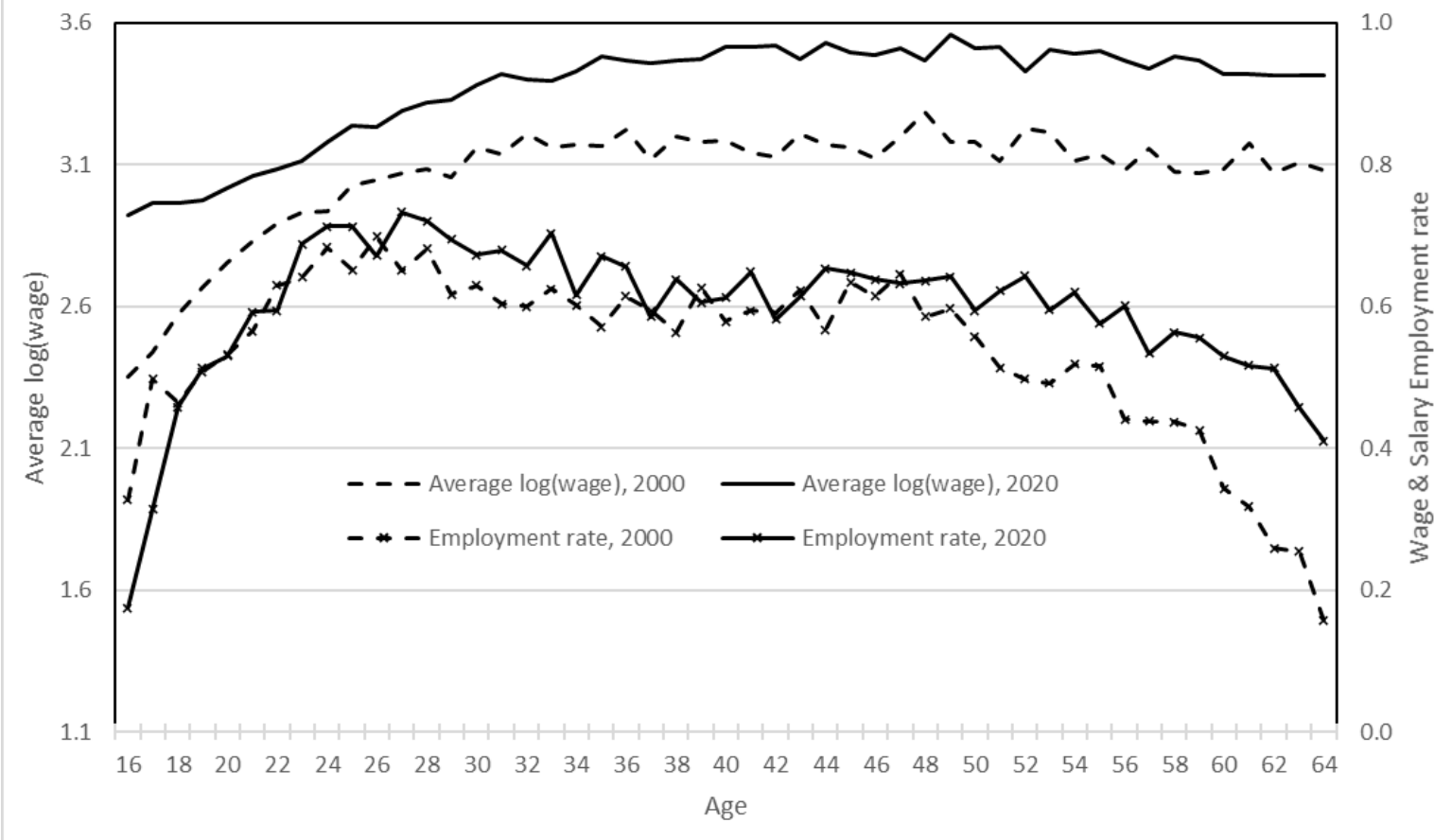

(b) Lower percentile log(wage) profiles

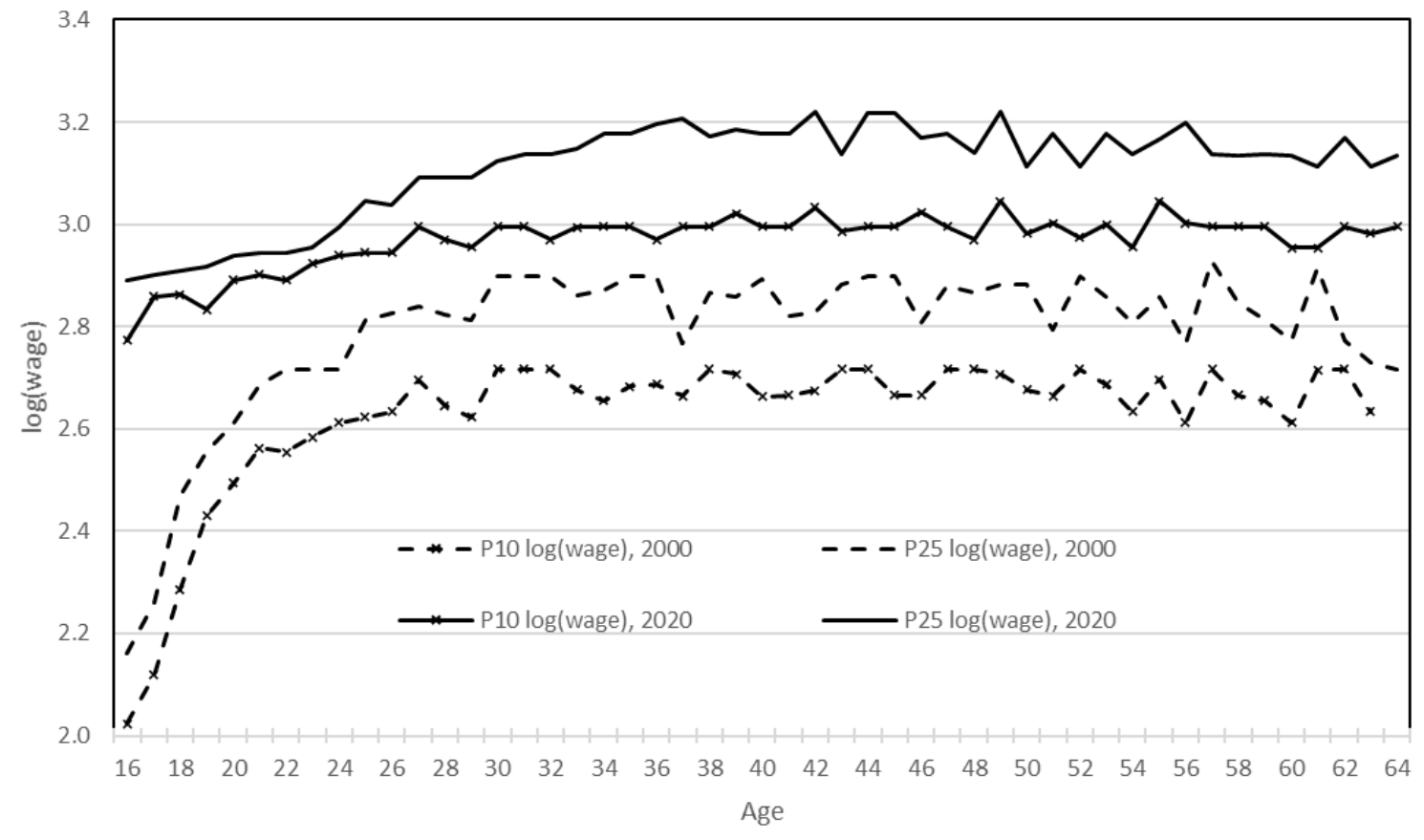


(c) Higher percentile log(wage) profiles

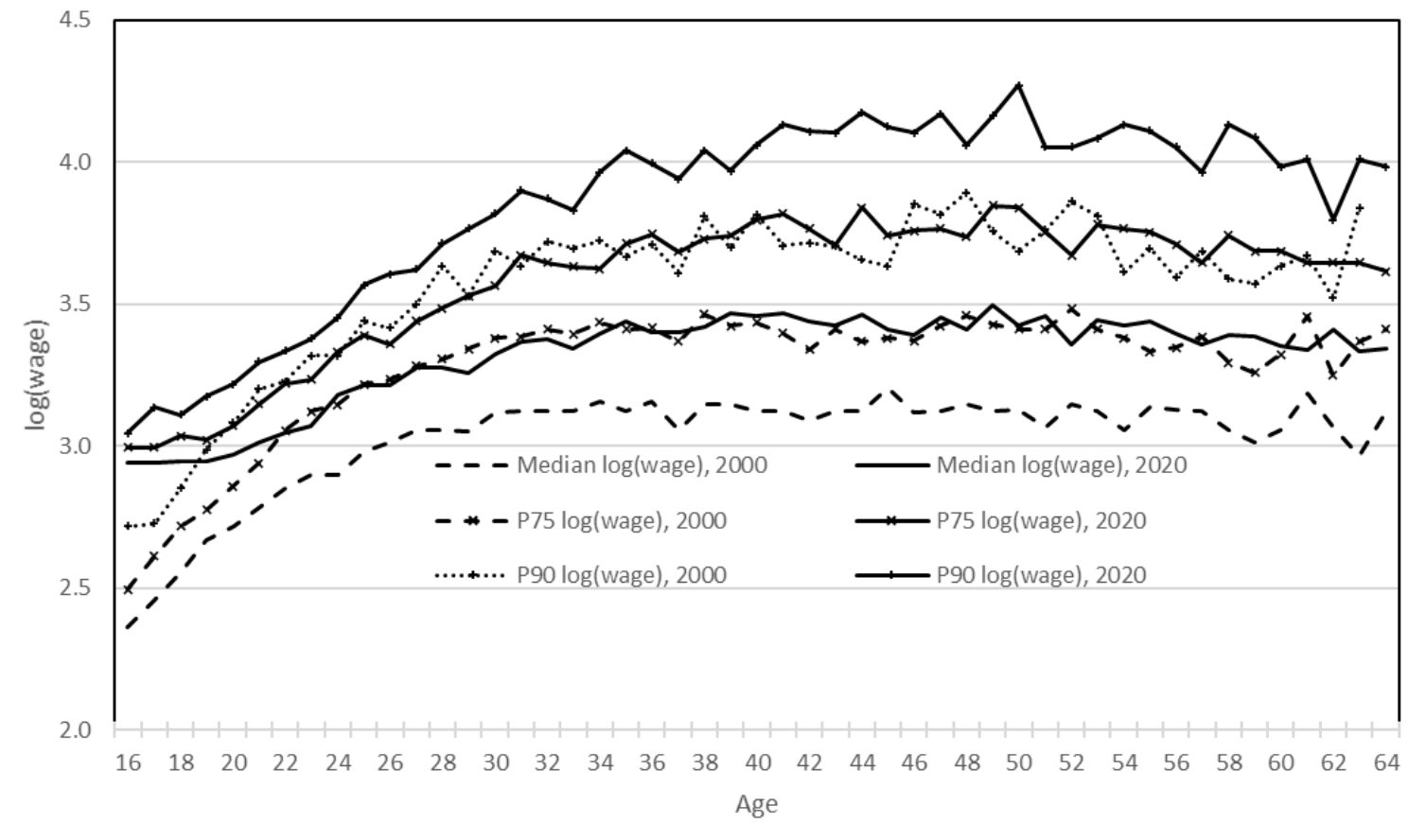

(d) $\log$ (wage) changes between 2000 and 2020

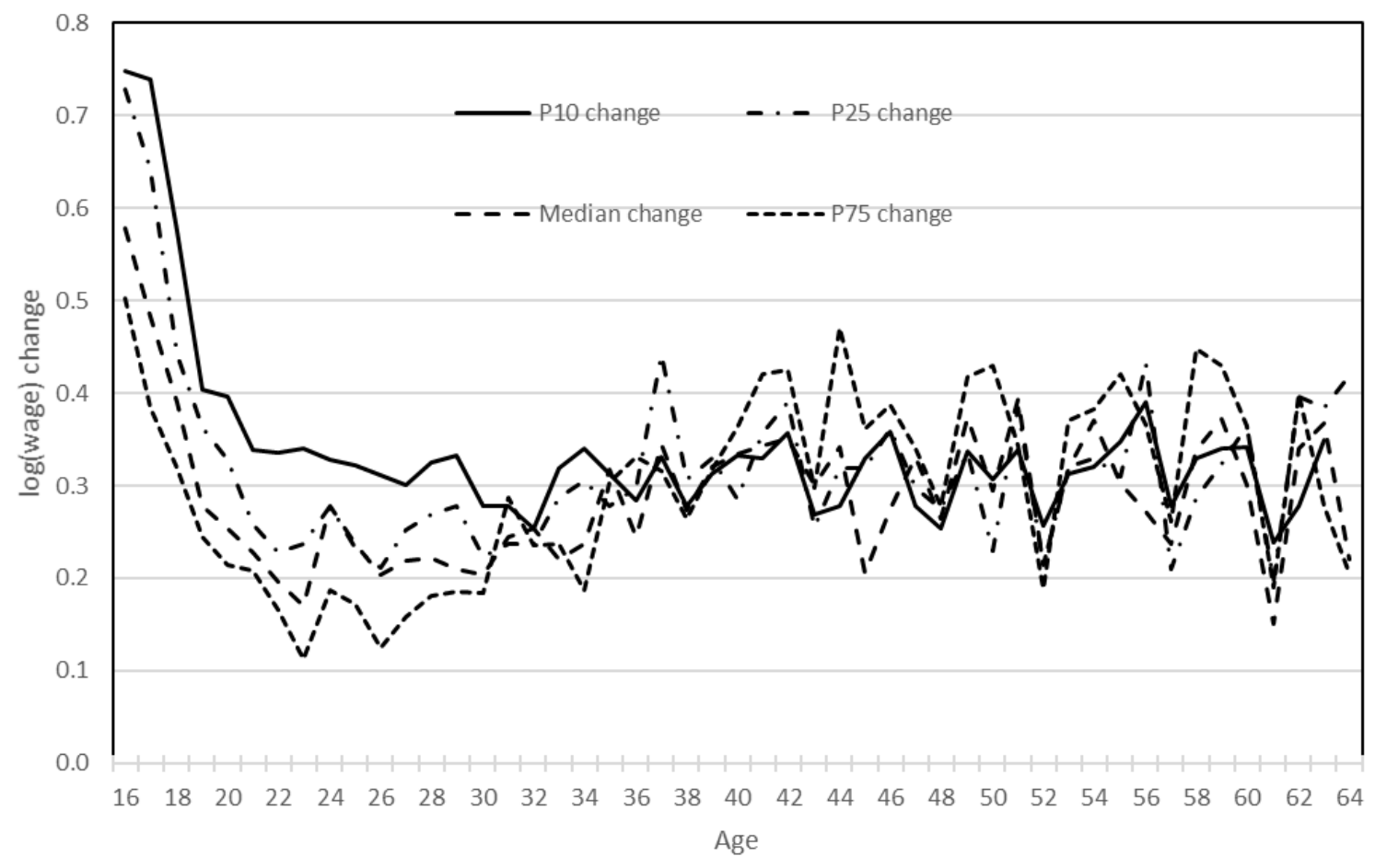

Source: Income Surveys, 2000 and 2020 
Figure 6: Alternative measures of the Minimum Wage "bite"

(a) All industries
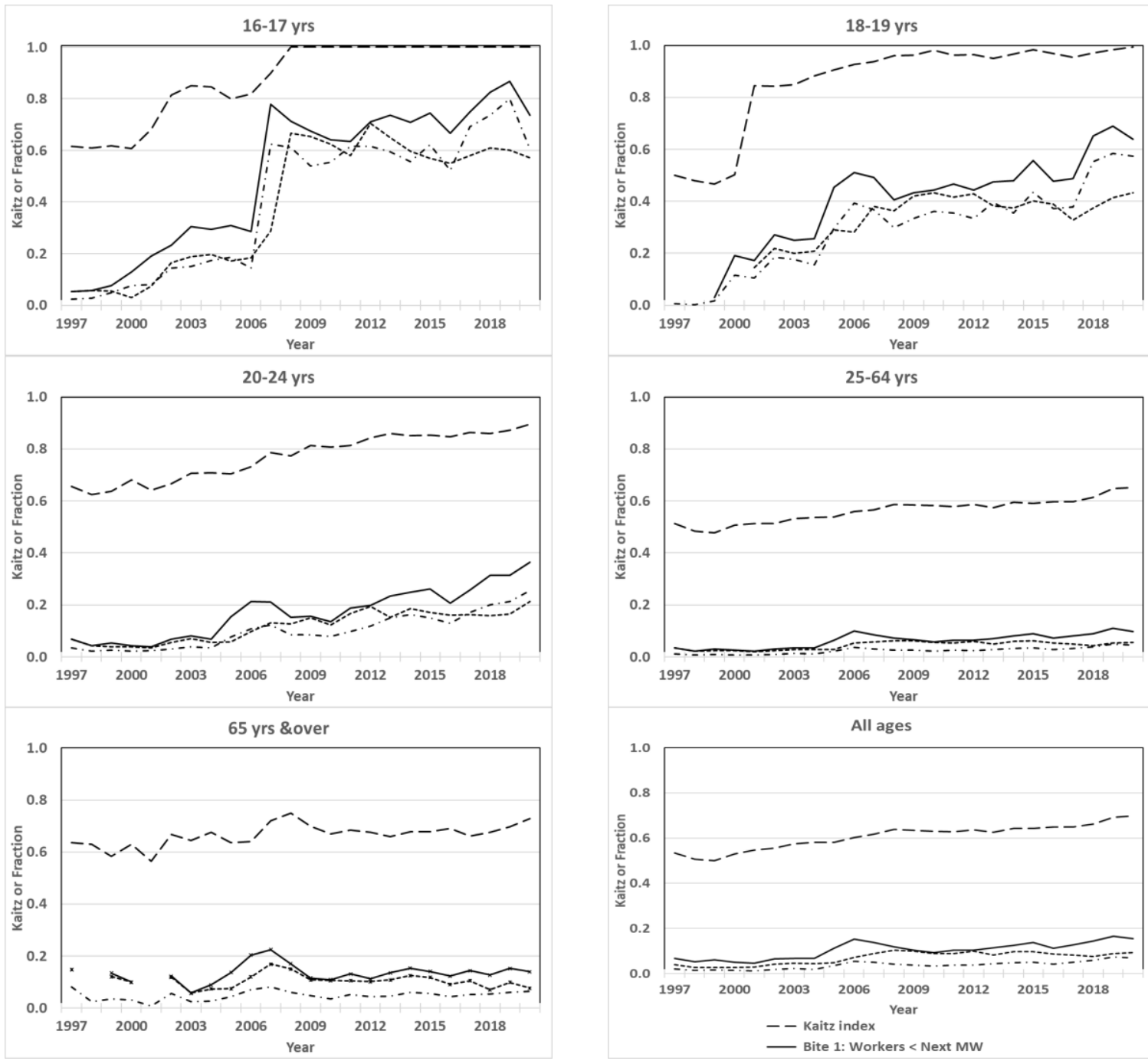

Source: Income Surveys, 1997-2020. 
Figure 5 (continued): Alternative measures of the Minimum Wage "bite"

(b) Teen industries
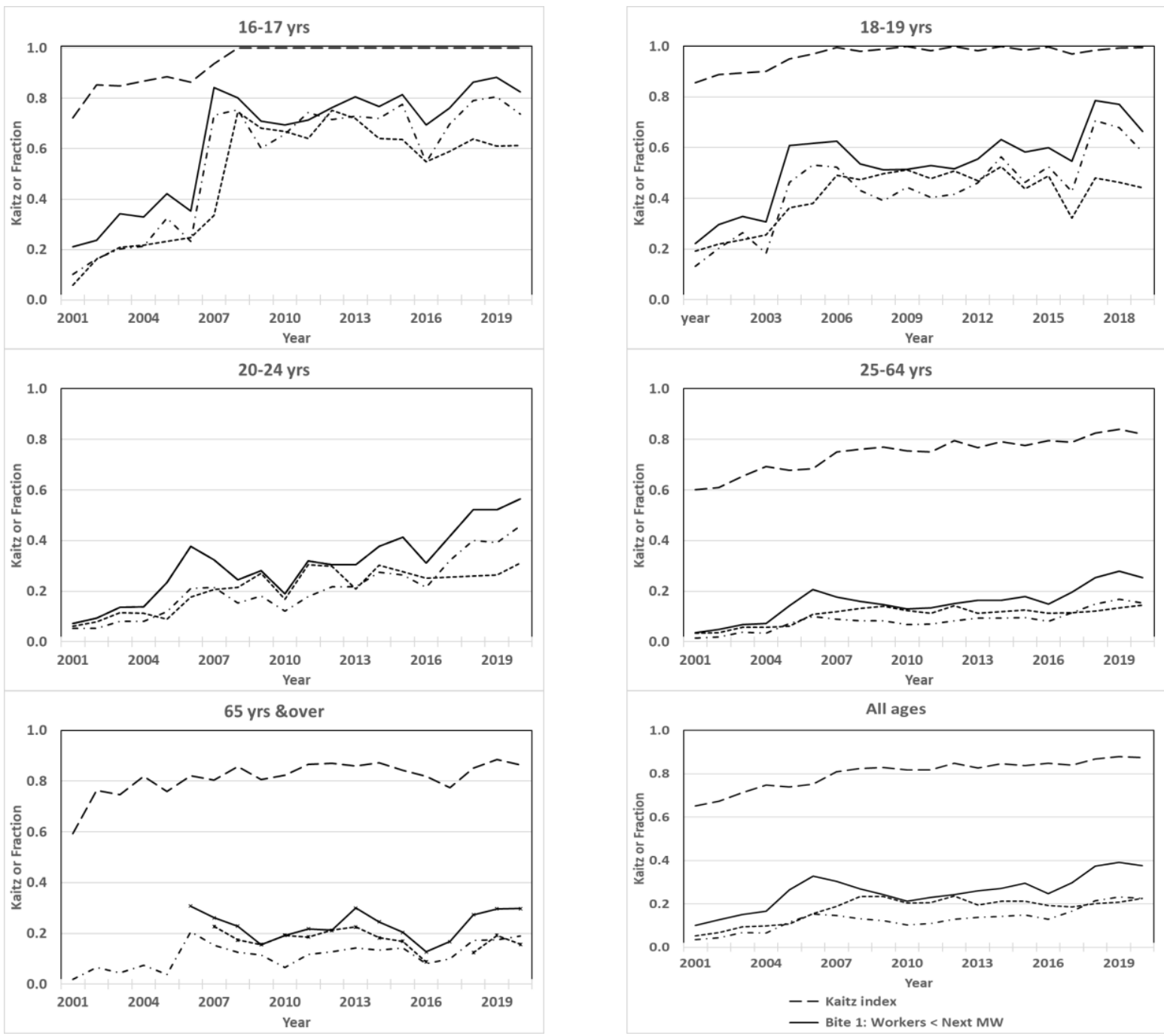

Source: Income Surveys, 2001-2020, due to the unavailablity of suitable industry coding pre-2001. 
Figure 7: Minimum Wages, employment, and study
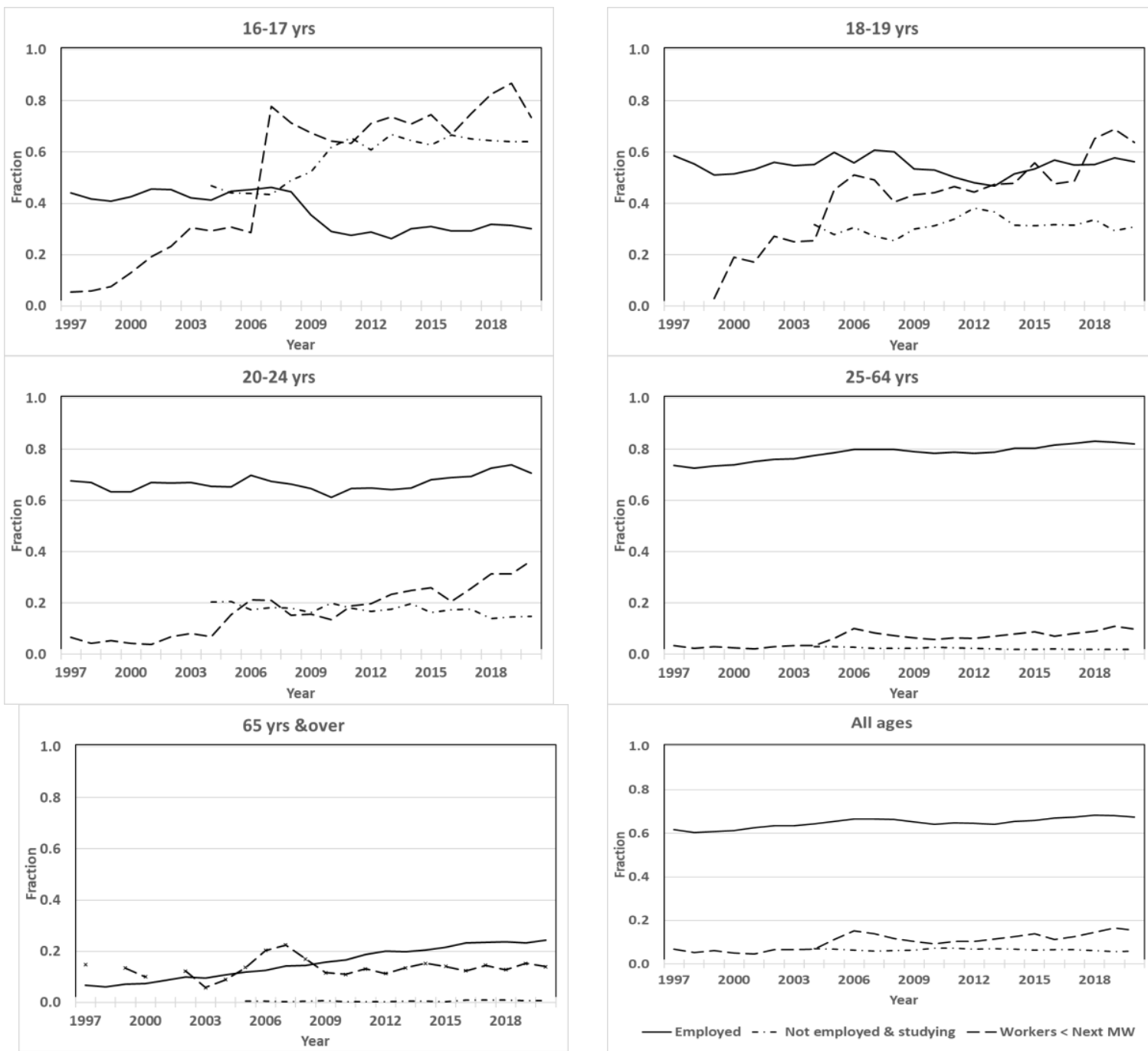

Source: Household Labour Force Survey and Income Survey, 1997-2020. 
Figure 8: Minimum wage and worker turnover rates
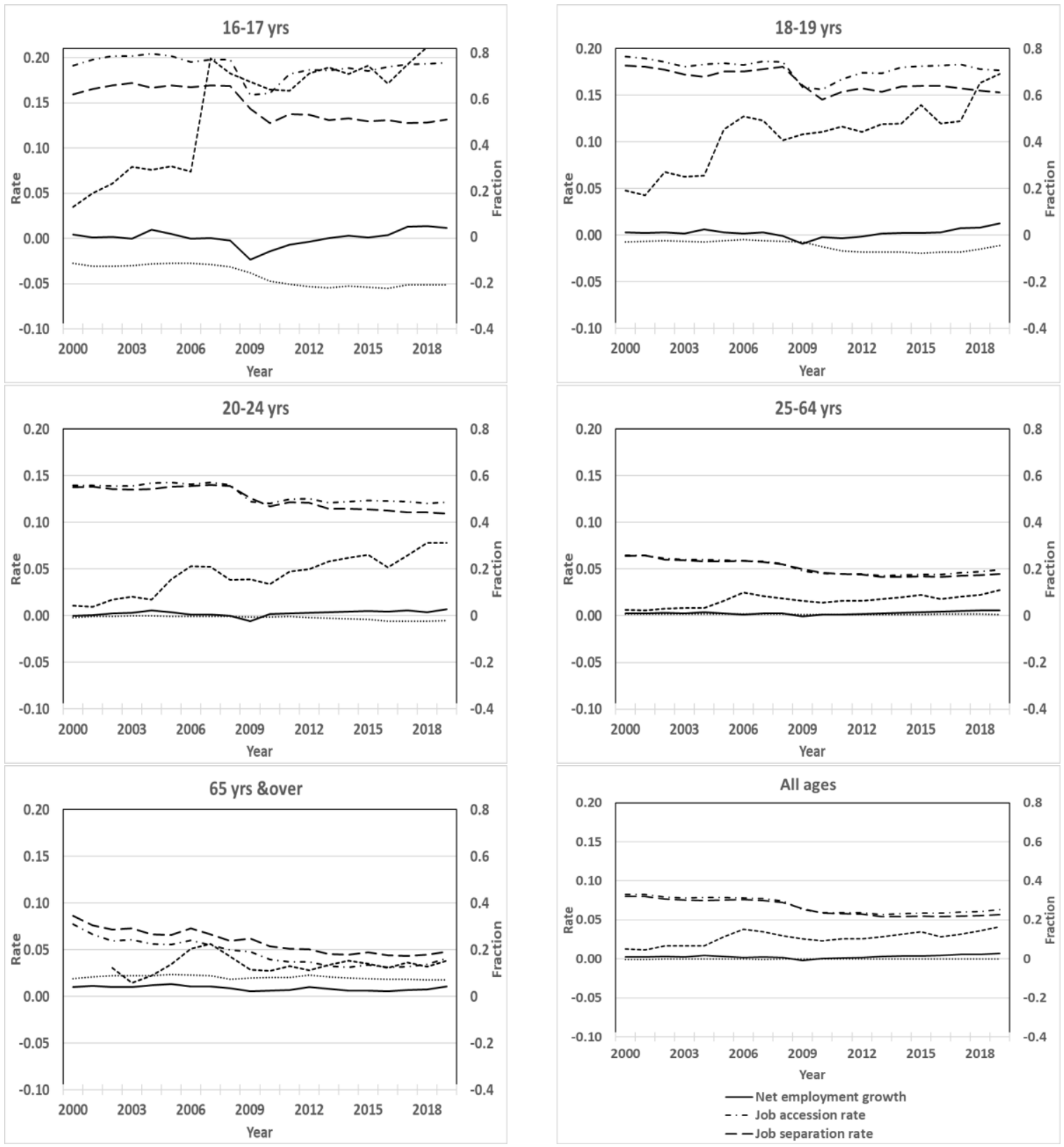

Notes: These figures do not include data from 2020 as they use labour tables that are currently available only through to 2019.

Source: Income Survey, Integrated Data Infrastructure. 
Figure 9: Minimum wage incidence across Individual income distribution

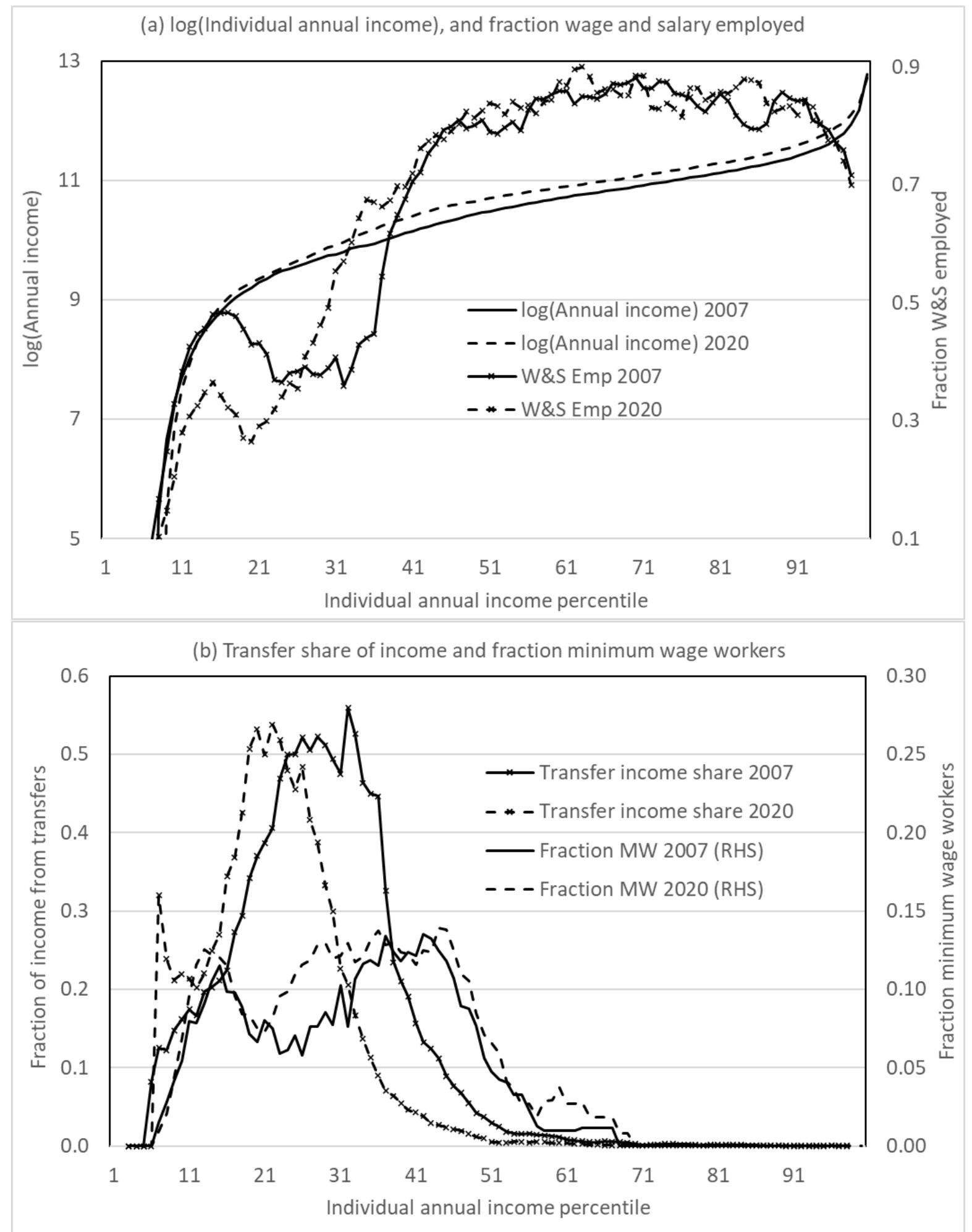

Source: Income Survey and Integrated Data Infrastructure. 
Figure 10: Minimum wage incidence across Household income distribution

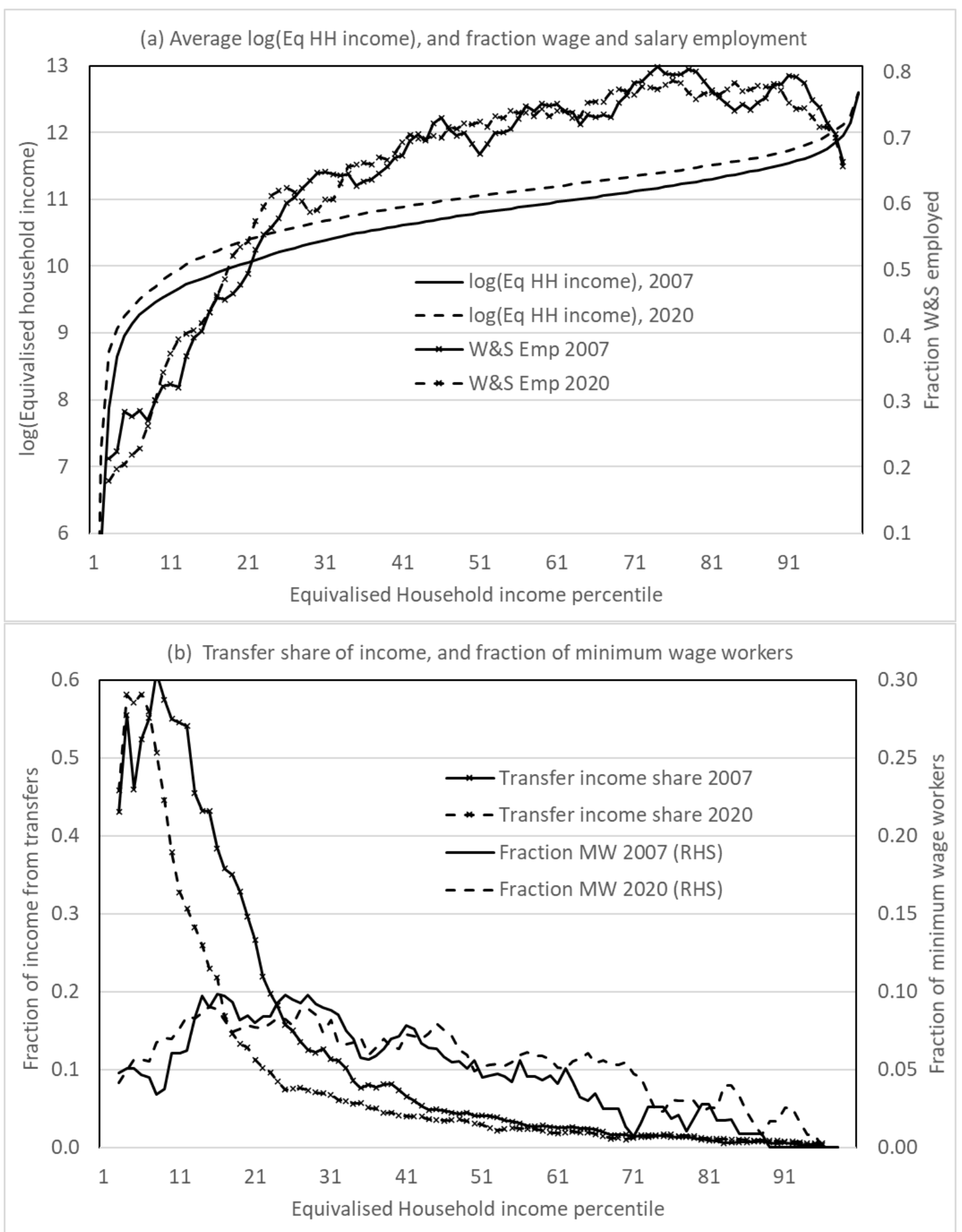

Source: Income Survey and Integrated Data Infrastructure. 
Figure 11: Incomes before and after being observed on the minimum wage

\section{Annual Income growth}

before and after being observed in the IS

for people observed 3 yrs before to 3 yrs after

controlling for year effects

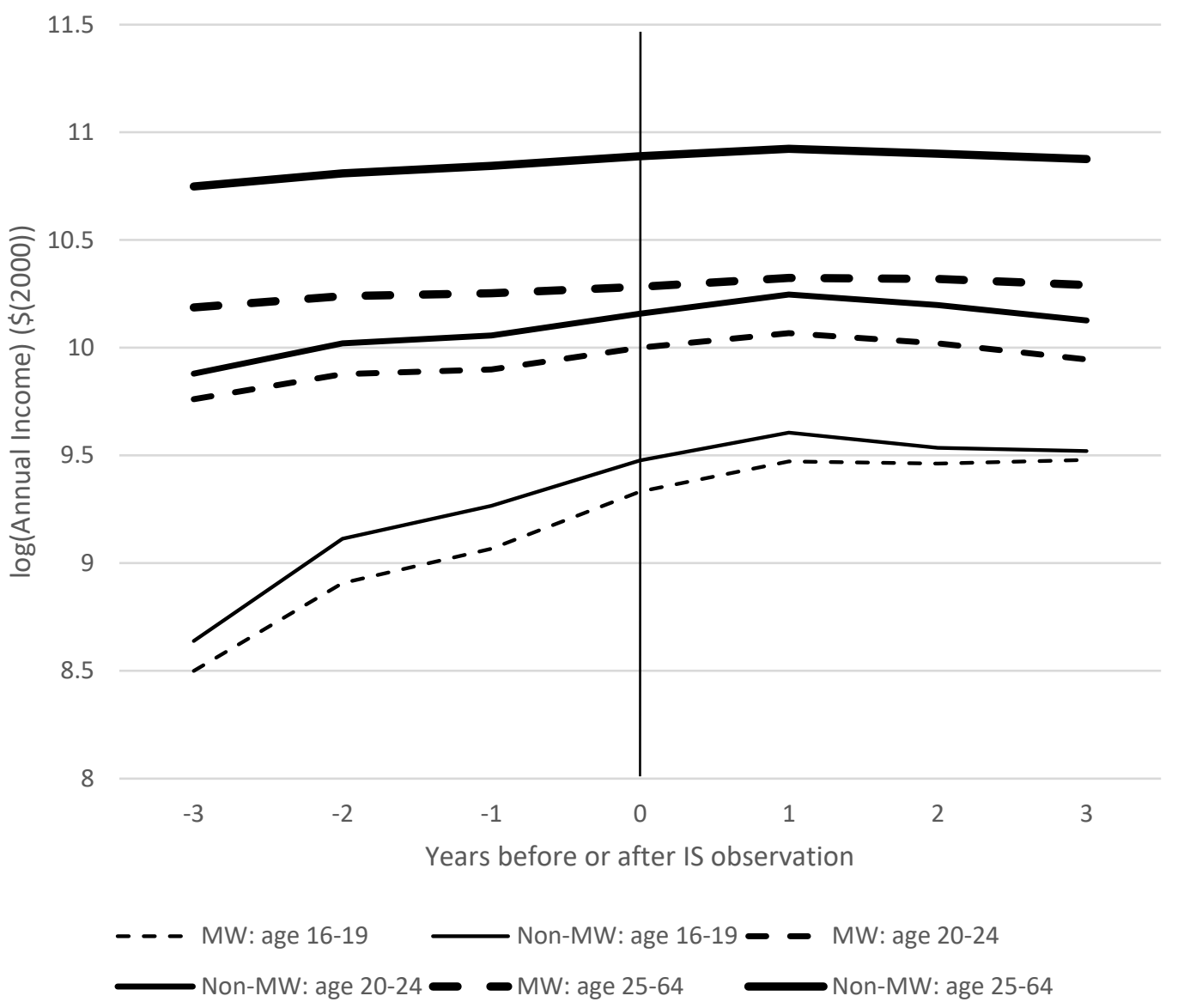

Source: Income Survey and Integrated Data Infrastructure. Estimation is on an unbalanced panel, meaning that the people observed 3 years prior to IS observation are a non-random subset of those observed in the IS. Annual income is shown on a log scale. Log(Annual income) of 9 is approximately $\$ 8,000$. Log(Annual income) of 10 is approximately $\$ 22,000$. Log(Annual income) of 11 is approximately $\$ 60,000$. 


\section{Appendix}

Table A1: Summary of New Zealand time series based minimum wage analyses

\begin{tabular}{|c|c|c|c|}
\hline $\begin{array}{l}\text { Research } \\
\text { paper }\end{array}$ & Outcomes & $\begin{array}{l}\text { Data, Specification \& } \\
\text { Controls }\end{array}$ & Results summary \& comments \\
\hline $\begin{array}{l}\text { Maloney } \\
\text { (1995) }\end{array}$ & $\begin{array}{l}\text { Young adult (20-24) } \\
\text { employment } \& \\
\text { unemployment } \\
\text { rates (compares } \\
\text { exempt teens) }\end{array}$ & $\begin{array}{l}\text { HLFS 1985-1993 (33 } \\
\text { quarters); Current \& 4-lags } \\
\text { log(MW/AvgW), prime-age } \\
\text { Urate, UB-rates, Ed- } \\
\text { enrolment, linear trend and } \\
\text { Q-controls }\end{array}$ & $\begin{array}{l}\text { Stat-sig cumulative MW effect } \\
\text { on } 20-24 \mathrm{~s} \text { (elas=-0.35, }-0.57 \\
\text { for No-quals); spillover to } \\
\text { teens (elas=0.69) }\end{array}$ \\
\hline $\begin{array}{l}\text { Chapple } \\
\text { (1997) }\end{array}$ & $\begin{array}{l}\text { Young adult } \\
\text { employment } \\
\text { (revisits Maloney } \\
\text { study): full } \\
\text { economy time } \\
\text { series \& Industry } \\
\text { panel analysis }\end{array}$ & $\begin{array}{l}\text { HLFS 1985-97, Current \& 4- } \\
\text { lags log(MW/PPO), 4-lags } \\
\text { log(AHE/PPO), 4-lags } \\
\text { log(PPI/PPO), linear trend, } \\
\text { log(E/Pop). } \\
\text { Annual QES 1980-97 }\end{array}$ & $\begin{array}{l}\text { Aggregate } \mathrm{MW} \text {-emp elas in } \\
\text { range }(-0.18,-0.34) ; \\
\text { Industry results: mixed sign } \\
\text { effects and generally insig; } \\
\text { critiques robustness of models } \\
\text { (stability over time, statistical } \\
\text { properties, etc) }\end{array}$ \\
\hline $\begin{array}{l}\text { Pacheco \& } \\
\text { Maloney } \\
(1999)\end{array}$ & $\begin{array}{l}\text { Employment rates } \\
\text { of Women with no } \\
\text { qualifications (cf } \\
\text { with quals), aged } \\
15+, 20+, 20-29\end{array}$ & $\begin{array}{l}\text { Quarterly HLFS 1986-2000; } \\
\text { Current and 4-lags MW, } \\
\text { Prime-male Urate, linear } \\
\text { trend }\end{array}$ & $\begin{array}{l}\text { Negative employment effects } \\
\text { for } 15+\& 20+(\text { stat-sig only } \\
\text { when linear trend excluded); } \\
\text { insig positive effects for } 20-29 \\
\text { (negative without trend) }\end{array}$ \\
\hline $\begin{array}{l}\text { Pacheco \& } \\
\text { Cruickshank } \\
\text { (2007) }\end{array}$ & $\begin{array}{l}\text { Education } \\
\text { enrolments of teens } \\
\text { (16-19) and young } \\
\text { adults (20-24) }\end{array}$ & $\begin{array}{l}\text { Synthetic panel data 1986- } \\
\text { 2004; MOE enrolment } \\
\text { rates, business cycle } \\
\text { controls (Urate, GDP), age- } \\
\text { specific FEs \& linear trends; } \\
\text { YMW dummy and PPI- } \\
\text { adjusted MW }\end{array}$ & $\begin{array}{l}\text { Consistently positive } \\
\text { enrolments rates associated } \\
\text { with YMW (from 1994); stat- } \\
\text { sig negative teen enrolment } \\
\text { response to MWs only with } \\
\text { trends; insig positive } \\
\text { enrolment for young adults. }\end{array}$ \\
\hline $\begin{array}{l}\text { Pacheco } \\
\text { (2011) }\end{array}$ & $\begin{array}{l}\text { Employment rates } \\
\text { of } 16-29 \text { year olds }\end{array}$ & $\begin{array}{l}\text { Unit record Quarterly HLFS } \\
\text { 1986-2004; Current \& 4-lags } \\
\text { log(MW/PPI) and YMW } \\
\text { dummy (post-1994), } \\
\text { demographics, age-specific } \\
\text { linear trends and business } \\
\text { cycles; also uses annual IS } \\
\text { data to predict whether } \\
\text { MW binds (pred), and then } \\
\text { focuses on the adjusted } \\
\text { bind*MW effects (ignores } \\
\text { main effects, and } \\
\text { interaction with other } \\
\text { controls) }\end{array}$ & $\begin{array}{l}\text { Positive combined YMW and } \\
\text { MW emp-effects (YMW =3.6\%, } \\
\text { MW elas=0.032: negative MW } \\
\text { effects for } 16-17 \text { (e=-0.08), 20- } \\
24(-0.09), 20-29(-0.05) \text {, nut } \\
\text { positive for } 18-19(0.13) \text {; } \\
\text { estimates negative combined } \\
\text { effect on MW*binds ( }=-0.08 \text {, } \\
\text { but YMW=48\%), overall e=- } \\
\text {.06; no mention of clustering } \\
\text { nor adjustment for } 1^{\text {st-stage }} \\
\text { bind-est, so assume OLS std } \\
\text { errors estimated (too small) }\end{array}$ \\
\hline
\end{tabular}


Table A2: Summary of New Zealand cross sectional minimum wage analyses

\begin{tabular}{|c|c|c|c|}
\hline $\begin{array}{l}\text { Research } \\
\text { paper }\end{array}$ & Outcomes & $\begin{array}{l}\text { Data, Specification \& } \\
\text { Controls }\end{array}$ & Results summary \& comments \\
\hline \multicolumn{4}{|c|}{ A: Labour market related outcomes } \\
\hline $\begin{array}{l}\text { Hyslop \& } \\
\text { Stillman } \\
(2007)\end{array}$ & $\begin{array}{l}\text { Employment \& } \\
\text { hours of teens (16- } \\
17,18-19) \text { relative } \\
\text { to young adults ( } 20- \\
24)\end{array}$ & $\begin{array}{l}\text { Quarterly HLFS and annual } \\
\text { IS 1997-2004; reg-adj } \\
\text { difference-in-differences } \\
\text { (about 2001), demographic, } \\
\text { age-specific FEs \& linear } \\
\text { trends }\end{array}$ & $\begin{array}{l}\text { Only weak employment } \\
\text { effects in year-3 (elas -0.03 } \\
(18-19 \mathrm{~s}) ;-0.05--0.1(16-17 \mathrm{~s})) \text {; } \\
10-20 \% \text { increase in hours } \\
\text { worked for } 16-17 \mathrm{~s}\end{array}$ \\
\hline $\begin{array}{l}\text { Hyslop \& } \\
\text { Stillman } \\
\text { (2011) }\end{array}$ & $\begin{array}{l}\text { Employment \& } \\
\text { hours of } 16-17 \mathrm{~s} \text {, } \\
\text { relative to } 18-19 \mathrm{~s} \text {, } \\
\text { and } 20-24 \mathrm{~s}\end{array}$ & $\begin{array}{l}\text { Quarterly HLFS and annual } \\
\text { IS 1997-2010; reg-adj } \\
\text { difference-in-differences } \\
\text { (about 2008), demographic, } \\
\text { age-specific FEs \& linear } \\
\text { trends }\end{array}$ & $\begin{array}{l}\text { 3-6pp lower employment after } \\
2-3 \text { years; all among students; } \\
\text { increase in study, } \\
\text { unemployment and activity } \\
\text { rates }\end{array}$ \\
\hline $\begin{array}{l}\text { Hyslop, Maré } \\
\text { Stillman \& } \\
\text { Timmins } \\
(2012)\end{array}$ & $\begin{array}{l}\text { Firm-based teen } \\
\text { employment; test } \\
\text { whether L-demand } \\
\text { responses vary by } \\
\text { teen-employment } \\
\text { intensity }\end{array}$ & $\begin{array}{l}\text { LEED data 1999-2007; firm- } \\
\text { level age-group } \\
\text { employment }\end{array}$ & $\begin{array}{l}\text { Hi-teen firms reduced teen- } \\
\text { emp } 15-20 \text { pp rel to other } \\
\text { firms; } 5 \% \text { lower survival rates } \\
\text { in main-teen industries, and } \\
10-20 \% \text { elsewhere; but new } \\
\text { firms in main-teen industries } \\
\text { had higher teen-employment. } \\
\text { No wage / hours mean } \\
\text { evidence is largely } \\
\text { circumstantial }\end{array}$ \\
\hline $\begin{array}{l}\text { Eckert, } \\
\text { Hyslop, } \\
\text { Stillman \& } \\
\text { Wunsch } \\
\text { (2018) }\end{array}$ & $\begin{array}{l}\text { Employment of } \\
\text { teens relative to } \\
\text { young adults }\end{array}$ & $\begin{array}{l}\text { LEED data } 2000-2011 \text {; } \\
\text { bite=MW/AvgW, BC=Adult } \\
\text { Urate, controls for } \\
\text { demographics, region, year } \\
\text { and monthly-seasonal }\end{array}$ & $\begin{array}{l}\text { Adverse employment effect } \\
\text { varies with MW bite and } \mathrm{BC} \text {, } \\
\text { and an interaction; } \\
\text { adjustments primary occur } \\
\text { through reduced hiring, with } \\
\text { little change in separations }\end{array}$ \\
\hline
\end{tabular}


Table A2 (continued)

\begin{tabular}{|c|c|c|c|}
\hline $\begin{array}{l}\text { Research } \\
\text { paper }\end{array}$ & Outcomes & $\begin{array}{l}\text { Data, Specification \& } \\
\text { Controls }\end{array}$ & Results summary \& comments \\
\hline \multicolumn{4}{|c|}{ B: Inequality related and miscellaneous outcomes } \\
\hline $\begin{array}{l}\text { Pacheco \& } \\
\text { Naiker } \\
(2006)\end{array}$ & $\begin{array}{l}\text { Stock market price } \\
\text { response to MW } \\
\text { announcements of } \\
32 \text { firms in } 5 \text { high- } \\
\text { MW industries } \\
\text { (Retail, Textile \& } \\
\text { Apparel, Acc Café \& } \\
\text { Rests, Ag For Fish) }\end{array}$ & $\begin{array}{l}\text { HLFS/IS data to measure } \\
\text { industry-level MW } \\
\text { exposure, NZ Investment } \\
\text { Yearbook (2001) to identify } \\
\text { firms, Datex for share } \\
\text { prices; Event study around } \\
10 \text { MW announcements } \\
\text { (Nov 1999-Dec 2000) }\end{array}$ & $\begin{array}{l}\text { Inconclusive / insignificant } \\
\text { effects; but focus around } 2001 \\
\text { YMW reform announcements } \\
\text { for all MW industries implies } \\
\text { weak id (also, Hyslop et al. } \\
\text { (2012) document variation in } \\
\text { firm-teen emp within High- } \\
\text { teen emp industries) }\end{array}$ \\
\hline $\begin{array}{l}\text { Pacheco } \\
(2009 a)\end{array}$ & $\begin{array}{l}\text { Youth }(16-19) \text { vs } \\
\text { adult }(20+) \text { wage } \\
\text { inequality: } 90 / 10 \text {, } \\
90 / 50,50 / 10\end{array}$ & $\begin{array}{l}\text { HLFS/IS 1997-07; simple } \\
\text { regs of Ineq on log(RMW), } \\
\text { and DiD between } 97-99 \& \\
05-07\end{array}$ & $\begin{array}{l}\text { MW increased inequality in } \\
\text { adult wages (both } 90 / 50 \text { \& } \\
50 / 10 \text { ); reduced inequality in } \\
\text { Youth wages (in } 50 / 10 \text { ); DiD } \\
\text { shows strong decline in Yth rel } \\
\text { to Adlt 50/10 }\end{array}$ \\
\hline $\begin{array}{l}\text { Maloney \& } \\
\text { Pacheco } \\
(2012)\end{array}$ & $\begin{array}{l}\text { Incidence of MW- } \\
\text { workers over time, } \\
\text { effects on Eq-HH } \\
\text { Income; HH Poverty } \\
\text { rates }\end{array}$ & $\begin{array}{l}\text { HLFS/IS 1997-2008; define } \\
\text { MW-workers as mw+/-\$0.5; } \\
\text { Poverty<(0.5 Med Eq-HH } \\
\text { Income) }\end{array}$ & $\begin{array}{l}\text { Incidence of MW-workers up } \\
\text { from 1-2\% (late-90s) to } 12 \% \\
\text { (2008); teens from } 2 \% \text { to } \\
60+\% \text {; MW-inds from 2-4\% to } \\
30+\% \text {; but spread widely over } \\
\text { HH IncDn (F3: MW-workers } \\
\text { over-rep in D2/3-4, under-rep } \\
\text { in D7/8-10; F5: \%workers as } \\
\text { MW falls across Deciles, and } \\
\text { increases strongly over } \\
\text { period); only mild effects on } \\
\text { poverty reduction (sim } 10 \% \\
\text { MW up reduce poverty } \\
<0.1 p p \text { ) }\end{array}$ \\
\hline $\begin{array}{l}\text { Alinaghi et al. } \\
\text { (2019) }\end{array}$ & $\begin{array}{l}\text { Effect of a } \\
\text { hypothetical } \\
\text { increase in } \\
\text { minimum wage on } \\
\text { inequality and } \\
\text { poverty }\end{array}$ & $\begin{array}{l}\text { Treasury's TaxWell-B } \\
\text { microsimulation model } \\
\text { based on } 2012 / 3 \text { HES data }\end{array}$ & $\begin{array}{l}\text { Small reduction in household } \\
\text { equivalised income inequality, } \\
\text { concentrated in sole parent } \\
\text { households. Focuses only on } \\
\text { wage and labour supply } \\
\text { responses (by low-wage } \\
\text { workers), ignoring labour- } \\
\text { demand effects }\end{array}$ \\
\hline
\end{tabular}


Table A2 (continued)

\begin{tabular}{lll}
\hline $\begin{array}{l}\text { Research } \quad \text { Outcomes } \\
\text { paper }\end{array}$ & $\begin{array}{l}\text { Data, Specification \& } \\
\text { Controls }\end{array}$ & Results summary \& comments \\
\hline C. Minimum wage incidence analysis &
\end{tabular}

\section{C: Minimum wage incidence analysis}

\begin{tabular}{|c|c|c|c|}
\hline $\begin{array}{l}\text { Pacheco } \\
(2007, \\
2009 b)\end{array}$ & $\begin{array}{l}\text { Characteristics of } \\
\text { sub-, and min- } \\
\text { wage (up to } 10 \% \\
\text { above mw) } \\
\text { workers }\end{array}$ & $\begin{array}{l}\text { HLFS-IS 1997-2004; focus } \\
\text { on changes from 1997-99 } \\
\text { to } 2002-04\end{array}$ & $\begin{array}{l}\text { Sub\&MW incidence increase } \\
\text { from } 4.6 \% \text { ( } 2000 \text { ) to } 8.1 \% \\
\text { (2004); sub-min broadly } \\
\text { similar to mw-workers } \\
\text { (young, female, Maori, } \\
\text { Pacific, No-quals, PT); age } \\
\text { most important for increase }\end{array}$ \\
\hline $\begin{array}{l}\text { Maloney \& } \\
\text { Pacheco } \\
(2010)\end{array}$ & $\begin{array}{l}\text { Decompose } \\
\text { change in mw- } \\
\text { incidence } \\
\text { (wage } \leq \mathrm{mw} \text { ) into } \\
\text { mechanical }\left(\Delta P_{i t}^{M}\right) \text {, } \\
\text { behaviour }\left(\Delta P_{i t}^{B}\right) \text {, } \\
\text { and other wage }\end{array}$ & $\begin{array}{l}\text { HLFS-IS 1997-2008; } \Delta P_{i t}^{M}= \\
\left(\mathrm{mw}_{\left.\mathrm{it}-1<\mathrm{w}_{\mathrm{it}-1} \leq \mathrm{mw}_{\mathrm{it}}\right)} \text {; }\right. \\
\Delta P_{i t}^{B}=\beta \Delta m w_{i t}+\epsilon_{i t} \\
\Delta P_{i t}^{O}=\delta_{i}+\gamma_{t}+v_{i t}\end{array}$ & $\begin{array}{l}\text { Incidence increase from } 2.5 \% \\
\text { (2000) to } 10.4 \% \text { ( } 2008) ; \\
\text { actual } \Delta P_{i t} \sim \text { one-third of } \\
\Delta P_{i t}^{M} \text {; no significant } \\
\text { behavioural/employment } \\
\text { effects; implies most of } \Delta P_{i t}^{M} \\
\text { offset by wage increases }\end{array}$ \\
\hline
\end{tabular}

$\left(\Delta P_{i t}^{O}\right)$ effects 